\section{Pacific Northwest}

National Laboratory

Operated by Battelle for the

U.S. Department of Energy

\title{
Monitoring and Commissioning Verification Algorithms for CHP Systems
}

MR Brambley

S Katipamula

W Jiang

March 2008

Prepared for the U.S. Department of Energy under Contract DE-AC05-76RL01830 


\title{
DISCLAIMER
}

This report was prepared as an account of work sponsored by an agency of the United States Government. Neither the United States Government nor any agency thereof, nor Battelle Memorial Institute, nor any of their employees, makes any warranty, express or implied, or assumes any legal liability or responsibility for the accuracy, completeness, or usefulness of any information, apparatus, product, or process disclosed, or represents that its use would not infringe privately owned rights. Reference herein to any specific commercial product, process, or service by trade name, trademark, manufacturer, or otherwise does not necessarily constitute or imply its endorsement, recommendation, or favoring by the United States Government or any agency thereof, or Battelle Memorial Institute. The views and opinions of authors expressed herein do not necessarily state or reflect those of the United States Government or any agency thereof.

\author{
PACIFIC NORTHWEST NATIONAL LABORATORY \\ operated by \\ BATTELLE \\ for the \\ UNITED STATES DEPARTMENT OF ENERGY \\ under Contract DE-AC05-76RL01830
}

Printed in the United States of America
Available to DOE and DOE contractors from the Office of Scientific and Technical Information,
P.O. Box 62, Oak Ridge, TN 37831-0062;
ph: (865) 576-8401
fax: (865) 576-5728
email: reports@adonis.osti.gov

\author{
Available to the public from the National Technical Information Service, \\ U.S. Department of Commerce, 5285 Port Royal Rd., Springfield, VA 22161 \\ ph: (800) 553-6847 \\ fax: (703) 605-6900 \\ email: orders@ntis.fedworld.gov \\ online ordering: http://www.ntis.gov/ordering.htm
}


PNNL-17432

\title{
Monitoring and Commissioning Verification Algorithms for CHP Systems
}

\author{
MR Brambley \\ S Katipamula \\ W Jiang
}

March 2008

Prepared for

the U.S. Department of Energy

under Contract DE-AC05-76RL01830

Pacific Northwest National Laboratory

Richland, Washington 99352 


\section{Executive Summary}

Pacific Northwest National Laboratory (PNNL) is assisting the U.S. Department of Energy (DOE) Distributed Energy (DE) Program by developing advanced control algorithms that provide the basis upon which tools to enhance performance and reliability, and reduce emissions of distributed energy technologies, including combined heat and power (CHP) technologies, could be developed.

The primary objective of this multiyear project is to develop algorithms for CHP systems. These algorithms will ensure optimal performance, increase reliability, and lead to the goal of clean, efficient, reliable and affordable next generation energy systems.

This document provides the algorithms for CHP system performance monitoring and commissioning verification $(\mathrm{CxV})$. It starts by presenting system-level and component-level performance metrics, followed by descriptions of algorithms for performance monitoring and commissioning verification, using the metric presented earlier. Verification of commissioning is accomplished essentially by comparing actual measured performance to benchmarks for performance provided by the system integrator and/or component manufacturers. The results of these comparisons are then automatically interpreted to provide conclusions regarding whether the CHP system and its components have been properly commissioned and where problems are found, guidance is provided for corrections. A discussion of uncertainty handling is then provided, which is followed by a description of how simulations models can be used to generate data for testing the algorithms. A model is described for simulating a CHP system consisting of a micro-turbine, an exhaust-gas heat recovery unit that produces hot water, an absorption chiller and a cooling tower. The process for using this model to generate data for testing the algorithms for a selected set of faults is described. The next section applies the algorithms developed to CHP laboratory and field data to illustrate their use. The report then concludes with a discussion of the need for laboratory testing of the algorithms on a physical CHP systems and identification of the recommended next steps. 


\section{Acknowledgements}

This work was supported the Distributed Energy Program of the Office of Electricity Delivery and Energy Reliability of the U.S. Department of Energy (DOE). The authors wish to thank Mario Sciulli, Project Manager at the National Energy Technology Laboratory, and Debbie Haught, the DOE Program Manager, for their support and guidance in the performance of this work. Members of the project advisory panel also provided valuable input through their review of project plans and reports. Their guidance was critical to the successful performance of this project.

\section{Project Advisory Panel}

Todd Amundson, Bonneville Power Administration

Gordon Bloomquist, Washington State University Extension Program and Northwest CHP Application Center

Michael O'Callaghan, United Technologies Research Center

Joe Haley, UTC Power

Steve Gable, Honeywell

Carlos Haiad, Southern California Edison

Sumit Ray, Trammell Crow

Randy Hudson II, Oak Ridge National Laboratory

Abdi Zaltash, Oak Ridge National Laboratory

Chris Marnay, Lawrence Berkeley National Laboratory. 
Variables

Notation

A

$A_{V}$

COP

Cost

$C_{p}$

$C_{S}$

$C_{v}$

$E U F_{V W}$

$h$

$h_{C}$

$h_{D}$

$H H V$

$k$

$k_{n g}$

$L$

LHV

$\dot{m}$

$P$

Price

$Q$

$Q_{\text {Fuel }}$

$Q_{g}$

$Q_{\text {th }}$

$R$

$R_{a}$

$R_{n g}$

$T$

$t$

$\dot{v}$

$V_{C T}$

W

W

$W_{\text {Elec }}$

$W_{l}$

$W_{p}$

$W_{t}$

Y

$\alpha$

$\Delta P_{l}$

$\varepsilon$

$\eta$

$\rho$

$\theta$

\section{Notation}

\section{Physical Variable}

Area

Surface area of water per unit volume of cooling tower

Coefficient of Performance

Cost

Specific heat at constant pressure

Saturation specific heat (average)

Specific heat at constant volume

Value-weighted Energy Utilization Factor

Specific enthalpy

Convective heat transfer coefficient

Mass transfer coefficient

Higher Heating Value

Specific heat ratio for air

Specific heat ratio for natural gas

Heat loss rate

Lower Heating Value

Mass flow rate

Pressure

Price

Rate of energy transfer (e.g., heat or fuel)

Fuel energy flow rate

Rate of energy input as gas fuel flow

Thermal Power

Universal gas constant

Specific gas constant for air

Specific gas constant for natural gas

Temperature

Time

Volumetric Flow Rate

Volume of cooling tower

Power

Power input or output

Electric power

Total micro-turbine power loss

Net power output of the microturbine

Turbine mechanic shaft power

Unit monetary value

Recuperator heat loss coefficient

Hydraulic loss of CHP system

Effectiveness

Efficiency

Density

Controller heat loss coefficient 
$\mu$

$\omega$

Dimensionless Parameters

$\xi$

Le

NTU

$r_{c}$

$r_{t}$

\section{Subscripts \\ Notation}

Components

absorber

gen

AbChiller

Chiller

c

$c c$

cond

cn

CT

$d$

evap

Fan or $f$

gearbox

HRSG

$H R U$

Prime Movers

Turbine or $t$

mtg

engine

Pump

\section{Substances}

a

$c w$

ex

F or Fuel

$g$

hotwater

ng

$s$ or steam

$w$
Molecular mass

Humidity ratio

Fraction of absorption chiller heat rejection taking place in the condenser

Lewis number

Heat-exchanger number of transfer units

Compressor pressure ratio

Turbine expansion rate

\section{$\underline{\text { Parameter }}$}

Absorption chiller absorber

Absorption chiller generator

Absorption chiller

Chiller (electric)

Compressor

Combustion chamber

Condenser

Controller

Cooling Tower

Desiccant System

Evaporator

Fan

Gear box

Heat Recovery Steam Generator

Heat Recovery Unit

Micro-turbine

Micro-turbine generator

Reciprocating Engine

Pump 


$\begin{array}{ll}\text { Notation } & \text { Parameter } \\ i & \text { Input } \\ o & \text { Output } \\ \text { Forms of Energy } & \\ \text { Elec } & \text { Electricity } \\ \text { th } & \text { Thermal } \\ \text { F or Fuel } & \text { Fuel } \\ & \\ \text { Other } & \\ \text { actual } & \text { Actual Value Based on Measurements } \\ \text { Cxb } & \text { Commissioning Baseline } \\ \text { discharge } & \text { Discharge } \\ \text { EE } & \text { Electric Generation } \\ \text { min } & \text { Minimum } \\ \text { max } & \text { Maximum } \\ \text { ref } & \text { Reference at which enthalpy of liquid water is zero } \\ s & \text { Saturation conditions } \\ \text { suction } & \text { Suction } \\ w b & \text { Wet bulb }\end{array}$




\section{Contents}

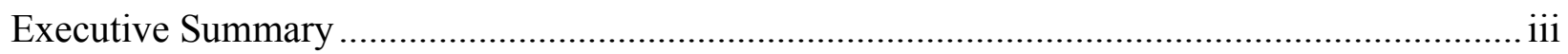

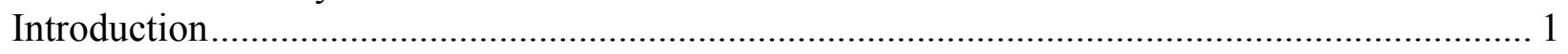

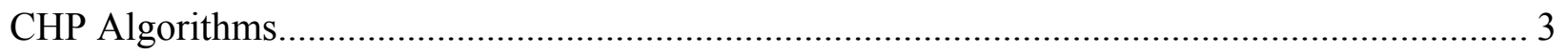

Summary of Equations for Metrics............................................................................... 3

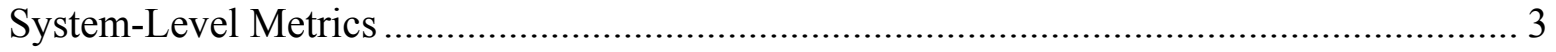

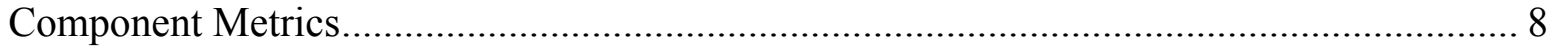

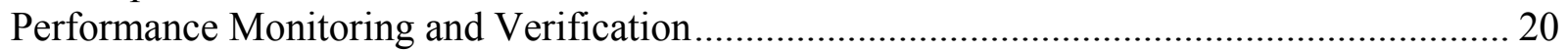

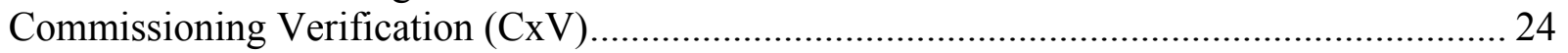

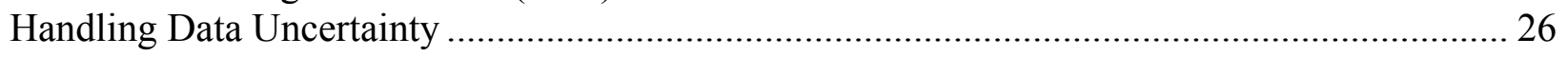

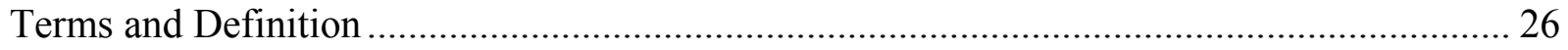

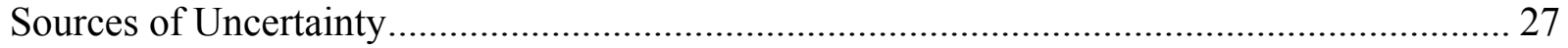

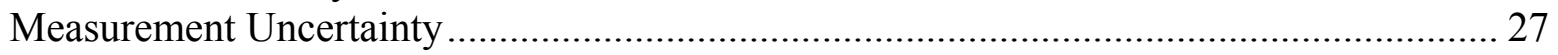

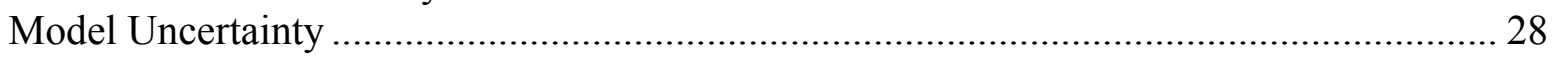

Uncertainty Calculation ................................................................................................... 31

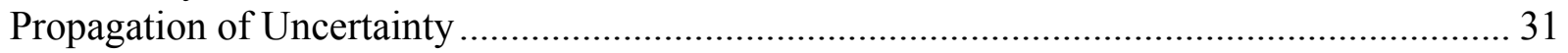

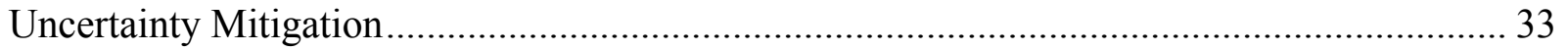

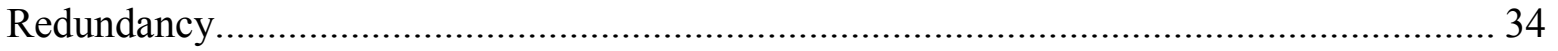

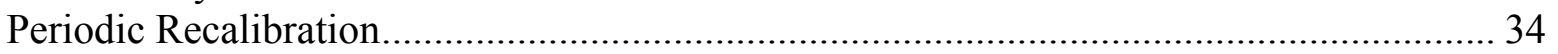

Example for Propagation of Errors and Uncertainty Mitigation ........................................... 34

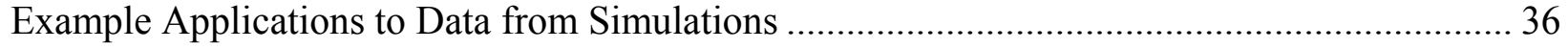

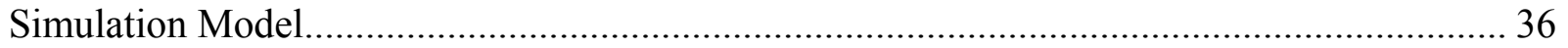

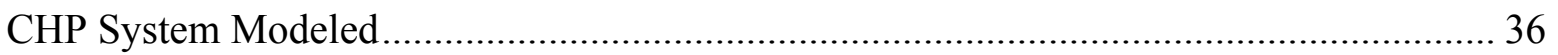

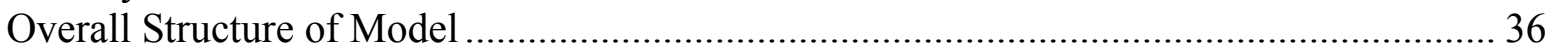

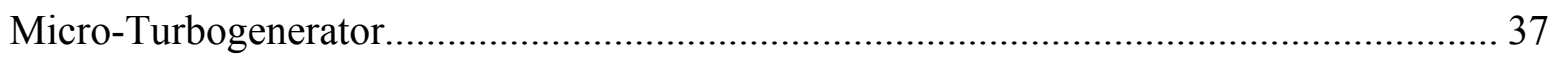

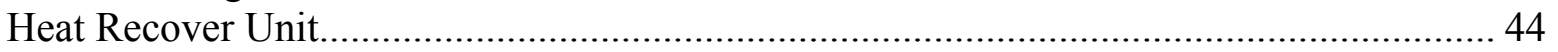

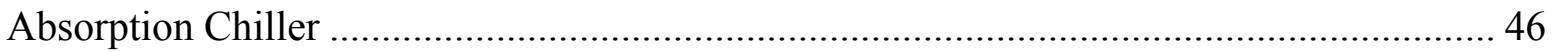

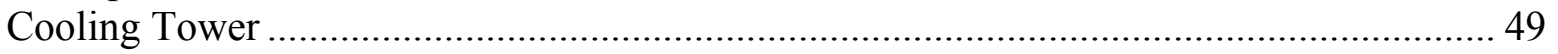

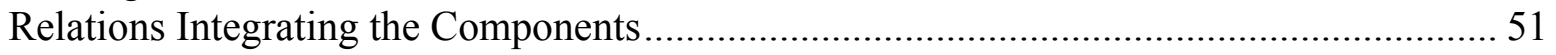

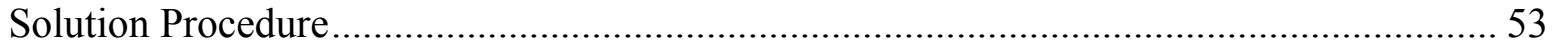

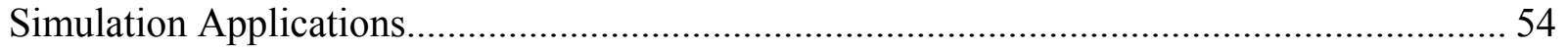

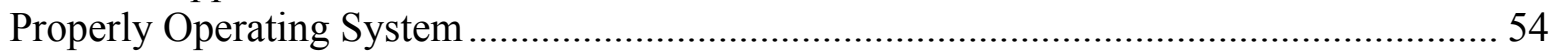

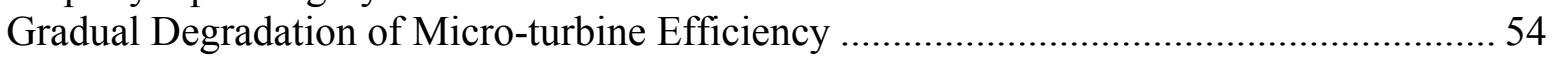

Deleterious Change in the Micro-turbine Air-Fuel Ratio ........................................................ 54

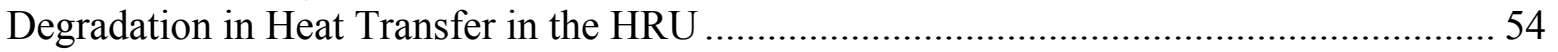

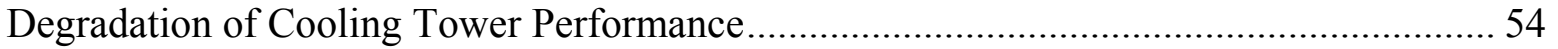

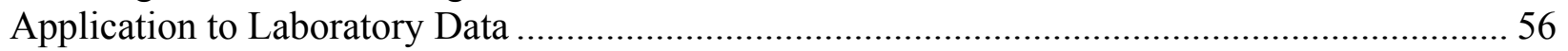

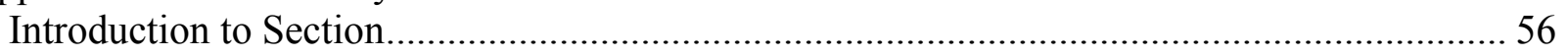

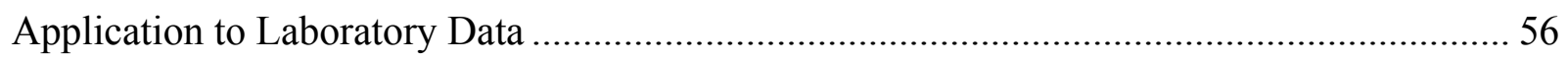

Need for Lab and Field Testing/Demonstration ......................................................................... 59

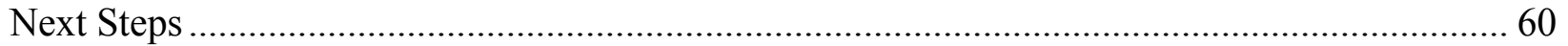

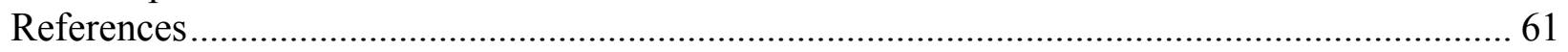




\section{Introduction}

Pacific Northwest National Laboratory (PNNL) is assisting the U.S. Department of Energy (DOE) Distributed Energy (DE) Program by developing advanced control algorithms that would lead to development of tools to enhance performance and reliability, and reduce emissions of distributed energy technologies, including combined heat and power (CHP) technologies ${ }^{1}$.

The primary objective of this multiyear project is to develop algorithms for CHP systems. These algorithms will help ensure optimal performance, increase reliability, and lead to the goal of clean, efficient, reliable and affordable next generation energy systems.

As part of the project, in FY 2005, an expert project advisory panel (PAP) was formed to help guide and review progress of the proposed multiyear research effort. The advisory panel now includes representatives from: 1) Bonneville Power Administration (BPA), 2) Honeywell Labs, 3) Northwest CHP Applications Center, 4) Lawrence Berkeley National Laboratory, 5) Oak Ridge National Laboratory, 6) Southern California Edison (SCE), 7) C. B. Richard Ellis, 8) United Technologies Research Center (UTRC), and 9) United Technology Corporation Power (UTC Power). This panel met to review project objectives, scope and plans in December 2005 and has provided report reviews and recommendations.

After defining the potential breadth of advanced controls for CHP systems, the project team narrowed down and better defined the project scope in a report titled Advanced CHP Control Algorithms: Scope Specification (Katipamula and Brambley 2006). In this report, working definitions of performance monitoring and commissioning verification $(\mathrm{Cx} V$ ) were provided, equations were given for energy performance metrics for CHP systems and their individual generic components, CHP use in the U.S. was characterized by size and application, and CHP system operator issues and needs developed from CHP site visits and an informal survey of CHP system operators and management were presented. This information then provided the basis for a refined project scope presented in the final section of the report.

In the next phase of the project, the PNNL team developed a detailed specification of algorithms for CHP monitoring and verification. This specification was detailed in the report Specification of Selected Performance Monitoring and Commissioning Verification Algorithms for CHP Systems (Brambley and Katipamula 2006). This report identified specific CHP system configurations for which algorithms were to be developed, develops detailed equations for performance metrics for each component of the selected CHP systems, and provided an input/output diagram for each set of algorithms, which identified all input and output variables. The report then provided algorithms for system-level performance monitoring and commissioning verification, including input/output diagrams. As part of the system level presentation, a detailed description was provided for a multi-dimensional bin-based modeling method, which the team proposes to use for detecting performance degradations. The report

\footnotetext{
${ }^{1}$ In the open literature, several different terms are used for combined heat and power systems, including building combined heat and power (BCHP), combined cooling, heating and power (CCHP), combined heat and power for buildings, and integrated energy systems. See Katipamula and Brambley (2006) and Brambley and Katipamula (2006) for additional discussion of terminology and the overall scope of this project.
} 
concluded with a discussion of how the algorithms developed in this project might be deployed, application scenarios that illustrate use of performance monitoring and commissioning verification based on the project algorithms, a brief summary of the report, and presentation of next steps for the project.

The current report documents the next phase of work, and provides a summary of the performance monitoring and $\mathrm{CxV}$ algorithms, a description of the implementation of the algorithms for testing, a discussion on handling of uncertainty in data, and presentation of results of application of the algorithms to data from laboratory tests and field installations of CHP systems. The report concludes with discussions of need for deployment of the algorithms in easy-to-use tools, the need for real-time field testing of the algorithms to establish their value, and proposed next steps in the project. 


\section{CHP Algorithms}

\section{Summary of Equations for Metrics}

In this section we present the summary of equations for system and component level metrics.

\section{System-Level Metrics}

The system shown in Figure 1 represents the most complete generic system identified for treatment in this project. Specific systems can be obtained from this figure by selecting a specific component, where more than one is shown (e.g., a reciprocating engine or a small turbine), and eliminating components (e.g., the desiccant system or absorption chiller and cooling tower) to obtain simpler systems. ${ }^{2}$

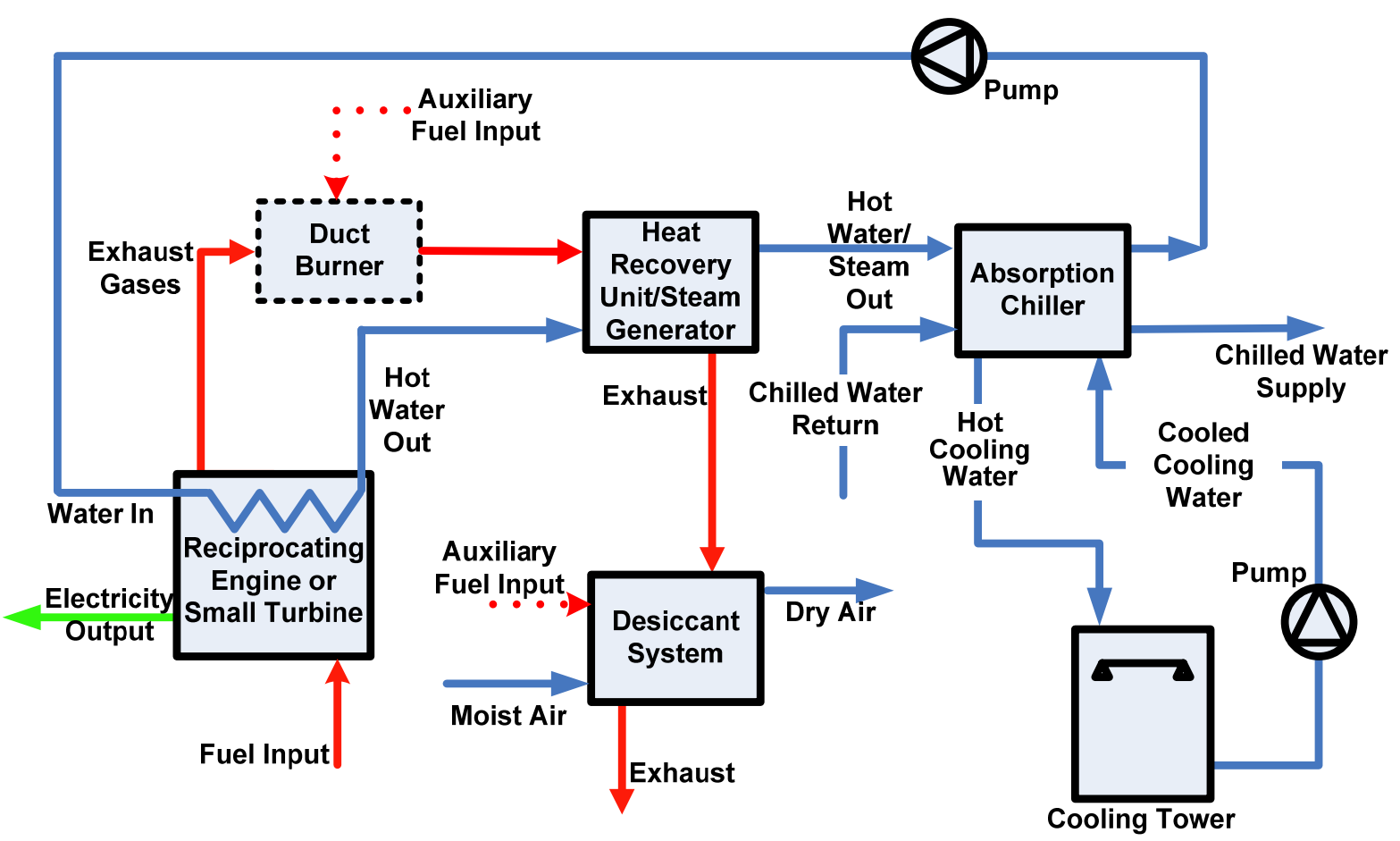

Figure 1. Generic CHP system from which all specific systems covered by this project can be derived.

To monitor the system-level performance of CHP systems, we have selected two metrics for efficiency and several other metrics calculated from sensed conditions or measured directly:

- Overall fuel utilization efficiency $\left(\eta_{F}\right)$

- Value-weighted energy utilization factor $\left(E U F_{V W}\right)$

- Current rate of useful heating or cooling output $\left(Q_{t h}\right)$

- Current electric power output $\left(W_{\text {Elec }}\right)$

- Current total rate of fuel use $\left(Q_{\text {Fuel }}\right)$

\footnotetext{
${ }^{2}$ See Brambley and Katipamula (2006) for diagrams of specific CHP systems selected for coverage in this project.
} 
- Current rate of expenditures on fuel $\left(\operatorname{Cost}_{F u e l}\right)$.

Equations for these metrics are summarized in Table 1. The rates can be integrated to obtain average values over selected time periods, and average efficiencies and utilization factors can be determined by integrating the numerator and denominator in the corresponding expression separately and then taking their ratio. Some generic example expressions for time-integrated quantities follow.

\section{Rates}

\section{Average value for time period $t_{0}$ to $t_{1}$}

$$
\begin{gathered}
\text { Average Quantity Over Last } n \text { Hours }=\int_{t_{0}}^{t_{1}}(\text { CurrentRate }) d t /\left(t_{1}-t_{0}\right) \\
\approx \sum_{j=n_{0}}^{n_{1}} \text { CurrentHourlyRate } e_{j} /\left(n_{1}-n_{0}\right),
\end{gathered}
$$

where $t_{0}$ and $t_{1}$ represent the start and end times for the time interval of interest for time measured from any arbitrary origin $t=0, n_{0}$ and $n_{l}$ are the corresponding time interval indices corresponding to times $t_{0}$ and $t_{1}, n_{1}-n_{0}=\left(t_{1}-t_{0}\right) / \Delta t$, and $\Delta t$ is the length of the time interval (e.g., 1 hour). Some specific example expressions based on Eq. (1) follow.

\section{Daily average value}

$$
\begin{gathered}
\text { Daily Average Value }=\int_{0}^{24 \text { hours }}(\text { CurrentRate }) d t \\
\approx \sum_{j=1}^{24} \text { CurrentHourly:Rate }_{j} / 24
\end{gathered}
$$

\section{Average value for the last $\boldsymbol{n}$ hours}

$$
\begin{gathered}
\text { Average Quantity Over Last } n \text { Hours }=\int_{t-n}^{t}(\text { CurrentRate }) d t / n \\
\approx \sum_{j=t-n}^{t}{\text { CurrentHourly } \text { Rate }_{j} / n}^{\prime}
\end{gathered}
$$

For example, the daily average value for electricity production by the CHP system based on Eq. (2) is give as

$$
\text { Daily Average Electric Power Output }=\int_{0}^{24 h o u r s} W_{\text {Elec }} d t \text {. }
$$

Table 1. Summary of functional relations for CHP system-level metrics. 


\begin{tabular}{|c|c|c|c|}
\hline Metric & Purpose & Functional Relation & Variables \\
\hline $\begin{array}{l}\text { Fuel } \\
\text { Utilization } \\
\text { Efficiency } \\
\left(\eta_{F}\right)\end{array}$ & $\begin{array}{l}\text { Indicate the } \\
\text { overall CHP } \\
\text { system } \\
\text { efficiency in } \\
\text { using fuel }\end{array}$ & $\begin{aligned} \eta_{F} & =\frac{\left(W_{\text {Elec }}+Q_{t h}\right)}{Q_{\text {Fuel }}} \\
& =\frac{\left(\sum_{j} W_{\text {Elec }, j}+\sum_{k} Q_{t h, k}\right)}{\sum_{l} Q_{\text {Fuel }, l}}\end{aligned}$ & 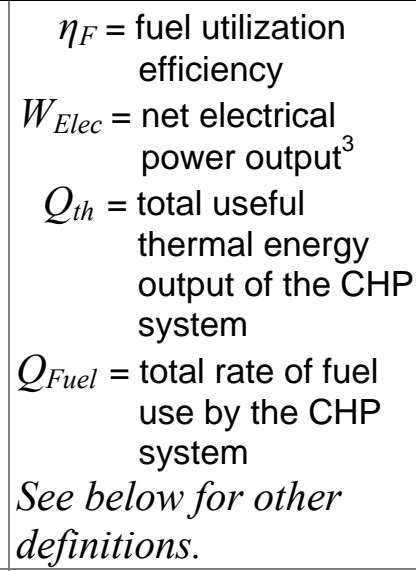 \\
\hline $\begin{array}{l}\text { Value- } \\
\text { Weighted } \\
\text { Energy } \\
\text { Utilization } \\
\text { Factor } \\
\left(E_{U} F_{v w)}\right.\end{array}$ & $\begin{array}{l}\text { Indicate the } \\
\text { overall CHP } \\
\text { system } \\
\text { efficiency } \\
\text { based on } \\
\text { monetary } \\
\text { value of } \\
\text { input fuel } \\
\text { and output } \\
\text { energy }\end{array}$ & $\begin{aligned} E U F_{V W}= & \frac{\text { Net Value of System Outputs }}{\text { Cost }_{\text {Fuel }}} \\
= & \frac{\sum_{j} W_{\text {Elec }, j} Y_{\text {Elec }, j}+\sum_{k} Q_{t h, k} Y_{\text {th }, k}}{\sum_{l} Q_{\text {Fuel }, l} \text { Price }_{\text {Fuel }, l}}\end{aligned}$ & $\begin{aligned} & E U F_{V W}= \text { value- } \\
& \text { weighted } \\
& \text { energy } \\
& \text { utilization } \\
& \text { factor } \\
& Y_{\text {Elec }}= \text { unit value of } \\
& \text { electricity } \\
& \text { produced } \\
& Y_{\text {th }, j}= \text { unit value of } \\
& \text { useful } \\
& \text { thermal } \\
& \text { energy } \\
& \text { output } \\
& \text { stream } j \\
& \text { Price }_{\text {Fuel, } j}= \text { price of fuel } \\
& \text { for fuel input } \\
& j \text { to the CHP } \\
& \text { system } \\
& \text { Cost }_{\text {Fuel }}= \text { total rate of } \\
& \text { expenditure } \\
& \text { on fuel for } \\
& \text { the system } \\
& \text { See below for other } \\
& \text { definitions }\end{aligned}$ \\
\hline $\begin{array}{l}\text { Current } \\
\text { Rate of } \\
\text { Useful } \\
\text { Thermal } \\
\text { Output }\left(Q_{t h}\right)\end{array}$ & $\begin{array}{l}\text { Indicate the } \\
\text { rate of } \\
\text { useful } \\
\text { thermal } \\
\text { output for } \\
\text { heating or } \\
\text { cooling by } \\
\text { the CHP } \\
\text { system }\end{array}$ & $Q_{t h}=\sum_{i} Q_{t h, j}$ & $\begin{aligned} Q_{t h}= & \text { total useful thermal } \\
& \text { energy output of } \\
& \text { the CHP system } \\
Q_{t h, j}= & \text { useful thermal } \\
& \text { energy output } j \text { of } \\
& \text { the CHP system }\end{aligned}$ \\
\hline
\end{tabular}

\footnotetext{
${ }^{3}$ The electricity terms include negative values corresponding to parasitic electricity use by pumps, fans, etc.
} 


\begin{tabular}{|c|c|c|c|}
\hline $\begin{array}{l}\text { Current } \\
\text { Electric } \\
\text { Power } \\
\text { Output } \\
\left(W_{E l e c}\right)\end{array}$ & $\begin{array}{l}\text { Indicate the } \\
\text { net electric } \\
\text { power } \\
\text { output from } \\
\text { the CHP } \\
\text { system }\end{array}$ & $W_{\text {Elec }}=\sum_{j} W_{E l e c, j}$ & $\begin{aligned} W_{\text {Elec }}= & \text { net electrical } \\
& \text { power output of } \\
& \text { the CHP system } \\
W_{\text {Elec }, j}= & \text { electrical output } j \\
& \text { from the CHP } \\
& \text { system (parasitic } \\
& \text { uses of electricity } \\
& \text { take negative } \\
& \text { values) }\end{aligned}$ \\
\hline $\begin{array}{l}\text { Current } \\
\text { Total Rate } \\
\text { of Fuel Use } \\
\left(Q_{\text {Fuel }}\right)\end{array}$ & $\begin{array}{l}\text { Indicate the } \\
\text { total rate of } \\
\text { fuel use by } \\
\text { the CHP } \\
\text { system }\end{array}$ & $Q_{\text {Fuel }}=\sum_{j} Q_{F u e l, j}$ & $\begin{aligned} Q_{\text {Fuel }}= & \text { total rate of fuel } \\
& \text { use by the CHP } \\
& \text { system } \\
Q_{\text {Fuel }, j}= & \text { rate of fuel use } \\
& \text { by fuel input } j \text { to } \\
& \text { the CHP system }\end{aligned}$ \\
\hline $\begin{array}{l}\text { Current } \\
\text { Expenditure } \\
\text { Rate for } \\
\text { Fuel } \\
\text { (Cost } \text { Cuel }_{\text {Ful }}\end{array}$ & $\begin{array}{l}\text { Indicate the } \\
\text { rate of } \\
\text { expenditure } \\
\text { of funds on } \\
\text { fuel for the } \\
\text { CHP plant }\end{array}$ & Cost $_{\text {Fuel }}=\sum_{j} Q_{\text {Fuel }, j}$ Price $_{\text {Fuel }, j}$ & $\begin{aligned} \text { Cost }_{\text {Fuel }}= & \text { total rate of } \\
& \text { monetary } \\
& \text { expenditure } \\
& \text { on fuel for } \\
& \text { the system } \\
Q_{\text {Fuel }, j}= & \text { rate of fuel } \\
& \text { use by fuel } \\
& \text { input } j \text { to the } \\
& \text { CHP system } \\
\text { Price }_{\text {Fuel }, j=}= & \text { price of fuel } \\
& \text { for fuel input } \\
& j \text { to the CHP } \\
& \text { system }\end{aligned}$ \\
\hline
\end{tabular}

\section{Efficiencies and Utilization Factors}

Average value for time period $t_{0}$ to $t_{1}$

$$
\begin{gathered}
\text { Daily Average Value }=\frac{\int_{t_{0}}^{t_{1}}(\text { MetricNum }) d t}{\int_{t_{0}}^{t_{1}}(\text { MetricDenom }) d t} \\
\approx \frac{\sum_{j=n_{0}}^{n_{1}} \text { MetricNum }_{j}}{\sum_{j=n_{0}}^{n_{1}} \text { MetricDenom }_{j}},
\end{gathered}
$$

Example applications of Eq. (5) to daily average efficiency or effectiveness and average over the last $\mathrm{n}$ hours follow. 


\section{Daily average value}

$$
\begin{gathered}
\text { Daily Average Value }=\frac{\int_{0}^{24 \text { hours }}(\text { MetricNum }) d t}{\int_{0}^{24 \text { hours }}(\text { MetricDenom }) d t} \\
\approx \frac{\sum_{j=1}^{24} \text { MetricNum }_{j}}{\sum_{j=1}^{24} \text { MetricDenom }_{j}},
\end{gathered}
$$

where MetricNum and MetricDenom are the numerator and denominator of the efficiency, effectiveness or utilization factor. For example, applying Eq. (6) to the fuel utilization efficiency,

$$
\begin{gathered}
\text { Average Daily } \eta_{F}=\frac{\int_{0}^{24 h o u r s}\left(W_{E l e c}+\sum_{j} Q_{t h, j}\right) d t}{\int_{0}^{24} Q_{\text {Fuel }} d t} \\
\approx \frac{\sum_{j=1}^{24}\left(W_{E l e c}+\sum_{k} Q_{t h, k}\right)_{j}}{\sum_{j=1}^{24} Q_{\text {Fuel }, j}},
\end{gathered}
$$

where the sum over the index $j$ is for the 24 hours of the day and the sum over index $k$ is over all useful thermal outputs of the CHP system.

Average value for the last $n$ hours

$$
\begin{aligned}
& \text { Average Metric Value Over Last } n \text { Hours }=\frac{\int_{t-n}^{t}(\text { MetricNum }) d t}{\int_{t-n}^{t}(\text { MetricDenom }) d t} \\
& \qquad \frac{\sum_{j=t-n}^{t} \text { MetricNum }_{j}}{\sum_{j=t-n}^{t} \text { MetricDenom }_{j}}
\end{aligned}
$$

As an example, applying Eq. (8) to the value-weighted energy utilization factor $\left(E U F_{V W}\right)$, 


$$
\begin{gathered}
\text { Average EUF } F_{V W} \text { Over Last } 8 \text { Hours }=\frac{\int_{t-8}^{t}\left(W_{\text {Elec }} Y_{\text {Elec }}+\sum_{k} Q_{t h, k} Y_{t h, k}\right) d t}{\left.\int_{t-8}^{t} \sum_{l} Q_{\text {Fuel }, l} \text { Price }_{\text {Fuel }, l}\right) d t} \\
\approx \frac{\sum_{j=-8}^{0}\left(W_{\text {Elec }} Y_{\text {Elec }}+\sum_{k} Q_{t h, k} Y_{t h, k}\right)_{j}}{\sum_{j=-8}^{0}\left(\sum_{l} Q_{\text {Fuel }, l} \text { Price }_{\text {Fuel }, l}\right)_{j}}
\end{gathered}
$$

Here, the summation over $j$ is for each of the last 8 hours, the summation over $k$ is for all useful thermal energy outputs from the system, and the summation over $l$ is for all fuel streams into the CHP system. All variables in Eq. (2) through Eq. (9) are defined in Table 1.

Eq. (1) through Eq. (9) can be used to determine average values of any of the system-level metrics identified earlier in this section and in Table 1. Averages for longer time periods (e.g., a week or a month) can be obtained by increasing the limits on the integrations or summations to the corresponding start and end times for which the average values are desired.

\section{Component Metrics}

The generic components of the CHP systems selected for development in this project are: turbines or reciprocating engines as prime movers, heat recovery units, including are heat exchangers, absorption chillers, which recovers waste heat from the prime mover to useful chilled water for cooling, supplemental vapor compression chillers to help meet cooling loads during times when the vapor compression chiller cannot or does not meet the entire load, ${ }^{4}$ cooling towers to reject heat, desiccant systems for dehumidifying air, pumps for moving liquid, and fans for moving air. Equations for the efficiency of these components are provided in Brambley and Katipamula (2006) and are summarized in Table 2.

\footnotetext{
${ }^{4}$ Vapor compression chillers used for this purpose often are not considered part of the CHP system, but because use of absorption chilling must be optimized as part of a larger system that includes vapor compression chilling, they must be included in decisions made by the supervisory controller regarding how much absorption chilling and how much vapor compression chilling to use to meet the total cooling load.
} 
Table 2. Summary of basic and detailed relations for CHP components efficiencies.

\begin{tabular}{|c|c|c|c|c|}
\hline Component & Purpose & $\begin{array}{c}\text { Basic } \\
\text { Efficiencyl } \\
\text { Effectiveness } \\
\text { Relation }\end{array}$ & $\begin{array}{c}\text { Detailed Efficiency/Effectiveness } \\
\text { Relation }\end{array}$ & Variables \\
\hline $\begin{array}{l}\text { Small turbine } \\
\text { generators }\end{array}$ & $\begin{array}{l}\text { Prime mover } \\
\text { to generate } \\
\text { electricity }\end{array}$ & $\eta_{E E}=\frac{W_{\text {Elec }}}{Q_{\text {Fuel,engine }}}$ & $\eta_{E E}=\frac{W_{\text {Elec }}}{\rho_{\text {Fuel }} \dot{v}_{\text {Fuel }} L H V_{\text {Fuel }}}$ & $\begin{aligned} \eta_{E E}= & \text { electric generation efficiency } \\
W_{\text {Elec }}= & \text { net electrical power output } \\
Q_{\text {Fuel.engine }}= & \text { total rate of input of fuel energy to } \\
& \text { the prime mover } \\
\rho_{\text {Fuel }}= & \text { fuel density } \\
\dot{v}_{\text {Fuel }} & =\text { fuel flow rate } \\
L H V_{\text {Fuel }}= & \text { lower heating value of the fuel }\end{aligned}$ \\
\hline $\begin{array}{l}\text { Reciprocating } \\
\text { Engines }\end{array}$ & $\begin{array}{l}\text { Prime mover } \\
\text { to generate } \\
\text { electricity }\end{array}$ & $\eta_{E E}=\frac{W_{\text {Elec }}}{Q_{\text {Fuel,engine }}}$ & $\eta_{E E}=\frac{W_{\text {Elec }}}{\rho_{\text {Fuel }} \dot{v}_{\text {Fuel }} L H V_{\text {Fuel }}}$ & $\begin{aligned} \eta_{E E}= & \text { electric generation efficiency } \\
W_{\text {Elec }}= & \text { net electrical power output } \\
Q_{\text {Fuel.engine }}= & \text { total rate of input of fuel energy to } \\
& \text { the prime mover } \\
\rho_{\text {Fuel }}= & \text { fuel density } \\
\dot{v}_{\text {Fuel }} & =\text { fuel flow rate } \\
L H V_{\text {Fuel }}= & \text { lower heating value of the fuel }\end{aligned}$ \\
\hline $\begin{array}{l}\text { Heat } \\
\text { Recovery } \\
\text { Units (HRU) - } \\
\text { Exhaust Gas } \\
\text { to Water }\end{array}$ & $\begin{array}{l}\text { Heat } \\
\text { exchange from } \\
\text { hot exhaust } \\
\text { gases from the } \\
\text { prime mover to } \\
\text { water }\end{array}$ & $\varepsilon_{H R U}=\frac{Q_{H R U, \text { actual }}}{Q_{H R U, \max }}$ & $\varepsilon_{H R U}=\frac{\left(T_{H R U, e x, i}-T_{H R U, e x, o}\right)}{\left(T_{H R U, e x, i}-T_{H R U, w, i}\right)}$ & $\begin{aligned} \varepsilon_{H R U}= & \text { heat recovery unit effectiveness } \\
Q_{H R U, a c t u a l}= & \text { rate of heat gain by the heat } \\
& \text { recovery fluid } \\
Q_{H R U, \text { max }}= & \text { maximum possible rate of heat } \\
& \text { loss from the waste heat stream } \\
& \text { from the prime mover in the HRU } \\
T_{H R U, \text { ex }, i}= & \text { temperature of the exhaust gas } \\
& \text { entering the HRU } \\
T_{H R U, e x, o}= & \text { temperature of the exhaust gas } \\
& \text { leaving the HRU } \\
T_{H R U, w, i}= & \text { temperature of water entering the } \\
& \text { HRU }\end{aligned}$ \\
\hline
\end{tabular}




\begin{tabular}{|c|c|c|c|c|}
\hline Component & Purpose & $\begin{array}{c}\text { Basic } \\
\text { Efficiencyl } \\
\text { Effectiveness } \\
\text { Relation }\end{array}$ & $\begin{array}{c}\text { Detailed Efficiency/Effectiveness } \\
\text { Relation }\end{array}$ & Variables \\
\hline $\begin{array}{l}\text { Heat } \\
\text { Recovery } \\
\text { Units (HRU) - } \\
\text { Exhaust Gas } \\
\text { to Air }\end{array}$ & $\begin{array}{l}\text { Heat } \\
\text { exchange from } \\
\text { hot exhaust } \\
\text { gases from the } \\
\text { prime mover to } \\
\text { air }\end{array}$ & $\varepsilon_{H R U}=\frac{Q_{H R U, \text { actual }}}{Q_{H R U, \max }}$ & $\begin{array}{c}\varepsilon_{H R U}=\frac{\left(T_{H R U, e x, i}-T_{H R U, e x, o}\right)}{\left(T_{H R U, e x, i}-T_{H R U, a, i}\right)} \\
\text { for }\left(\rho \dot{v} c_{p}\right)_{H R U, \text { min }}= \\
\rho_{H R U, e x, i} \dot{v}_{H R U, e x, i} c_{p, H R U, e x} \\
\varepsilon_{H R U}=\frac{\left(T_{H R U, a, o}-T_{H R U, a, i}\right)}{\left(T_{H R U, e x, i}-T_{H R U, a, i}\right)} \\
\text { for }\left(\rho \dot{v} c_{p}\right)_{H R U, \min }=\rho_{H R U, a, i} \dot{v}_{H R U, a, i} c_{p, H R U, a}\end{array}$ & $\begin{aligned} \varepsilon_{H R U}= & \text { heat recovery unit effectiveness } \\
Q_{H R U, a c t u a l}= & \text { actual rate of heat gain by the } \\
& \text { heat recovery fluid } \\
Q_{H R U, \text { max }}= & \text { maximum possible rate of heat } \\
& \text { loss from the waste heat stream } \\
& \text { from the prime mover in the HRU } \\
T_{H R U, e x, i}= & \text { temperature of the exhaust gas } \\
& \text { entering the HRU } \\
T_{H R U, e x, o}= & \text { temperature of the exhaust gas } \\
& \text { leaving the HRU } \\
T_{H R U, a, i}= & \text { temperature of air entering the } \\
& \text { HRU } \\
T_{H R U, a, o}= & \text { temperature of air leaving the } \\
& \text { HRU } \\
\rho_{H R U, e x, i}= & \text { density of exhaust gas entering } \\
& \text { the HRU } \\
\dot{v}_{H R U, e x, i}= & \text { volumetric flow rate of exhaust } \\
& \text { gas entering the HRU } \\
c_{p, H R U, e x}= & \text { heat capacity of the exhaust gas } \\
& \text { evaluated at the average of the } \\
& \text { exhaust inlet and outlet } \\
& \text { temperatures of the HRU } \\
\dot{v}_{H R U, a, i}= & \text { density of air entering the HRU } \\
= & \text { volumetric flow rate of air entering } \\
\dot{v}_{H R U, a, i}= & \text { the HRU } \\
c_{p, H R U, a}= & \text { heat capacity of air evaluated at } \\
& \text { the average of the air inlet and air } \\
& \text { outlet temperatures of the HRU }\end{aligned}$ \\
\hline
\end{tabular}




\begin{tabular}{|c|c|c|c|c|}
\hline Component & Purpose & $\begin{array}{c}\text { Basic } \\
\text { Efficiencyl } \\
\text { Effectiveness } \\
\text { Relation } \\
\end{array}$ & $\begin{array}{c}\text { Detailed Efficiency/Effectiveness } \\
\text { Relation }\end{array}$ & Variables \\
\hline $\begin{array}{l}\text { Heat } \\
\text { Recovery } \\
\text { Steam } \\
\text { Generators } \\
\text { (HRSG) }\end{array}$ & $\begin{array}{l}\text { Heat } \\
\text { exchange from } \\
\text { hot exhaust } \\
\text { gases from the } \\
\text { prime mover to } \\
\text { generate } \\
\text { steam }\end{array}$ & $\varepsilon_{H R S G}=\frac{Q_{H R S G, \text { actual }}}{Q_{H R S G, \max }}$ & $\varepsilon_{H R S G}=\frac{T_{H R S G, e x, i}-T_{H R S G, e x, \mathrm{o}}}{T_{H R S G, e x, i}-T_{H R S G, w, i}}$ & $\begin{aligned} \varepsilon_{H R S G}= & \text { heat recovery steam generator } \\
& \text { effectiveness } \\
Q_{H R S G, a c t u a l}= & \text { actual rate of heat gain by the } \\
& \text { feed water } \\
Q_{H R S G, \text { max }}= & \text { maximum possible rate of heat } \\
& \text { loss from the exhaust heat } \\
& \text { stream from the prime mover in } \\
& \text { the HRSG } \\
T_{H R S G, e x, i}= & \text { temperature of the exhaust gas } \\
& \text { entering the HRSG } \\
T_{H R S G, e x, o}= & \text { temperature of the exhaust gas } \\
& \text { leaving the HRSG } \\
T_{H R S G, w, i}= & \text { temperature of water entering } \\
& \text { the HRSG }\end{aligned}$ \\
\hline
\end{tabular}




\begin{tabular}{|c|c|c|c|c|}
\hline Component & Purpose & $\begin{array}{l}\text { Basic } \\
\text { Efficiencyl } \\
\text { Effectiveness } \\
\text { Relation }\end{array}$ & $\begin{array}{l}\text { Detailed Efficiency/Effectiveness } \\
\text { Relation }\end{array}$ & Variables \\
\hline $\begin{array}{l}\text { Absorption } \\
\text { Chillers - } \\
\text { Direct Fired }\end{array}$ & $\begin{array}{l}\text { Generate } \\
\text { chilled water } \\
\text { using heat } \\
\text { directly from } \\
\text { exhaust gases } \\
\text { to drive } \\
\text { refrigerant } \\
\text { from solution } \\
\text { in an } \\
\text { absorption } \\
\text { refrigeration } \\
\text { cycle }\end{array}$ & $C O P_{A b \text { Chiller }}=\frac{Q_{\text {evap }}}{Q_{\text {gen }}}$ & $\begin{array}{l}C O P_{\text {AbChiller }} \\
=\frac{\dot{v}_{\text {evap }, w, i} \rho_{\text {evap }, w, i} c_{p, w}\left(T_{\text {evap }, w, i}-T_{\text {evap }, w, \mathrm{o}}\right)}{\dot{v}_{e x, i} \rho_{e x, i} c_{p, e x}\left(T_{e x, i}-T_{e x, \mathrm{o}}\right)}\end{array}$ & $\begin{aligned} C O P_{A b C h i l l e r}=\text { coefficient of performance of the } & \text { absorption chiller } \\
Q_{\text {evap }}= & \text { rate of heat loss from chilled water } \\
& \text { as it passes through the evaporator } \\
Q_{g e n}= & \text { rate of heat loss from the exhaust } \\
& \text { gases as they pass through the } \\
& \text { refrigerant generator } \\
T_{\text {evap }, w, i}= & \text { temperature of the chilled water } \\
& \text { entering the evaporator } \\
T_{\text {evap }, w, o=}= & \text { temperature of the chilled water } \\
& \text { leaving the evaporator } \\
T_{e x, i}= & \text { temperature of exhaust entering the } \\
& \text { chiller } \\
T_{e x, o}= & \text { temperature of exhaust leaving the } \\
& \text { chiller } \\
\rho_{\text {evap }, w, i}= & \text { density of water entering the chiller } \\
\dot{v}_{\text {evap }, w, i}= & \text { volumetric flow rate of water entering } \\
& \text { the chiller } \\
\rho_{e x, i}= & \text { density of exhaust gas entering the } \\
& \text { chiller } \\
\dot{v}_{e x, i}= & \text { volumetric flow rate of exhaust gas } \\
& \text { entering the chiller } \\
c_{p, e x}= & \text { heat capacity of the exhaust gas } \\
& \text { evaluated at the average of its } \\
& \text { entering and leaving temperatures } \\
c_{p, w}= & \text { heat capacity of water }\end{aligned}$ \\
\hline
\end{tabular}




\begin{tabular}{|c|c|c|c|c|}
\hline Component & Purpose & $\begin{array}{c}\text { Basic } \\
\text { Efficiencyl } \\
\text { Effectiveness } \\
\text { Relation }\end{array}$ & $\begin{array}{l}\text { Detailed Efficiency/Effectiveness } \\
\text { Relation }\end{array}$ & Variables \\
\hline $\begin{array}{l}\text { Absorption } \\
\text { Chillers - Hot } \\
\text { Water Fired }\end{array}$ & $\begin{array}{l}\text { Generate } \\
\text { chilled water } \\
\text { using heat } \\
\text { from hot water } \\
\text { generated by } \\
\text { an HRU to } \\
\text { drive } \\
\text { refrigerant } \\
\text { from solution } \\
\text { in an } \\
\text { absorption } \\
\text { refrigeration } \\
\text { cycle }\end{array}$ & $C O P_{A b \text { Chiller }}=\frac{Q_{\text {evap }}}{Q_{\text {gen }}}$ & 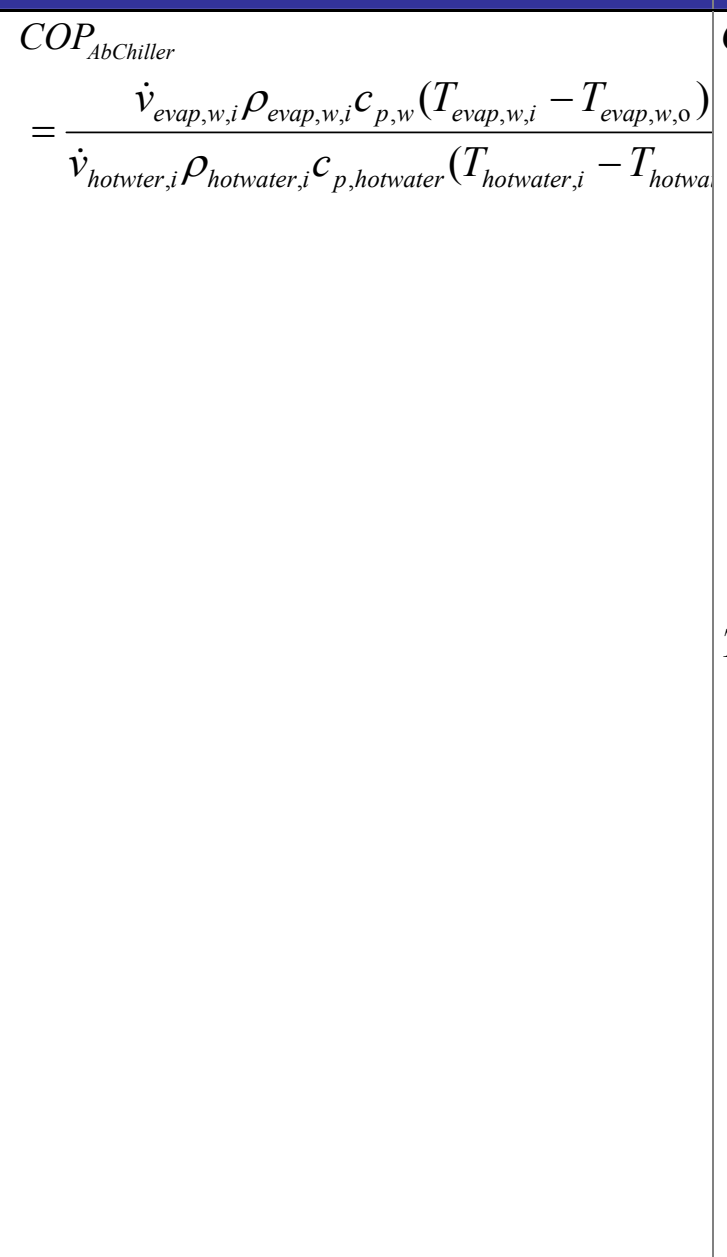 & $\begin{aligned} C O P_{A b C h i l l e r}= & \text { coefficient of performance of the } \\
& \text { absorption chiller } \\
Q_{\text {evap }}= & \text { rate of heat loss from the chilled } \\
& \text { water as it passes through the } \\
& \text { evaporator } \\
Q_{\text {gen }}= & \text { rate of heat loss from the hot water } \\
& \text { as it passes through the refrigerant } \\
& \text { generator } \\
T_{\text {evap }, w, i}= & \text { temperature of the chilled water } \\
& \text { entering the evaporator } \\
T_{\text {evap }, w, o}= & \text { temperature of the chilled water } \\
& \text { leaving the evaporator } \\
T_{\text {hotwter }, i}= & \text { temperature of the hot water } \\
& \text { entering the chiller } \\
T_{\text {hotwater }, o}= & \text { temperature of the hot water } \\
& \text { leaving the chiller } \\
\rho_{\text {evap }, w, i}= & \text { density of chilled water entering the } \\
& \text { chiller } \\
\dot{v}_{\text {evap }, w, i}= & \text { volumetric flow rate of chilled water } \\
& \text { entering the chiller } \\
\rho_{\text {hotwater }, i}= & \text { density of hot water entering the } \\
& \text { chiller } \\
\dot{v}_{\text {hotwater }, i}= & \text { volumetric flow rate of the hot water } \\
& \text { entering the chiller } \\
c_{p, \text { hotwater }}= & \text { heat capacity of the hot water } \\
c_{p, w}= & \text { heat capacity of the chilled water }\end{aligned}$ \\
\hline
\end{tabular}




\begin{tabular}{|c|c|c|c|c|}
\hline Component & Purpose & $\begin{array}{l}\text { Basic } \\
\text { Efficiencyl } \\
\text { Effectiveness } \\
\text { Relation }\end{array}$ & $\begin{array}{l}\text { Detailed Efficiency/Effectiveness } \\
\text { Relation }\end{array}$ & Variables \\
\hline $\begin{array}{l}\text { Absorption } \\
\text { Chillers - } \\
\text { Steam Fired }\end{array}$ & $\begin{array}{l}\text { Generate } \\
\text { chilled water } \\
\text { using heat } \\
\text { from steam } \\
\text { generated by } \\
\text { an HRSG to } \\
\text { drive } \\
\text { refrigerant } \\
\text { from solution } \\
\text { in an } \\
\text { absorption } \\
\text { refrigeration } \\
\text { cycle }\end{array}$ & $C O P_{A b \text { Chiller }}=\frac{Q_{\text {evap }}}{Q_{\text {gen }}}$ & $\begin{array}{l}C O P_{\text {AbChiller }} \\
=\frac{\dot{v}_{\text {evap }, w, i} \rho_{\text {evap }, w i} c_{p, w}\left(T_{\text {evap }, w, i}-T_{\text {evap }, w, \mathrm{o}}\right)}{\dot{v}_{s, i} \rho_{s, i}\left[h\left(T_{i}, P_{i}\right)_{s, i}-h\left(T_{o}, P_{o}\right)_{s, 0}\right]}\end{array}$ & $\begin{aligned} C O P_{\text {AbChiller }}= & \text { coefficient of performance of the } \\
& \text { absorption chiller } \\
Q_{\text {evap }}= & \text { rate of heat loss from the chilled } \\
& \text { water as it passes through the } \\
& \text { evaporator } \\
Q_{g e n}= & \text { rate of heat loss from the hot } \\
& \text { water as it passes through the } \\
& \text { generator } \\
T_{\text {evap }, w, i}= & \text { temperature of the chilled water } \\
& \text { entering the evaporator } \\
T_{\text {evap } w, o}= & \text { temperature of the chilled water } \\
& \text { leaving the evaporator } \\
h\left(T_{i}, P_{i}\right)_{s, i}= & \text { specific enthalpy of steam } \\
& \text { entering the chiller generator at } \\
& \text { temperature } T_{i} \text { and pressure } P_{i} \\
h\left(T_{o}, P_{o}\right)_{s, o}= & \text { specific enthalpy of steam leaving } \\
& \text { the chiller generator at } \\
& \text { temperature } T_{o} \text { and pressure } P_{o} \\
\rho_{\text {evap }, w, i}= & \text { density of chilled water entering } \\
& \text { the chiller } \\
\dot{v}_{\text {evap }, w, i}= & \text { volumetric flow rate of chilled } \\
& \text { water entering the chiller } \\
\rho_{\text {steam }, i}= & \text { density of steam entering the } \\
& \text { chiller } \\
\dot{v}_{\text {steam }, i}= & \text { volumetric flow rate of the steam } \\
& \text { entering the chiller } \\
c_{p, w}= & \text { heat capacity of the chilled water }\end{aligned}$ \\
\hline
\end{tabular}




\begin{tabular}{|c|c|c|c|c|}
\hline Component & Purpose & $\begin{array}{c}\text { Basic } \\
\text { Efficiencyl } \\
\text { Effectiveness } \\
\text { Relation }\end{array}$ & $\begin{array}{c}\text { Detailed Efficiency/Effectiveness } \\
\text { Relation }\end{array}$ & Variables \\
\hline $\begin{array}{l}\text { Vapor- } \\
\text { Compression } \\
\text { Chillers }\end{array}$ & $\begin{array}{l}\text { Generate } \\
\text { chilled water } \\
\text { using electric } \\
\text { power to drive } \\
\text { compressors } \\
\text { in a vapor- } \\
\text { compression } \\
\text { refrigeration } \\
\text { cycle }\end{array}$ & $C O P_{\text {Chiller }}=\frac{Q_{\text {evap }}}{W_{\text {ChillerElec }}}$ & $\begin{array}{l}\text { COP } P_{\text {Chiller }} \\
=\frac{\dot{v}_{\text {evap }, w, i} \rho_{\text {evap }, w, i} c_{p, w}\left(T_{\text {evap }, w, i}-T_{\text {evap }, w, \mathrm{o}}\right)}{W_{\text {ChillerElec }}}\end{array}$ & $\begin{aligned} C O P_{\text {Chiller }}= & \text { coefficient of performance of the } \\
& \text { chiller } \\
Q_{\text {evap }}= & \text { rate of heat loss from chilled water } \\
& \text { passing through the evaporator } \\
W_{\text {ChillerElec }}= & \text { electric power input to the chiller } \\
T_{\text {evap }, w, i}= & \text { temperature of the chilled water } \\
& \text { entering the evaporator } \\
T_{\text {evap }, w, o}= & \text { temperature of the chilled water } \\
& \text { leaving the evaporator } \\
\rho_{\text {evap }, w, i}= & \text { density of chilled water entering } \\
& \text { the chiller } \\
\dot{v}_{\text {evap }, w, i}= & \text { volumetric flow rate of chilled } \\
& \text { water entering the chiller } \\
c_{p, w}= & \text { heat capacity of the chilled water }\end{aligned}$ \\
\hline
\end{tabular}




\begin{tabular}{|c|c|c|c|c|}
\hline Component & Purpose & $\begin{array}{c}\text { Basic } \\
\text { Efficiencyl } \\
\text { Effectiveness } \\
\text { Relation }\end{array}$ & $\begin{array}{c}\text { Detailed Efficiency/Effectiveness } \\
\text { Relation }\end{array}$ & Variables \\
\hline $\begin{array}{l}\text { Cooling } \\
\text { Towers }\end{array}$ & $\begin{array}{l}\text { Cool chiller } \\
\text { cooling water } \\
\text { via } \\
\text { evaporation } \\
\text { and sensible } \\
\text { heat transfer } \\
\text { to ambient air }\end{array}$ & $\begin{array}{c}\eta_{C T}=\frac{\left(T_{C T, w, i}-T_{C T, w, o}\right)}{\left(T_{C T, w, i}-T_{w b}\right)} \\
\eta_{C T, \text { Elec }}=\frac{Q_{C T, t h}}{W_{C T, \text { elec }}}\end{array}$ & $\begin{array}{c}\eta_{C T}=\frac{\left(T_{C T, w, i}-T_{C T, w, o}\right)}{\left(T_{C T, w, i}-T_{w b}\right)} \\
\eta_{C T, \text { Elec }}=\frac{\rho_{w} \dot{v}_{C T, w} c_{p, w}\left(T_{C T, w, i}-T_{C T, w, o}\right)}{\sum_{j} W_{C T, \text { elec }, j}}\end{array}$ & $\begin{aligned} \eta_{C T}= & \text { cooling tower efficiency } \\
& \text { (effectiveness) } \\
\eta_{C T, \text { Elec }}= & \text { cooling tower electric utilization } \\
& \text { efficiency } \\
T_{C T, w, i}= & \text { inlet temperature of condenser } \\
& \text { water to the tower } \\
T_{C T, w, o}= & \text { outlet temperature of condenser } \\
& \text { water from the tower } \\
T_{w b}= & \text { wet bulb temperature of the ambient } \\
& \text { air } \\
Q_{C T, t h}= & \text { rate of heat loss by the cooling } \\
& \text { water as it passes through the } \\
& \text { cooling tower } \\
W_{C T, \text { elec }}= & \text { electric power use by the cooling } \\
& \text { tower fans and pumps } \\
W_{C T, \text { elec }, j}= & \text { electric power use by cooling tower } \\
& \text { fan or pump j } \\
\rho_{w}= & \text { density of water } \\
\dot{v}_{C T, w}= & \text { water volumetric flow rate } \\
c_{p, w}= & \text { heat capacity of water }\end{aligned}$ \\
\hline
\end{tabular}




\begin{tabular}{|c|c|c|c|c|}
\hline Component & Purpose & $\begin{array}{c}\text { Basic } \\
\text { Efficiencyl } \\
\text { Effectiveness } \\
\text { Relation }\end{array}$ & $\begin{array}{c}\text { Detailed Efficiency/Effectiveness } \\
\text { Relation }\end{array}$ & Variables \\
\hline $\begin{array}{l}\text { Desiccant } \\
\text { Systems }\end{array}$ & $\begin{array}{l}\text { Remove } \\
\text { moisture from } \\
\text { air with the } \\
\text { desiccant } \\
\text { regenerated } \\
\text { using waste } \\
\text { heat }\end{array}$ & $\eta_{D}=\frac{Q_{d}}{Q_{d, \text { input }}}$ & $\begin{array}{l}\eta_{D} \\
=\frac{(\dot{v} \rho)_{d, a}\left[h(T, D P)_{d, a, i}-h(T, D P)_{d, a, o}-c_{p, d, a}\left(T_{d . a, i}\right.\right.}{\left(\dot{v} \rho c_{p}\right)_{d, e x}\left(T_{d . e x, i}-T_{d, e x, o}\right)+W_{d, E l e c}}\end{array}$ & $\begin{aligned} \eta_{D}= & \text { desiccant system efficiency } \\
Q_{d}= & \text { rate of heat transferred to the } \\
& \text { moist air stream specifically } \\
& \text { used to remove moisture } \\
& \text { (dehumidification load) } \\
Q_{\text {d.input }}= & \text { total rate of energy (heat and } \\
& \text { electricity) input for desiccant } \\
& \text { regeneration } \\
W_{d, E l e c}= & \text { total electric power input to the } \\
& \text { desiccant system } \\
(\dot{v} \rho)_{d, a}= & \text { product of the volumetric flow } \\
& \text { rate and density (mass flow } \\
& \text { rate) of air through the air-side } \\
& \text { of the desiccant system } \\
(\dot{v} \rho)_{\mathrm{d}, \mathrm{ex}}= & \text { product of volumetric flow rate } \\
& \text { and density (mass flow rate) of } \\
& \text { exhaust through the } \\
& \text { regeneration side of the } \\
& \text { desiccant system } \\
\mathrm{c}_{\mathrm{p}, \mathrm{d}, \mathrm{a}}= & \text { heat capacity of air in the } \\
& \text { process (air) side of the } \\
& \text { desiccant system } \\
\left(\mathrm{c}_{\mathrm{p}}\right)_{\mathrm{d}, \mathrm{ex}}= & \text { heat capacity of exhaust gas in } \\
& \text { the regeneration side of the } \\
& \text { desiccant system } \\
h(T, D P)_{d, a, i}= & \text { specific enthalpy of air at the } \\
& \text { inlet dry-bulb and dew-point } \\
& \text { temperatures }(\mathrm{T}, \mathrm{DP})_{\mathrm{d}, \mathrm{a}, \mathrm{i}} \text { of the } \\
& \text { desiccant system } \\
= & \text { specific enthalpy of air at the } \\
& \text { outlet dry-bulb and dew-point }\end{aligned}$ \\
\hline
\end{tabular}




\begin{tabular}{|c|c|c|c|c|}
\hline Component & Purpose & $\begin{array}{c}\text { Basic } \\
\text { Efficiencyl } \\
\text { Effectiveness } \\
\text { Relation }\end{array}$ & $\begin{array}{c}\text { Detailed Efficiency/Effectiveness } \\
\text { Relation }\end{array}$ & Variables \\
\hline & & & & $\begin{aligned} & \text { temperatures }(\mathrm{T}, \mathrm{DP})_{\mathrm{d}, \mathrm{a}, \mathrm{o}} \text { of the } \\
& \text { desiccant system } \\
& T_{d, a, i}= \text { dry-bulb temperature of the air } \\
& \text { at the inlet to the desiccant unit } \\
& T_{d, a, o}= \text { dry-bulb temperature of the air } \\
& \text { at the outlet of the desiccant } \\
& \text { unit } \\
& T_{d, e x, i}= \begin{array}{l}\text { dry-bulb temperature of the } \\
\text { exhaust at the inlet to the } \\
\text { regeneration side of the } \\
\text { desiccant unit }\end{array} \\
& T_{d, e x, o}= \text { dry-bulb temperature of the } \\
& \text { exhaust at the outlet of the } \\
& \text { regeneration side of the } \\
& \text { desiccant unit }\end{aligned}$ \\
\hline Pumps & $\begin{array}{l}\text { Create a } \\
\text { pressure } \\
\text { difference in } \\
\text { liquid to } \\
\text { instigate flow } \\
\text { using an } \\
\text { electric motor } \\
\text { as a source of } \\
\text { mechanical } \\
\text { rotational } \\
\text { energy }\end{array}$ & $\eta_{\text {Pump }}=\frac{W_{\text {Pump }}}{W_{\text {Pump }, \text { Elec }}}$ & $\eta_{\text {Pump }}=\frac{\dot{v}_{\text {Pump }}\left(P_{\text {disch arge }}-P_{\text {suction }}\right)}{W_{\text {Pump }, \text { elec }}}$ & $\begin{aligned} \eta_{\text {Pump }}= & \text { pump efficiency } \\
W_{\text {Pump }}= & \text { mechanical power output from the } \\
& \text { pump to the liquid } \\
W_{\text {Pump }, \text { Elec }}= & \text { electric power input to the pump } \\
& \text { motor } \\
\dot{v}_{\text {Pump }}= & \text { volumetric flow rate through the } \\
& \text { pump } \\
P_{\text {discharge }}= & \text { discharge pressure at the pump } \\
& \text { outlet } \\
P_{\text {suction }}= & \text { suction pressure at the pump inlet }\end{aligned}$ \\
\hline
\end{tabular}




\begin{tabular}{|c|c|c|c|c|}
\hline Component & Purpose & $\begin{array}{c}\text { Basic } \\
\text { Efficiencyl } \\
\text { Effectiveness } \\
\text { Relation }\end{array}$ & $\begin{array}{c}\text { Detailed Efficiency/Effectiveness } \\
\text { Relation }\end{array}$ & Variables \\
\hline Fans & $\begin{array}{l}\text { Create a } \\
\text { pressure } \\
\text { difference in } \\
\text { air to support } \\
\text { flow, using an } \\
\text { electric motor } \\
\text { as the source } \\
\text { of mechanical } \\
\text { rotational } \\
\text { energy }\end{array}$ & $\eta_{\text {Fan }}=\frac{W_{\text {Fan }}}{W_{\text {Fan,elec }}}$ & $\eta_{\text {Fan }}=\frac{\dot{v}_{F a n}\left(P_{F a n, o}-P_{F a n, i}\right)}{W_{F a n, e l e c}}$ & $\begin{aligned} \eta_{\text {Fan }} & =\text { overall efficiency of the fan } \\
W_{F a n} & =\text { useful power output from the fan } \\
W_{\text {Fan,elec }} & =\text { electric power input to the fan motor } \\
\dot{v}_{F a n} & =\text { volumetric flow rate through the fan } \\
P_{\text {Fan,o }}= & \text { pressure immediately downstream of } \\
& \text { the fan } \\
P_{\text {Fan,i }}= & \text { pressure immediately upstream of } \\
& \text { the fan }\end{aligned}$ \\
\hline
\end{tabular}




\section{Performance Monitoring and Verification}

System level monitoring is provided to ensure that the overall CHP system is performing up to specifications and that significant degradation in performance has not occurred. If degradation is detected and quantified, monitored component-level information can be used to isolate the cause of degradation and correct it. This process is illustrated in the Application Scenario section of Brambley and Katipamula (2006).

Performance verification is a part of performance monitoring and focuses on comparing the performance of the system and its major components to their original (ideally commissioned) performance during routine operation of the CHP system. The purpose of performance verification is to ensure that peak performance is preserved during operation of the system and to provide a basis for condition-based maintenance and performance adjustments. When performance significantly deviates from the expected level (baseline), alarms are automatically triggered to alert operators to the performance degradation so that actions can be taken to improve system performance and get it back to its expected level. The approach selected for performance monitoring constantly compares overall CHP system as well as individual component performance metrics to the values for this specific system and its components during a baseline period.

A multi-dimensional bin-based method for modeling the initial (baseline) performance of the system and its components was presented in Brambley and Katipamula (2006). The method can be applied to both new and existing CHP systems. In both cases, ideally, the system is commissioned or re-commissioned shortly before starting performance monitoring.

Commissioning at that time will help ensure that performance verification is done relative to the best performance levels; however, the method will work even on existing systems that have not been commissioned recently.

The values of the performance metrics provided by the models are compared to actual measured values (or values calculated from measurements) to determine whether the current measured performance deviates sufficiently from the expected (modeled) performance to warrant an alarm [i.e., the difference between the measurement-based value and the baseline value from the model exceeds a specified alarm threshold; see Eq. (55) in Brambley and Katipamula (2006)].

The generic algorithm for performance verification of individual components, subsystems, and the entire CHP system is shown as a flow chart in Figure 2 through Figure 4. This process can be applied to any of the performance metrics identified in the preceding sections. Creation of the baseline (see Figure 2) requires careful selection of all independent variables for the model, which have a significant impact on performance of the system or component but are not controllable by system operators (e.g., outdoor-air temperature for gas turbines) or are dictated by other decisions (e.g., electrical output for a turbine-generator in a CHP system that follows the thermal load). 


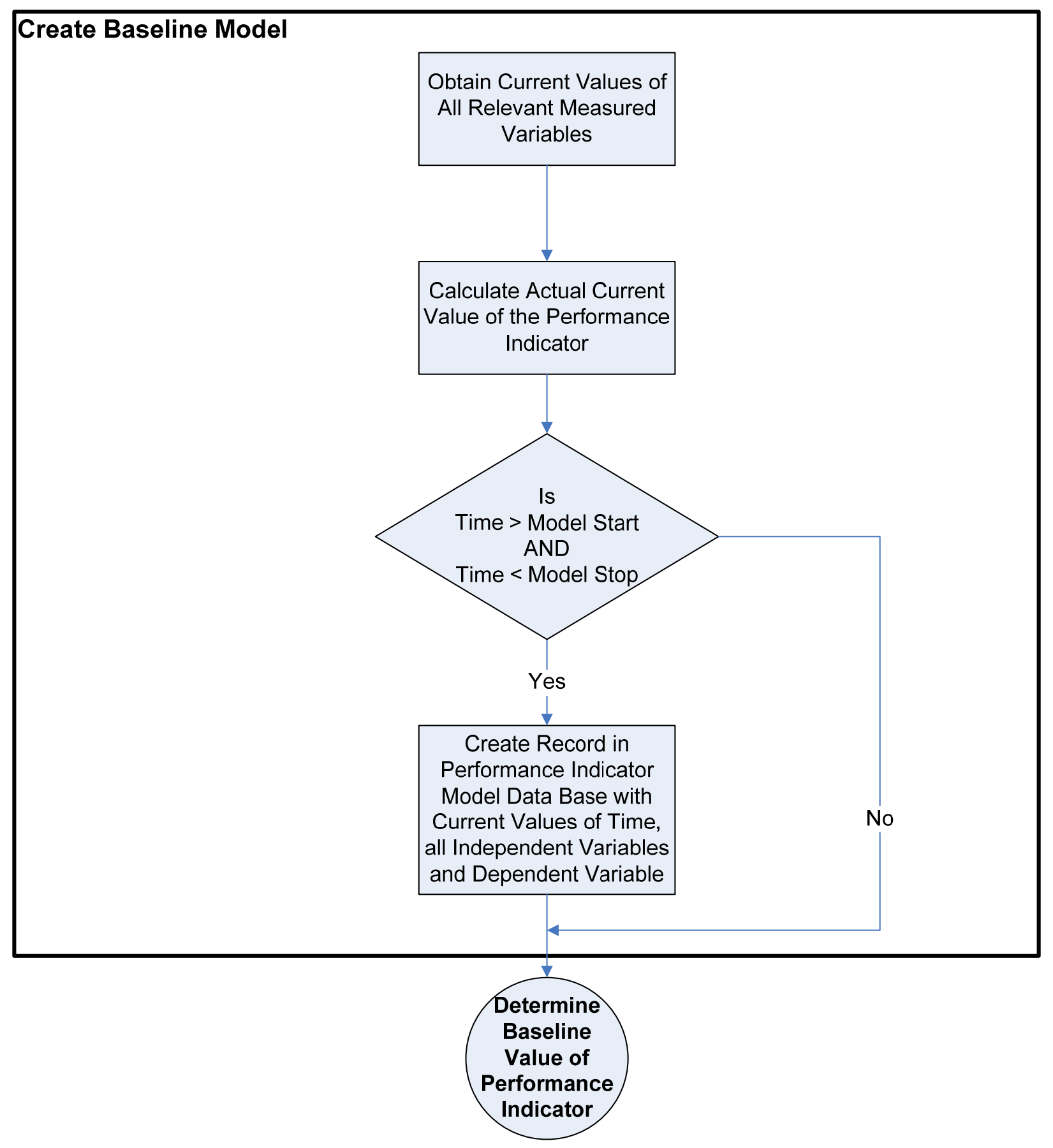

Figure 2. Flow chart for performance monitoring/verification sub-process of creating a baseline model. 


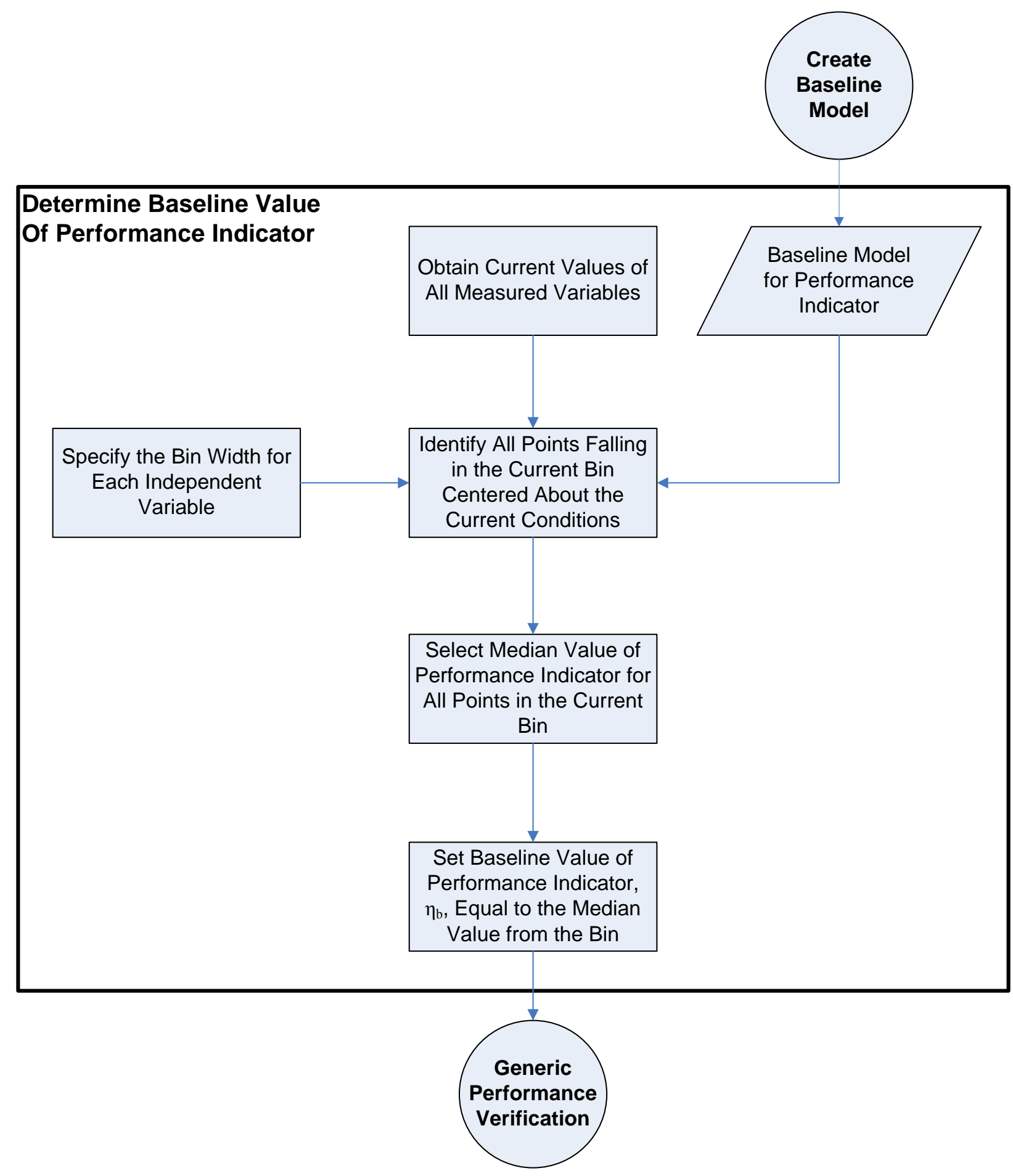

Figure 3. Flow chart for performance monitoring/verification sub-process of determining the baseline (expected) value of the performance indicator. 


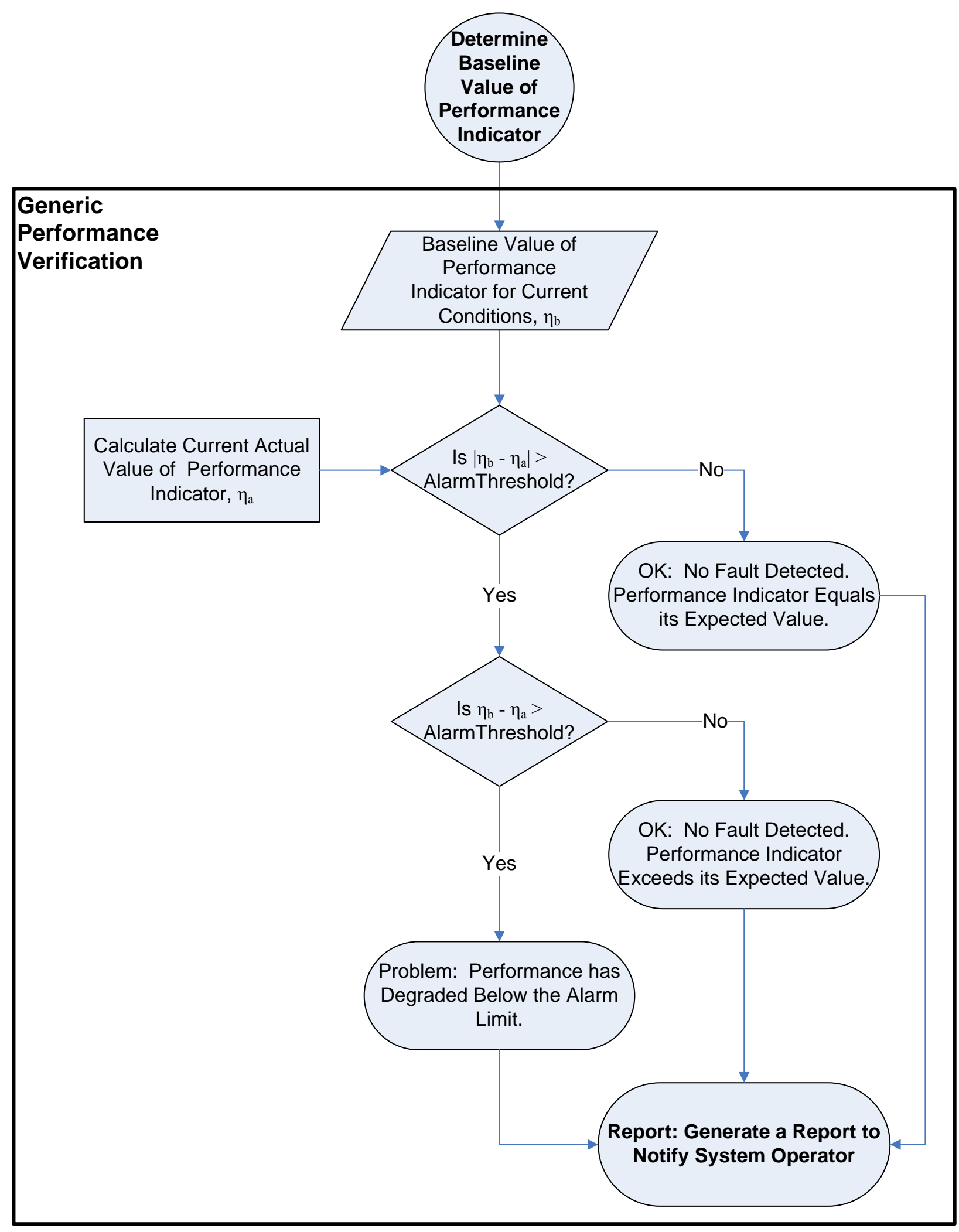

Figure 4. Flow chart for performance monitoring/verification. 


\section{Commissioning Verification (CxV)}

Commissioning verification $(\mathrm{CxV})$ is a process by which the actual performance of the individual components in a CHP system and the performance of the CHP system as a whole are verified to comply with the designers' and manufacturers' specified and recommended performance. Verification of proper commissioning generally would be done prior to beginning performance monitoring. The $\mathrm{CxV}$ process ensures that all adjustments required to maximize performance of the system were adequately performed during the commissioning process. If they were not, components not adequately commissioned will fail and be identified in the $\mathrm{CxV}$ process. These components can then be further commissioned to acceptable performance levels. Although commissioning is commonly associated with new systems just being put into operation, an existing system can be re-commissioned, in which case the $\mathrm{CxV}$ process is just as valuable as to a new system.

The metrics for CHP system-level and component performance identified in earlier sections of this document can be used for $\mathrm{CxV}$. The primary difference between $\mathrm{CxV}$ and performance monitoring/verification is in the baseline to which actual measured performance is compared. In performance monitoring/verification, we compare measured performance to baseline performance of the specific system and its components. This is done to enable application of the performance monitoring algorithms to any CHP system, new or existing, and to provide a potentially more meaningful baseline than possible using performance maps from manufacturers. Although manufacturer performance maps can cover a full range of operating conditions, installation of components often results in system effects, which derate performance (see, for example, Vidal et al. (2006), Figure 5). Before commissioning or re-commissioning are complete, no better benchmarks for performance exist to which to compare the performance of the CHP system and its components. However, after all components have been tested and tuned to their peak performance as a system, significant differences between the benchmarks and actual performance may still exist. Therefore, after commissioning, we use empirical performance models for the actual system, while for commissioning verification, we make comparisons to benchmarks based on manufacturer data.

The algorithm for the generic $\mathrm{CxV}$ process is shown as a flow chart in Figure 5. Note that as described above, no model is built, and the benchmark values of performance metrics (indicators) are determined from manufacturer data. The end result of the process is a report indicating which components passed the process, which failed, whether the overall CHP system passed, numerical values for all measured and benchmark metrics, and potentially, (from software using the algorithm) suggestions for correcting deficiencies with underperforming components. 


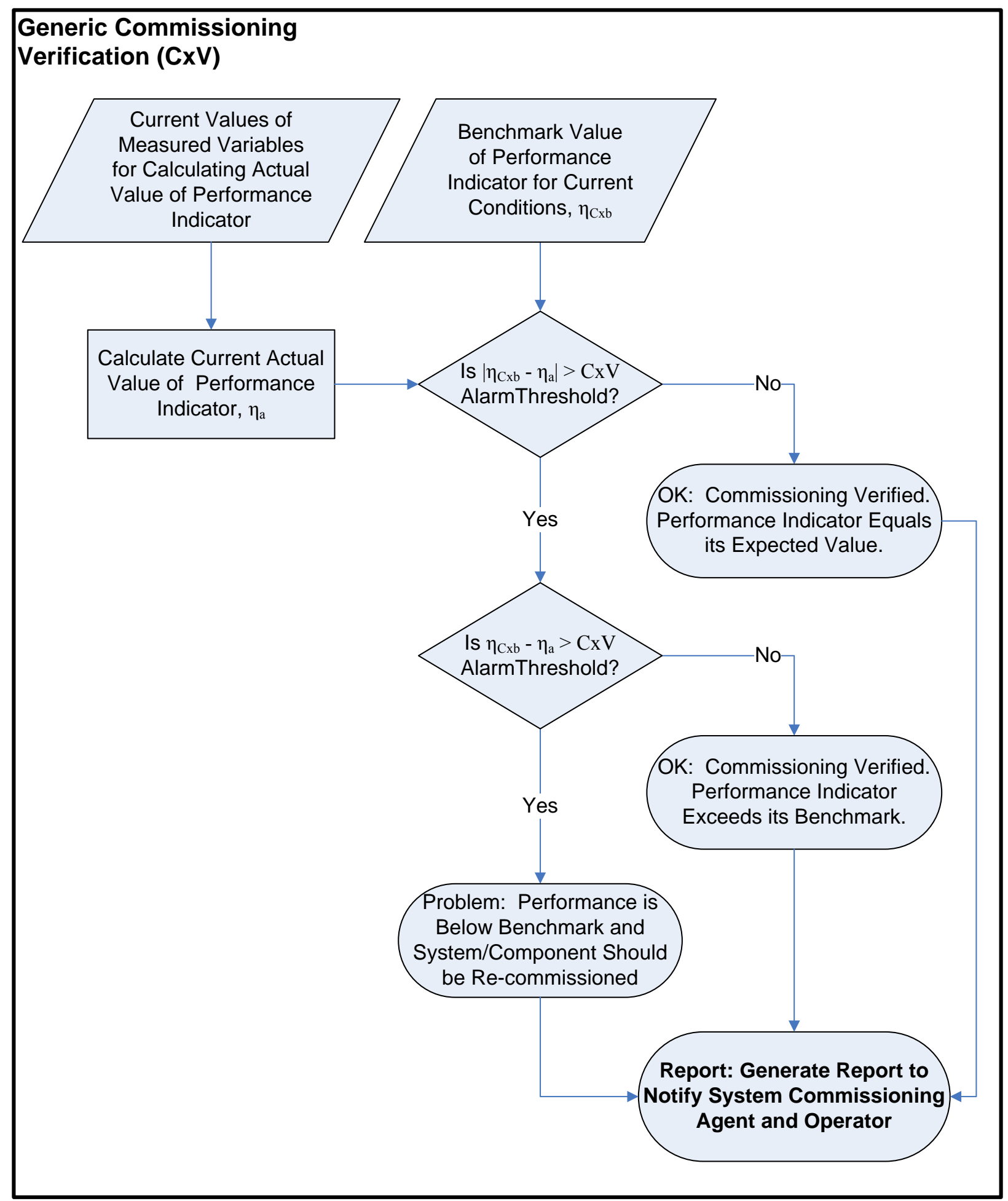

Figure 5. Flow chart for the generic commissioning verification process. 


\section{Handling Data Uncertainty}

Whenever dealing with measurements using sensors, we are faced with the problem of noisy, incomplete knowledge or erroneous data, which can all be grouped as measurement uncertainty. A statement of measured value without an accompanying uncertainty statement has limited value (Dieck, 1992). The purpose of a systematic and quantitative uncertainty analysis is to use available information to quantify the degree of confidence in existing data and models, and provide guidance in identifying critical sources of uncertainty and improving data accuracy and model reliability.

This section presents background information on uncertainty concepts and sources of uncertainties. The steps to estimate uncertainties are discussed and applied to two examples of the CHP performance monitoring, and commissioning verification algorithms introduced in previous sections. Finally, the approaches to mitigating uncertainty are discussed.

\section{Terms and Definition}

The term uncertainty has been defined in many ways. The key uncertainty concept is that true value (or the actual value) and observed (or measured) values are likely to be different because of uncertainties. Some important terms and definitions in the uncertainty analysis are listed as the following.

(a) Accuracy is a measure (or an estimate) of the maximum deviation of measured values from the true value;

(b) Error is defined as the difference between a measured or estimated value and the true value; it is comprised of bias error and precision error;

(c) Precision(random) error is the random component of the total error and is sometimes called the repeatability or repeatability error;

(d) Bias (fixed or systematic) error is the fixed, systematic, or constant component of the total error;

(e) Uncertainty is an estimate of error as a possible range of values at a certain confidence level, usually expressed as \pm error. Because the true value is unknown, the true error cannot be determined; however, the error limits may be estimated.

Figure 6 illustrates the concept of error, which is comprised of precision error and bias error. It is assumed that we have repeated measurements of the same true value. The probability distribution shown in the figure illustrates the spread of measured values, which is attributed to the precision error of the measurement. The discrepancy between the true value and the average result obtained from the measurements is the bias error. 


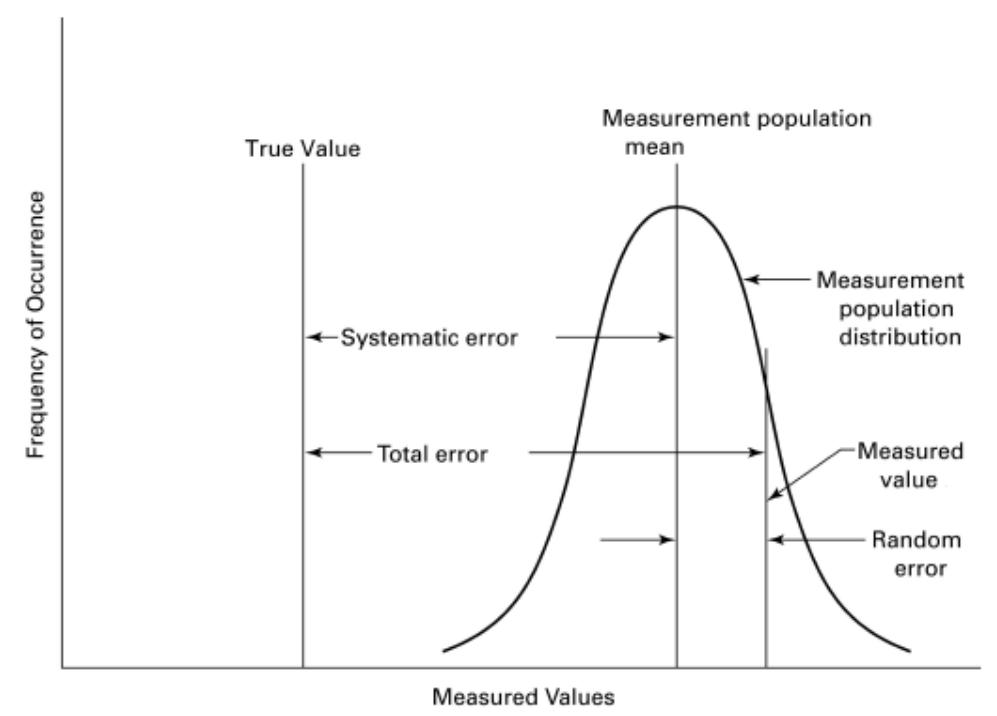

Figure 6. Illustration of Precision Error and Bias Error (Reprinted (with minor changes) from ASME PTC 19.1-2005, by permission of The American Society of Mechanical Engineers. All rights reserved.)

\section{Sources of Uncertainty}

While there are many hierarchical classifications of the sources of uncertainty, the common highlevel categories are measurement uncertainty and model uncertainty.

\section{Measurement Uncertainty}

Any measurement has some error associated with it. Measurement accuracy is partially determined from instrument accuracy itself, although the inherent instrument errors associated with the equipment are in all likelihood small when compared to other potential error sources such as installation and application errors. The instrument accuracy is usually published by manufacturers.

The total uncertainty in a measurement is the combination of uncertainty from precision error and uncertainty from bias error. According to American Society of Mechanical Engineers (ASME 2005), the uncertainties in the measurement process can be grouped as the following:

(a) Calibration uncertainty. Calibration is always accompanied by some uncertainty, which is caused by random noise, inexact knowledge of calibration sources, environmental influences (power fluctuations, thermal instability), procedural errors and so on.

(b) Uncertainty resulting from test article and/or instrumentation installation. Examples of these types of uncertainty are interactions between the test instrumentation and test media and interactions between the test article and test facility.

(c) Data acquisition uncertainty. Data acquisition uncertainty may arise from a variety of sources, such as quantization error, operator bias and finite sampling rates.

(d) Data reduction uncertainty may arise from curve fitting and computer resolution (Abernethy and Thompson 1973).

(e) Uncertainty from methods and other effects are defined as those additional uncertainty sources that originate from the techniques or methods inherent in the measurement process. 
Measurement uncertainty is also dependent on the data collection method chosen. There are typically six types of data collection methods (Nexant 2001). Table 3 shows the data collection method used to measure the variables in the CHP system performance monitoring and verification process.

(a) Stipulation. The value is estimated based on the knowledge of the variable with reasonable certainty.

(b) Single Spot Measurement. The value is obtained from a single spot measurement of the variable, and the uncertainty of the value is obtained from the measurement instrument precision and bias uncertainty.

(c) Averaged Spot Measurements. The variable value is obtained from the average of a number of measurements, using the same measurement instrument. The uncertainty is the uncertainty of the average of those measurements.

(d) Multiple Spot Measurements. A series of measurements of dependent and independent variables is made as the equipment is manually forced through its entire range of operation.

(e) Short-term Monitoring. Measurements of variables are made at constant intervals over a short-term period. For measuring operation-dependent variables, the period length must be long enough to capture the entire range of equipment operation.

(f) Continuous Monitoring. Measurements of variables are made at constant intervals continuously; uncertainty is obtained from the measurement instrument, summed over the total number of measurements recorded.

When measurements are performed at a representative sample of equipment operation conditions and used to estimate the population average, the uncertainty introduced by sampling should be included. Sampling is adopted primarily to reduce monitoring costs. Sampling increases uncertainty - by how much depends on the data scatter and the sample size. Sampling errors also can include a random component and a bias component. An accepted practice in the industry is using the standard error of the measurements about the mean to estimate the uncertainty introduced by sampling (Nexant 2001). Usually, standard deviation, precision and confidence level are used to specify the number of sample points to measure. The sampling uncertainty is combined with the measurement uncertainty to obtain the population uncertainty.

\section{Model Uncertainty}

As shown in the previous sections, mathematical models (metrics) are used to monitor CHP system performance. However, the inability to completely characterize natural systems makes it difficult not only to determine the parameters for these models with certainty, but many times available data are insufficient to determine which of several models apply. Model uncertainty, including model mis-specification uncertainty, model prediction uncertainty and model bias uncertainty, has been discussed extensively by Reddy et al. (Reddy 1999). 
(a) Model specification uncertainty occurs when the functional form of the model does not adequately approximate the true behavior of the response variable. More specifically, the uncertainty is caused by (i) inclusion of irrelevant regressor variables, or noninclusion of important regressors; (ii) error of simplifying assumptions of appropriate interactions of regressor variables; (iii) incorrect order of regressor variables.

(b) Model prediction uncertainty occurs when a regression model is fit to data. The coefficients have some inherent error because any regression model with an $R^{2}<1$ is incapable of explaining the entire variation present in the regressor variable. This is known as model prediction uncertainty.

(c) Model bias uncertainty occurs when a model is used for prediction outside the region covered by the original data from which the model has been identified. The model may consistently overpredict or underpredict outside the covered data region. An example is when an energy savings calculation model developed from data collected over a shortterm period (a few weeks or months) is extrapolated to generate results for a longer time period, such as 1 year.

How well a regression model fits, the observations is quantified statistically by the well-known coefficient of determination $\left(\mathrm{R}^{2}\right)$ (see any statistical textbook, for example, Chatterjee and Price $1981)$ and by the root mean square error (RMSE). The RMSE of a model identified from data is defined as follows:

$$
R M S E=\left[\frac{\sum_{i=1}^{n}\left(Y_{i}-\hat{Y}_{i}\right)^{2}}{n-p}\right]^{1 / 2}, \quad \text { Eq. (10) }
$$

where $\mathrm{Y}$ is the response variable of the model, $\mathrm{n}$ the number of observations, and $\mathrm{p}$ the number of model parameters. The RMSE is an absolute measure and its range is $0 \leq \mathrm{RMSE} \leq \infty$.

The classical ordinary least-squares (OLS) regression method is commonly used for model identification. OLS regression is designed to estimate the response variable (Y), by minimizing the sum of squared errors in $\mathrm{Y}$ with respect to regressor variables $(\mathrm{X})$. One of the basic assumptions in OLS regression is that the errors in the response variable are (spatially) independent and that there are no errors in regression variables. In cases when the error in observed variables and data are not negligible, this assumption is unrealistic. A consequence of neglecting the errors in the regressor variables is that model parameter estimation is biased (Draper and Smith 1998). There are extensive publications for the error-in-variable (EIV) problem, and methods such as maximum likelihood estimator and Monte Carlo simulation are often used to minimize or eliminate the bias caused by the errors in variables (Qian 1997).

Andersen and Reddy illustrated the advantages of the Corrected Least Squares (CLS) EIV regression modeling approach over the OLS method in the framework of Gordon and $\mathrm{Ng}$ (Gordon and Ng 2002) chiller model (Andersen and Reddy 2002). This method assumes that the 
variance of the response variables is the same as that of the regressor variables (Draper and Smith, 1998). A brief description of this method is introduced below.

A general form of a simple linear regression is

$$
Y_{i}=\alpha+\beta X_{i}+\varepsilon_{i},
$$

where $\mathrm{Y}$ is the response variable and $\mathrm{X}$ is the regressor, $\alpha$ and $\beta$ are the model parameters and $\varepsilon$ is the error term, which is assumed to be normally distributed with mean 0 and variance $\sigma_{\varepsilon}{ }^{2}$.

The OLS estimation assumes $\mathrm{Y}$ is subject to error $\varepsilon$ and $\mathrm{X}$ is not subject to error. If both $\mathrm{X}$ and $\mathrm{Y}$ are subject to error, we can write

$$
Y_{i}=\eta_{i}+\varepsilon_{i} \quad \varepsilon_{i} \in N\left(0, \sigma_{\varepsilon}^{2}\right),
$$

$$
X_{i}=\zeta_{i}+\delta_{i} \quad \delta_{i} \in N\left(0, \sigma_{\delta}^{2}\right)
$$

where $\zeta_{i}$ and $\eta_{i}$ are the mean values of the random variables $X_{i}$ and $Y_{i}$.

The general EIV model assumes that observed pairs $\left(\mathrm{X}_{\mathrm{i}}, \mathrm{Y}_{\mathrm{i}}\right)$ are discrete sampled realizations of random variables whose mean values hold the linear relationship

$$
\eta_{i}=\alpha+\beta \xi_{i}
$$

If we attempt to obtain the maximum likelihood estimates of $\beta_{0}$ and $\beta_{1}$ under the distributional assumptions made in connection with Eq. (2), we find that there is an identifiability problem. This estimation can not be carried through without some additional information of $\lambda=\frac{\sigma_{\varepsilon}^{2}}{\sigma_{\delta}^{2}}$. If $\lambda$ were known, maximum likelihood leads to estimates

$\hat{\beta}_{1}=\left[S_{Y Y}-\lambda S_{X X}+\left\{\left(S_{Y Y}-\lambda S_{X X}\right)^{2}+4 \lambda S_{X Y}^{2}\right\}^{1 / 2}\right] /\left(2 S_{X Y}\right)$

and

$\hat{\beta}_{0}=\bar{Y}-\hat{\beta}_{1} \bar{X}$

where $S_{X X}=\sum_{i=1}^{n}\left(X_{i}-\bar{X}\right)^{2}, S_{Y Y}=\sum_{i=1}^{n}\left(Y_{i}-\bar{Y}\right)^{2}, S_{X Y}=\sum_{i=1}^{n}\left(X_{i}-\bar{X}\right)\left(Y_{i}-\bar{Y}\right)$

$\bar{X}$ and $\bar{Y}$ are mean values of $\mathrm{X}$ and $\mathrm{Y}, \hat{\beta}_{0}$ and $\hat{\beta}_{1}$ are maximum likelihood estimates

This case is often called a functional relationship model. Note that if $\lambda=\frac{S_{Y Y}}{S_{X X}}, \hat{\beta}_{1}=\left(\frac{S_{Y Y}}{S_{X X}}\right)^{1 / 2}$,

this is the geometric mean functional relationship, which minimizes the sum of the areas obtained by drawing horizontal (parallel to the X-axis) and vertical (parallel to the $\mathrm{Y}$-axis) lines from each data point. Note that if $\lambda=1, \hat{\beta}_{1}=\left[S_{Y Y}-S_{X X}+\left\{\left(S_{Y Y}-S_{X X}\right)^{2}+4 S_{X Y}^{2}\right\}^{1 / 2}\right] /\left(2 S_{X Y}\right)$. 


\section{Uncertainty Calculation}

There are several guidelines/standards that address planning, analyzing data and reporting the uncertainty of experiments and tests. For example, ANSI/ASME PTC Report 6-1985 (ASME 1985) provides guidance for evaluation of measurement uncertainty in performance tests of steam turbines and includes a procedure for uncertainty calculation of an overall result.

The overall measurement uncertainty of a variable $X$ can be expressed as the following equation:

$$
U_{X}=\sqrt{B_{X}^{2}+\left(t \times S_{X}\right)^{2}}
$$

where

$U_{X}=$ overall uncertainty in the value $\mathrm{X}$

$B_{X}=$ uncertainty in the fixed (bias) component

$S_{X}=$ standard deviation estimates for the random (precision) component

$t=t$-value from statistics reference at the specified confidence level for the appropriate degrees of freedom

While precision error is usually estimated by the standard deviation of the measurements, determining bias error is not as straightforward as precision error. Bias error requires knowledge of the device or system under measurement. To determine the magnitude of bias in a given measurement situation, we must define the true value of the quantity being measured. However, this true value is usually unknown and unknowable. Usually we rely on the engineering judgment of instrumentation and measurement engineers to provide an upper limit or bound on the bias (Abernethy and Thompson 1973) or assume one single value for bias when bias distribution is small and a normal distribution for the bias when the bias distribution is large (ASHRAE 2003).

The overall uncertainty of a result is dependent upon the collective influence of the component uncertainties, and determining the overall uncertainty involves:

(a) Identify all uncertain independent variables and characterize the uncertainties of these variables including both precision uncertainty and bias uncertainty.

(b) Determine the uncertainties of calculated or estimated variables. This includes defining the functional relationship between the independent variables and calculated variables and propagating the uncertainties of independent variables through the functional relationship (mathematical model).

(c) Calculate the overall uncertainty by combining the precision uncertainty and the bias uncertainty.

\section{Propagation of Uncertainty}

According to the definition in ASHRAE Guideline 2-1986R (ASHRAE, 2003), measurements are categorized as either primary measurements or derived measurements. A primary measurement is one that is obtained directly from the measurement sensor. Examples of primary 
variables are air or water temperatures, etc. A derived measurement is one that is calculated using one or more measurements. This calculation can occur at the sensor level (e.g., an energy meter uses flow and temperature difference to report an energy flow rate), it can be done by a data logger, or it can occur during data processing.

In many cases the variable of interest is not directly measured, but is some function (equation) of one or more other measured quantities. The propagation of uncertainty is used to determine the uncertainty of the calculated variable $(Y)$ given the relationship between the calculated variable and individual measured variables $\left(X_{i}\right)$ and their associated uncertainties $\left(U_{X i}\right)$. The random and bias components, which together constitute the overall uncertainty, have to be estimated separately. The same error propagation concepts could apply to either source of uncertainty. There are a number of uncertainty propagation methods; for example, the perturbation analysis approach, Taylor series expansion methods, derived distribution approach and Monte Carlo simulation methods (Dettinger and Wilson 1981). EPA (1999) provided detailed comparisons of a number of uncertainty analysis approaches discussing the assumptions, strengths and weakness for each method.

The Monte Carlo simulation method (Vose 1996), one of the sampling based methods, is probably the most widely used technique with a wide range of applicability in the propagation of uncertainty that can be applied using either simple or complex models. Monte Carlo simulation involves randomly sampling each probability distribution within the model to produce hundreds or even thousands of trials. Each probability distribution is sampled in a manner that reproduces the distribution's shape. The relationships between the variables are then used to generate the estimate of uncertainty that is itself described by a probability distribution. The drawback of using Monte Carlo simulation for propagating uncertainty and developing probability densities of model outputs is that it may require performing a large number of model simulations.

The Taylor series expansion methods generally expand the analytical or numerical solution of the governing equation around the expected values of the parameters and independent variables to deduce various probabilistic moments (e.g., mean, variance/covariance) of the dependent variable (Taylor and Kuyatt 1994). Assuming the individual measurements are independent, random and all given with the same confidence level, and the higher order terms in the Taylor series expansion are negligible compared to the first order terms, the uncertainty propagation equations for some basic operations are given as the following (ASHRAE 2003):

$$
U_{Y}=\sqrt{\sum_{i=1}^{n}\left[\left(\frac{\partial Y}{\partial X_{i}}\right) U_{X_{i}}\right]^{2}},
$$

where

$Y=f\left(X_{1}, X_{2} \ldots X_{n}\right)$

$U_{Y}=$ uncertainty of calculated variable

$U_{X i}=$ uncertainty of the measured quantity $X_{i}$. 
The propagation equations for some of the basic operations, derived from Eq. (16) are given in Eq. (17) through Eq. (24).

(a) Addition/subtraction operation

$$
Y \pm U_{Y}=\left(X_{1} \pm U_{X_{1}}\right)+\left(X_{2} \pm U_{X_{2}}\right),
$$

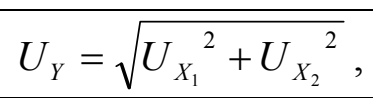

(b) Multiplication operation

$$
\begin{gathered}
Y \pm U_{Y}=\left(X_{1} \pm U_{X_{1}}\right) \times\left(X_{2} \pm U_{X_{2}}\right), \\
U_{Y}=\left(X_{1} \times X_{2}\right) \sqrt{\left(\frac{U_{X_{1}}}{X_{1}}\right)^{2}+\left(\frac{U_{X_{2}}}{X_{2}}\right)^{2}},
\end{gathered}
$$

(c) Division operation

$$
\begin{gathered}
Y \pm U_{Y}=\frac{\left(X_{1} \pm U_{X_{1}}\right)}{\left(X_{2} \pm U_{X_{2}}\right)} \\
U_{Y}=\left(\frac{X_{1}}{X_{2}}\right) \sqrt{\left(\frac{U_{X_{1}}}{X_{1}}\right)^{2}+\left(\frac{U_{X_{2}}}{X_{2}}\right)^{2}}
\end{gathered}
$$

(d) Power operation

$$
Y \pm U_{Y}=\left(X_{1} \pm U_{X_{1}}\right)^{p} \times\left(X_{2} \pm U_{X_{2}}\right)^{q},
$$

$$
U_{Y}=\left(X_{1}^{p} \times X_{2}^{q}\right) \times \sqrt{\left(\frac{p \times U_{X_{1}}}{X_{1}}\right)^{2}+\left(\frac{q \times U_{X_{2}}}{X_{2}}\right)^{2}},
$$

\section{Uncertainty Mitigation}

There are different approaches to reducing measurement uncertainty and increasing model reliability depending on components of uncertainty: precision error versus bias error. For example, precision error of measurements can be estimated by inspecting the measurement scatter and can be decreased by conducting multiple measurements; measurement bias errors can be minimized by performing periodic instrument calibration; model bias error can be reduced by collecting data over the whole expected ranges of variables. 


\section{Redundancy}

Redundancy can mean using multiple copies of measurement systems or taking multiple measurements. This approach is normally used to reduce the precision error. For example, if we measure a quantity 15 times in a 15-minute period and average the measurements, the precision error will decrease by about a factor of $15^{1 / 2}=3.87$, compared with the precision error related with a single measurement.

\section{Periodic Recalibration}

Calibration is the act of establishing, under specified conditions, the relationship between values read on an instrument and the corresponding values represented by a reference standard, and the subsequent adjustment of the instrument to match those values. The main purpose of periodic instrument recalibration is to reduce the large bias errors and establish the traceability with referenced standards. Data obtained by periodic calibration of instrument parameters can be used to estimate bias errors. One approach is to adjust gain and offset of the instrument itself to compensate for the bias errors during the course of experiments to bring the instrument output back into agreement with the reference standards. An alternate approach is to account for the bias errors during the data analysis phase (ASHRAE, 2003).

\section{Example for Propagation of Errors and Uncertainty Mitigation}

The following example illustrates the use of propagation of errors algorithm in estimating the uncertainty in heat recovery steam generator effectiveness. Uncertainty mitigation by conducting multiple measurements is also examined in this example.

1. Use of propagation of errors in estimating uncertainty in heat recovery steam generator effectiveness

Heat recovery steam generator effectiveness is expressed in Table 2.

\begin{tabular}{|l|l|}
\hline$\varepsilon_{H R S G}=\frac{T_{H R S G, e x, i}-T_{H R S G, e x, \mathrm{o}}}{T_{H R S G, e x, i}-T_{H R S G, w, i}}$, & Eq. (25) \\
\hline
\end{tabular}

Assumptions for this example include:

(a) Temperature sensor accuracy: $\pm 0.2^{\circ} \mathrm{F}$,

(b) Instrumentation bias is zero,

(c) Sampling frequency is 15 minutes and hourly averages of samples are used to calculate the $\varepsilon_{H R S G}$ and the uncertainty associated with it.

A set of hypothetical measurements taken at 15 minute intervals is given in Table 3. 
Table 3. Independent Variable Measurements Used in the Example

\begin{tabular}{|l|c|c|c|c|}
\hline Time $(\mathrm{hr}: \mathrm{min})$ & $0: 00$ & $0: 15$ & $0: 30$ & $0: 45$ \\
\hline$T_{H R S G, e x, i}\left({ }^{\circ} \mathrm{F}\right)$ & 620.3 & 622.9 & 621.5 & 621.1 \\
\hline$T_{H R S G, e x, \mathrm{o}}\left({ }^{\circ} \mathrm{F}\right)$ & 400.5 & 402.1 & 401.9 & 402.5 \\
\hline$T_{H R S G, w, i}\left({ }^{\circ} \mathrm{F}\right)$ & 300.5 & 301.4 & 300.9 & 303.1 \\
\hline
\end{tabular}

Step 1: Calculate hourly average values and uncertainties of measurements

$$
\begin{aligned}
& T_{H R S G, e x, i, \text { hourly }} \pm U_{T_{H R S G, e x, i, h o u r l y}}=\frac{620.3+622.9+621.5+621.1}{4} \pm \frac{0.2}{\sqrt{4}}=621.5 \pm 0.1^{\circ} \mathrm{F} \\
& T_{H R S G, e x, o, \text { hourly }} \pm U_{T_{H R S G, e x, o, h o u r l y}}=\frac{400.5+402.1+401.9+402.5}{4} \pm \frac{0.2}{\sqrt{4}}=401.8 \pm 0.1^{\circ} \mathrm{F} \\
& T_{H R S G, w, i, \text { hourly }} \pm U_{T_{H R S G, w, i, h o u r l y}}=\frac{300.5+301.4+300.9+303.1}{4} \pm \frac{0.2}{\sqrt{4}}=301.5 \pm 0.1^{\circ} \mathrm{F}
\end{aligned}
$$

Step 2: Calculate heat recovery steam generator effectiveness and uncertainty associated with it

$$
\begin{aligned}
& \varepsilon_{H R S G} \pm U_{\varepsilon_{\text {HRSG }}}=\frac{T_{H R S G, \text { ex }, \text {, hourly }}-T_{H R S G, e x, \text {, hourly }}}{T_{H R S G, \text { ex }, \text { i,hourly }}-T_{H R S G, w, i, h o u r l y}}=\frac{(621.5 \pm 0.1)-(401.8 \pm 0.1)}{(621.5 \pm 0.1)-(301.5 \pm 0.1)} \\
& =\frac{219.7 \pm \sqrt{0.1^{2}+0.1^{2}}}{320.0 \pm \sqrt{0.1^{2}+0.1^{2}}}=\frac{219.7 \pm 0.141}{320.0 \pm 0.141}=0.687 \pm\left(\frac{219.7}{320.0} \times \sqrt{\left(\frac{0.141}{219.7}\right)^{2}+\left(\frac{0.141}{320.0}\right)^{2}}\right) \\
& =0.68656 \pm 0.00054
\end{aligned}
$$

Step 3: Calculate heat recovery steam generator effectiveness and uncertainty associated with it using the first measurement only

$$
\begin{aligned}
& \varepsilon_{H R S G} \pm U_{\varepsilon_{H R S G}}=\frac{T_{H R S G, e x, i}-T_{H R S G, e x, o}}{T_{H R S G, e x, i}-T_{H R S G, w, i}}=\frac{(620.3 \pm 0.2)-(400.5 \pm 0.2)}{(620.3 \pm 0.2)-(300.5 \pm 0.2)} \\
& =\frac{219.8 \pm \sqrt{0.2^{2}+0.2^{2}}}{319.8 \pm \sqrt{0.2^{2}+0.2^{2}}}=\frac{219.8 \pm 0.283}{319.8 \pm 0.283}=0.687 \pm\left(\frac{219.8}{319.8} \times \sqrt{\left(\frac{0.283}{219.8}\right)^{2}+\left(\frac{0.283}{319.8}\right)^{2}}\right) \\
& =0.68656 \pm 0.001074
\end{aligned}
$$

Comparing the uncertainty of the heat recovery steam generator effectiveness using a single measurement with that using four measurements, we can see that the uncertainty is reduced by a factor of $4^{1 / 2}=2$. 


\section{Example Applications to Data from Simulations}

This section demonstrates the use of the algorithms developed in this project for monitoring the performance of a CHP system and detecting faults and performance degradation. A model is constructed for simulating the performance of a CHP system under properly operating conditions and with selected faults imposed by perturbing component characteristics in ways that correspond to physical faults occurring in the CHP system. The results demonstrate the potential value of a monitoring system in detecting faults, troubleshooting them, and correcting their underlying causes.

\section{Simulation Model}

The subsections that follow first describe the simulation model and then present and discuss the results of its application.

\section{CHP System Modeled}

The system simulated represents a simplified configuration of the CHP system in the Integrated Energy Systems (IES) Laboratory at Oak Ridge National Laboratory (Rizy et al. 2002; Rizy et al. 2003; Zaltash et al. 2006). It consists of a micro-turbine generator (MTG), exhaust-to-water heat recovery unit (HRU), hot-water-fired absorption chiller, and cooling tower (see Figure 7). The MTG is a $30-\mathrm{kW}$ natural-gas-fired Capstone unit that produces three-phase 480 -volt AC electric power and releases exhaust gases in the approximate temperature range 480 to $560^{\circ} \mathrm{F}$. A gas compressor is used to raise the pressure of the natural gas provided by the distributor (at 5 psig) to the pressure of $55 \mathrm{psig}$ required by the MTG. The unit uses heat recuperation to preheat the air before it enters the combustion chamber to raise the efficiency at full load from about $13 \%$ to $23 \%$ (based on the higher heating value of the fuel). The hot exhaust gases pass through a gas-to-water heat recover unit, producing hot water at 185 to $203^{\circ} \mathrm{F}$. The exhaust gases are then vented to the atmosphere at approximately $248^{\circ} \mathrm{F}$. These vented gases could be used to feed a direct-fired desiccant unit, which is possible at the IES Lab, but this simulation models the system with exhaust venting from the HRU directly to the atmosphere. The hot water output from the heat recover unit is used to regenerate refrigerant in a 10-ton $(35 \mathrm{~kW})$ single-effect LiBr-water absorption chiller, providing chilled water at approximately $44^{\circ} \mathrm{F}$. Cooling of the chiller condenser is provided by a closed cooling water loop that uses a wet cooling tower to reject heat to the environment.

\section{Overall Structure of Model}

The overall model, shown schematically in Figure 8, is a set of 29 simultaneous equations. A sub-model is used to represent the behavior of each component; these are described in the subsections that follow. The components are linked by the mass flow rate, temperature, and pressure (where relevant) of the fluid flows between them (e.g., the hot water leaving the HRU enters the absorption chiller at the same temperature and flow rate as those of the hot water leaving the HRU); these "connecting" relationships are enumerated in the subsection entitled "Relations Integrating the Components," which follows the component-model descriptions. 


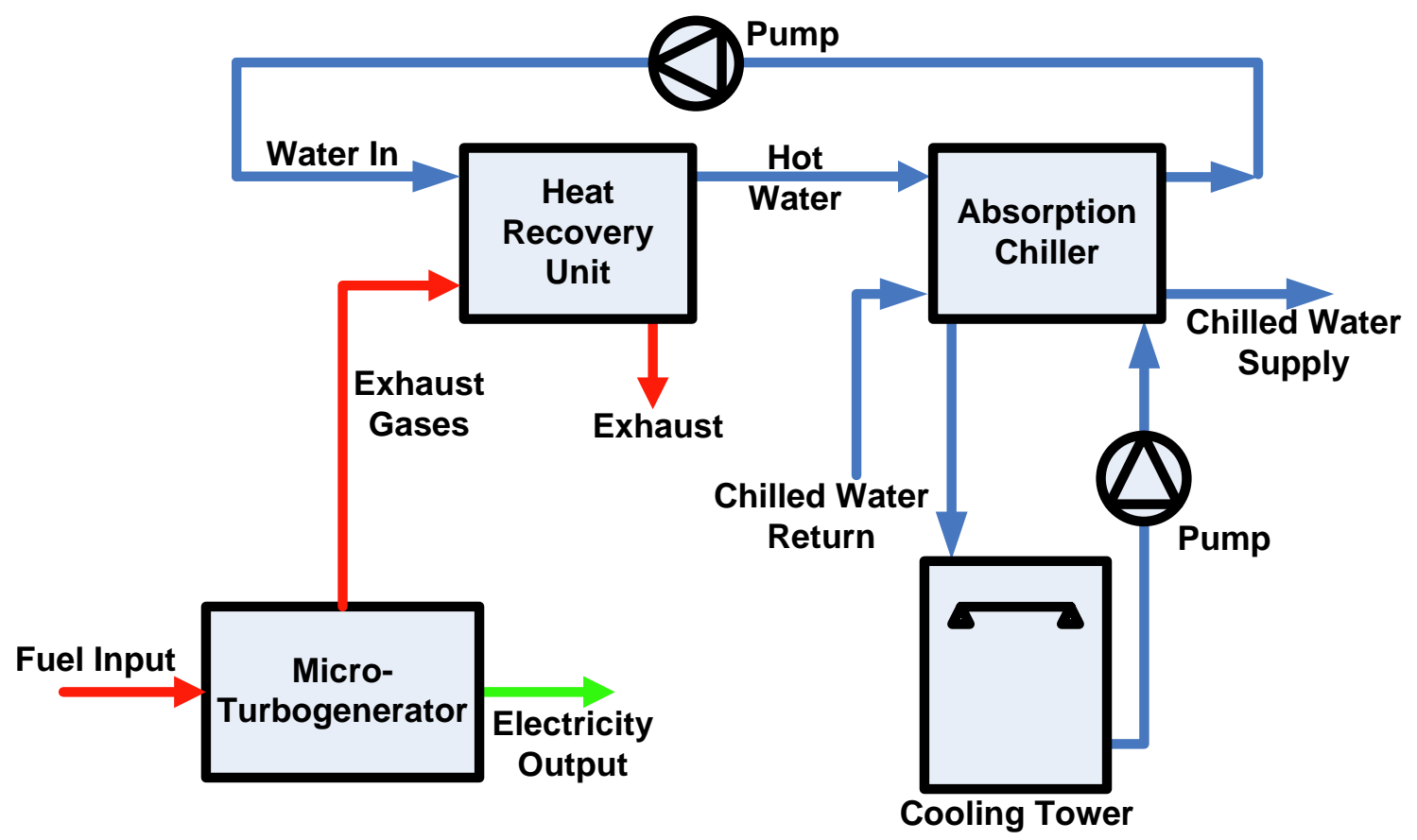

Figure 7. Diagram of CHP system simulated.

All processes are assumed to be quasi-steady-state, and all ducts and piping connecting components are assumed perfectly insulated so that no (or negligible) heat loss occurs through them. As a result, the temperature of a flow stream leaving one component is equal to the temperature of the same stream at the entrance to another component (e.g., $\left.\dot{m}_{H R U, w, o}=\dot{m}_{A b C h i l l e r, w, i}\right)$.

\section{Micro-Turbogenerator}

The micro-turbine generator is simulated using the equations provided by a team from Oak Ridge National Laboratory (Labinov et al. 2002), which are based on earlier work by Burghardt

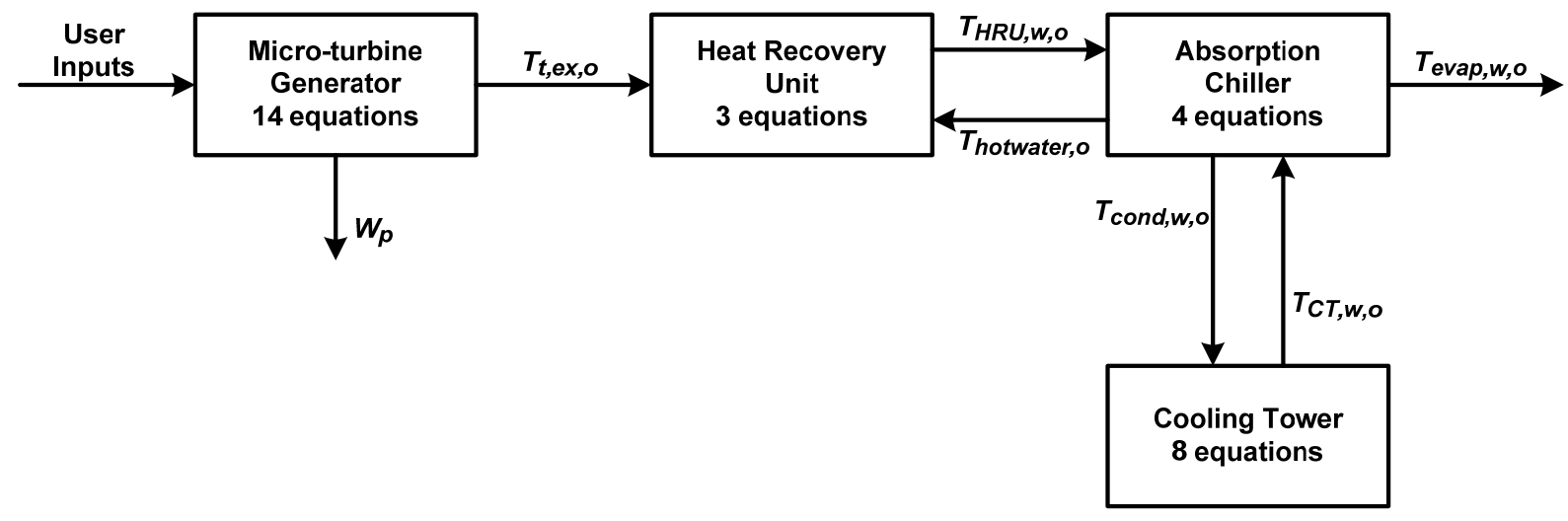

Figure 8. Schematic of the overall CHP system simulation model. 
(1982) and Fairchild et al. (2001)..$^{5}$ The micro-turbine generator modeled is a single-shaft (i.e., micro-turbine and generator on the same shaft), natural-gas-fired, air-cooled unit. The primary components of the micro-turbine generator are the air compressor, the recuperator, the combustion chamber, the turbine, and the generator (see Figure 8). The fuel is pressurized with a separate, electrically-driven, gas compressor to raise the fuel from distribution line pressure of about 5 psi to the inlet pressure required by the micro-turbine Because of the high rotational speed at which micro-turbines operate (e.g., the test unit in the Oak Ridge lab has a maximum rotational speed of $96,000 \mathrm{rpm}$ ), a digital power controller (DPC) is used to control operation, converts power to a constant DC voltage and invert it to constant-frequency AC power. This DPC is cooled by electric fans, and the resulting DPC load is included in the micro-turbine generator model.

Ambient air enters the micro-turbine at local ambient temperature $T_{a}$ and pressure $P_{a}$ through the compressor entrance duct. While passing through this duct, which surrounds the electric generator, it is heated by waste heat given off by the generator and exits the duct at temperature $T_{1}$ and pressure $P_{1}$. The air is then polytropically compressed in the compressor and exits at temperature $T_{2}$ and pressure $P_{2}$. The ratio $P_{2} / P_{1}$ is the compressor pressure ratio $\left(r_{c}\right)$, which is determined by both the specific compressor design and the current operating conditions (e.g., the

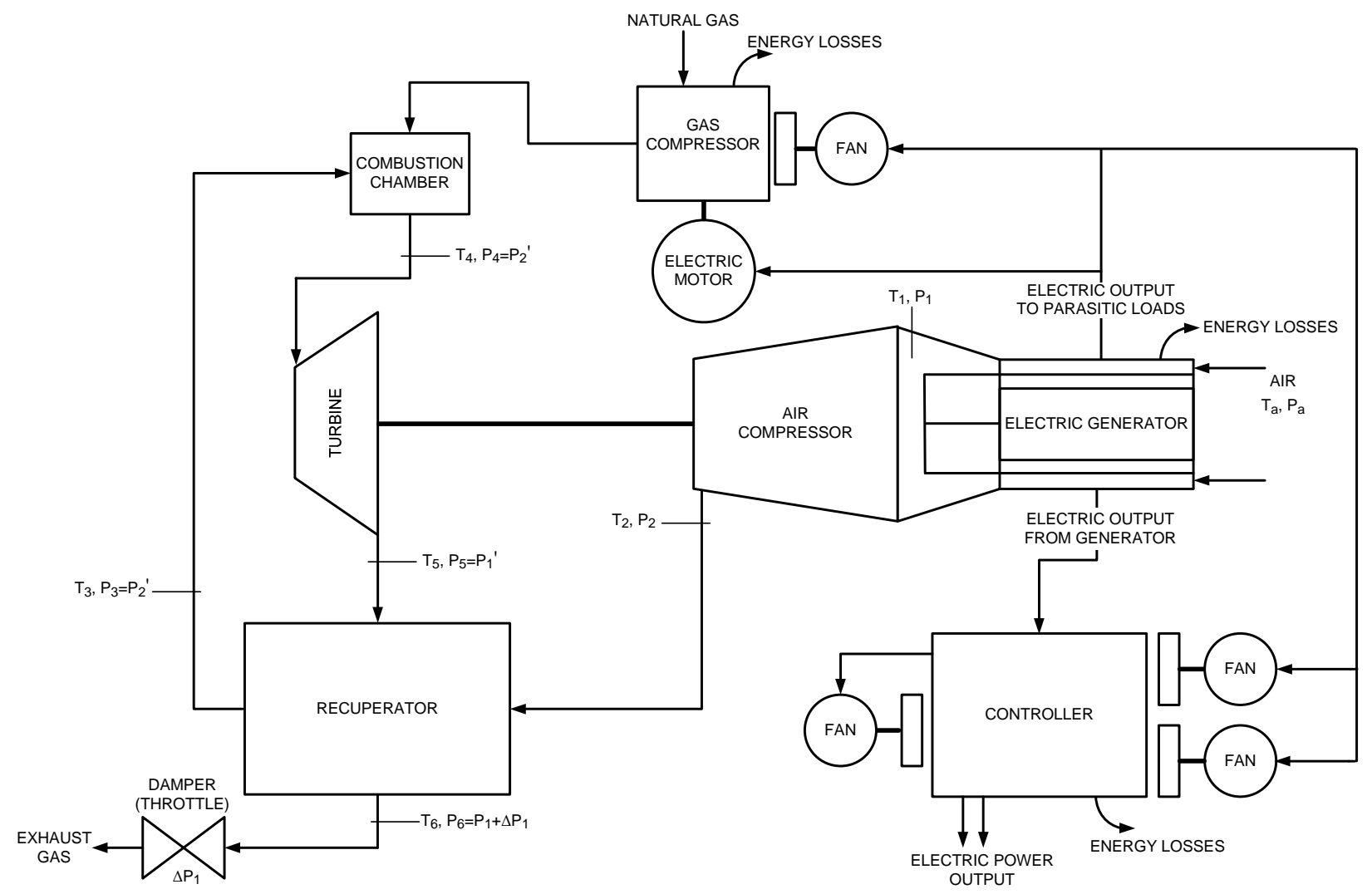

Figure 9. Schematic diagram of the micro-turbine generator (after Labinov et al. 2002).

\footnotetext{
${ }^{5}$ Although the model presented is identical to that described by Labinov et al. (2002), some notation has been changed to increase consistency with other parts of this report.
} 
rotational speed of the compressor). The air exiting the compressor enters the recuperator, where it is heated by turbine exhaust gases to temperature $T_{3}$. The pressure drops somewhat because of flow resistance in the recuperator from $P_{2}$ to $P_{3}=P_{2}^{\prime}$. The air then enters the combustion chamber, where it mixes with fuel and supports combustion.

Fuel enters the combustion chamber separately, having first passed through a separate electrically-driven compressor, where its pressure is increased from the service line pressure to the pressure required by the micro-turbine. Combustion of the fuel in the combustion chamber releases the stored chemical energy of the fuel and increases the temperature of the fuel-air mixture (which is mostly air) to temperature $T_{4}$ (remaining at pressure $P_{2}^{\prime}=P_{4}$ ). The mixture then polytropically expands through the turbine, which captures part of the energy as rotational shaft work of the turbine $\left(W_{t}\right)$. The exhaust gas mixture exits the turbine at temperature $T_{5}$ and pressure $P_{5}=P_{1}^{\prime}$, which is slightly greater than $P_{1}$. The ratio $P_{4} / P_{5}=P_{2}^{\prime} / P_{1}^{\prime}$ is the turbine rate of expansion $\left(r_{t}\right)$, which depends on the specific turbine design and the current operating conditions. Exiting the turbine, the exhaust gases pass to the recuperator, where they decrease in temperature from $T_{5}=T_{t, e x, o}$ (the temperature of exhaust gases leaving the micro-turbine) to $T_{6}$ and release heat, some of which heats the air passing through the other side of the recuperator. As with the compressed air, flow resistance in the recuperator causes pressure losses, which decrease the exhaust gas pressure from $P_{5}=P_{1}^{\prime}$ to $P_{6}$, which is somewhat lower than $P_{1}^{\prime}$. When the turbine is installed as part of a CHP system, where the exhaust gases pass through additional components (e.g., a heat recovery unit) before exhausting to the ambient atmosphere, $P_{6}$ will still be greater than $P_{a}$.

The equations describing the thermodynamic performance of each of the micro-turbine generator components and the relationships among these components follows. See Labinov et al. (2002) for additional discussion of the equations.

For heating of the entering ambient air (and cooling of the electric generator), the rate of heat gain by the air is given by

$$
Q_{a-1}=Q_{e g}=\dot{m}_{t, a} C_{p a}\left(T_{1}-T_{a}\right)
$$

where $Q_{a-1}$ is the rate of heat gain by the air as it passes from the ambient through the compressor inlet duct, $Q_{e g}$ is the rate of heat loss by the electrical generator, $\dot{m}_{t, a}$ is the mass flow rate of air through the duct, and $C_{p a}$ is the heat capacity of air at the average of the temperatures at the compressor inlet $\left(T_{a}\right)$ and outlet $\left(T_{1}\right)$.

The power to drive the compressor is given by the relation

$$
W_{c}=\left[k_{c} /\left(k_{c}-1\right)\right] T_{1} R_{a} \dot{m}_{t, a}\left[r_{c}^{\left(k_{c}-1\right) / k_{c}}-1\right] / \eta_{c},
$$

and the temperature of the compressed air exiting the compressor $\left(T_{2}\right)$ is given by 


$$
T_{2}=T_{1} \times\left\{1+\left[r_{c}^{\left(k_{c}-1\right) / k_{c}}-1\right] / \eta_{c}\right\},
$$

where $R_{a}=R / \mu_{a}$ is the specific gas constant for air, $R$ is the universal gas constant $(8.314 \mathrm{~kJ} / \mathrm{kg}$ mole-K), $\mu_{a}$ is the molecular weight of air $(\approx 28.966), k_{c}$ is the average value of the specific heat ratio $C_{p a} / C_{v a}$ in the air compressor, $C_{v a}$ is the specific heat of air at constant volume, $\eta_{c}$ is the compressor efficiency, and all other variables have been defined previously.

The rate of heat transfer $\left(Q_{r}\right)$ to the air from the exhaust gases as both pass through the recuperator is given by

$$
Q_{r}=\dot{m}_{t, a} C_{p a}\left(T_{3}-T_{2}\right)=\dot{m}_{t, e x} C_{p e x}\left(T_{5}-T_{6}\right) \eta_{r}
$$

where $\dot{m}_{t, e x}$ is the mass flow rate of exhaust gas mixture, $C_{p e x}$ is the specific heat at constant pressure of the exhaust gas, $\eta_{r}$ is the efficiency of the recuperator given by

$$
\eta_{r}=1-\alpha
$$

$\alpha$ is the recuperator heat loss coefficient, and all other variables have been defined previously.

The natural gas compressor is also modeled as a polytropic compression process, so that the work required by this compressor is given by the relation

$$
W_{n g}=\left[k_{n g} /\left(k_{n g}-1\right)\right] T_{a} R_{n g} \dot{m}_{n g}\left\{\left[r_{c} a_{1} /\left(P_{n g} / P_{1}\right)\right]^{\left(k_{n g}-1\right) / k_{n g}}-1\right\} / \eta_{n g}
$$

where $k_{n g}$ is the average value of the specific heat ratio $C_{p n g} / C_{v n g}$ of the natural gas fuel in the gas compressor, $C_{p n g}$ is the average specific heat at constant pressure for natural gas at the conditions in the gas compressor, $C_{v n g}$ is the average specific heat at constant volume for natural gas at the conditions in the gas compressor, the natural gas is assumed to enter at the same temperature as the ambient air, $T_{a}, R_{n g}$ is the specific gas constant for natural gas, $\dot{m}_{n g}$ is the mass flow rate of natural gas, $r_{c}$ is the compression ratio for the stand-alone natural gas compressor (assumed equal to $r_{c}$ for the air compressor), $a_{1}$ is a factor used to account for hydraulic losses in the natural gas line from the compressor to the combustion chamber, which Labinov et al. (2002) assign a constant value of 1.1, $P_{n g}$ is the pressure of the natural gas entering the compressor, and $\eta_{n g}$ is the efficiency of the natural-gas compressor. 
The heat transfer in the combustion chamber can be modeled by the equation

$$
Q_{g} \eta_{c c}=\dot{m}_{g} C_{p g}\left(T_{4}-T_{3}\right)
$$

where the left-hand term represents the rate of heat release by combustion of the natural gas fuel and the right-hand side represents the difference in enthalpy between the flow of exhaust gas mixture leaving the combustion chamber and the flow of fuel-air mixture entering. Here, $\eta_{c c}$ is the combustion efficiency and $Q_{g}$ is the rate of energy input with the flow of fuel into the combustion chamber based on the heating value of the natural gas. ${ }^{6}$

The turbine is modeled as a single-stage, polytropic expansion process, and the rotational power output is given by the relation

$$
W_{t}=\left[k_{t} /\left(k_{t}-1\right)\right] R_{g} T_{4} \dot{m}_{g}\left[1-r_{t}^{\left(1-k_{t}\right) / k_{t}}\right] \eta_{t},
$$

where $R_{g}=R / \mu_{g}$ is the specific gas constant for the air-combustion products exhaust-gas mixture, $\mu_{g}$ is the molecular weight of the exhaust gas, $k_{t}$ is the average value of the specific heat ratio $C_{p t} / C_{v t}$ of the exhaust gas in the turbine, $r_{t}$ is the expansion rate for the turbine, and $\eta_{t}$ is the turbine efficiency.

The exhaust gas temperature at the outlet of the turbine $\left(T_{5}\right)$ is given by

$$
T_{5}=T_{4}\left\{1-\left[1-r_{t}^{\left(1-k_{t}\right) / k_{t}}\right] \eta_{t}\right\}
$$

The net work balance on the micro-turbine system provides a relation for the net power output of the system $\left(W_{p}\right)$, which is

$$
W_{p}=W_{t}-W_{c}-W_{l}
$$

Here, $W_{l}$ is the total power loss of the system, which is the sum of the parasitic power uses and the heat losses, given by

$$
W_{l}=W_{n g}+W_{f}+Q_{c n}+Q_{e g},
$$

where $W_{f}$ is the total electric power use by the motors of fans in the system. The variable $Q_{c n}$ represents the heat loss from the controller, which can be expressed as

\footnotetext{
${ }^{6} Q_{g}$ can be based on either the lower heating value or higher heating value of the fuel. In either case, the same heating value should be used in all analyses for which results are compared, and the specific value used should be included in reports of results for efficiency calculations.
} 


$$
Q_{c n}=\dot{m}_{c n} C_{p a}\left(T_{1}-T_{a}\right) \theta=\left(W_{p}+W_{l}\right) \eta_{c n},
$$

where $\dot{m}_{c n}$ is the mass flow rate of air cooling the controller, $\theta$ is the controller heat loss coefficient, and $\eta_{c n}$ is the controller efficiency.

An energy balance on the entire micro-turbine systems yield the relation

$$
Q_{g} \eta_{c c}-\dot{m}_{g} C_{p g}\left[\left(T_{6}-T_{1}\right)+\left(T_{5}-T_{6}\right) \alpha\right]-W_{l}=W_{p} .
$$

The system of simultaneous equations, Eq. (26) through Eq. (38), represents the model of the micro-turbine generator subsystem with no back pressure. The model is represented as an input/output diagram in Figure 10. The resulting value of $W_{p}$ can be used along with $Q_{g}$ to determine the overall efficiency of the micro-turbine generator $\left(\eta_{m t g}\right)$, using the relation

$$
\eta_{m t g}=W_{p} / Q_{g} .
$$

Labinov et al. (2002) report that the values of $\eta_{c}, \eta_{r}$ and $\eta_{t}$ are not significantly influenced by changes in the micro-turbine load. Therefore, the values for these three variables can be solved

User Inputs

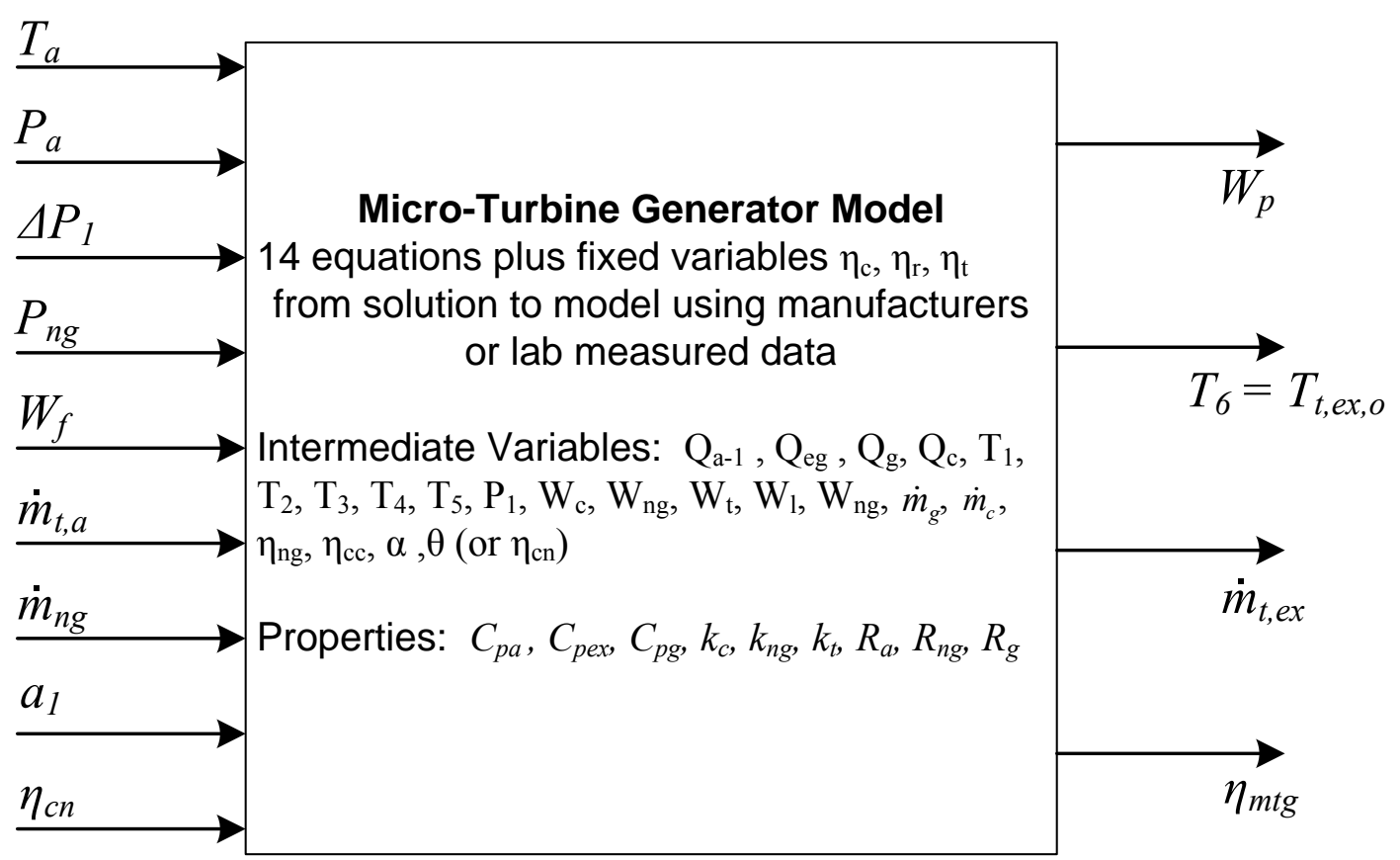

Figure 10. Input/output diagram of the micro-turbine generator subsystem with no back pressure. 
once using laboratory and manufacturer's data (which Labinov et al. provide for the microturbine in the Oak Ridge lab), and the values then fixed for simulation of the same micro-turbine under other loads.

The heat recovery components of the CHP system that use the exhaust gas downstream of the micro-turbine impose back pressure on the turbine created by the hydraulic resistance to flow of those components [e.g., the heat recovery unit in the CHP system modeled in this report (see Figure 1) and other components such as directly-fired desiccant systems and directly-fired absorption chillers in other CHP system configurations]. The back pressure decreases the power output and efficiency of the micro-turbine. These effects can be estimated using linear multipliers for $W_{p}$ and overall micro-turbine generator system efficiency $\eta_{m t g}$. The correction for $W_{p}$ is as follows

$$
\begin{gathered}
W_{p, \text { adjusted }}=W_{p}\left(1+\Delta W_{p}\right), \\
\frac{\Delta W_{p}}{W_{p}}=Z \frac{\Delta P_{l}}{P_{l}}-\left(\frac{\Delta T_{4}}{T_{4}}+\frac{\Delta \dot{m}_{g}}{\dot{m}_{g}}\right) \frac{W_{t}}{W_{p}}+\left(\frac{\Delta T_{1}}{T_{1}}+\frac{\Delta \dot{m}_{a}}{\dot{m}_{a}}\right) \frac{W_{c}}{W_{p}}+\frac{\Delta W_{l}}{W_{l}} \frac{W_{l}}{W_{p}},
\end{gathered}
$$

where

$$
Z=\frac{k_{c}-1}{k_{c}}\left[\frac{r_{c}^{\left(k_{c}-1\right) / k_{c}}}{r_{c}^{\left[\left(k_{c}-1\right) / k_{c}\right]-1}}\right] \frac{W_{c}}{\left(W_{t}-W_{c}\right)} \frac{1}{r_{c}}+\frac{k_{t}-1}{k_{t}}\left[\frac{1-\frac{1}{r_{t}}}{r_{t}^{\left(k_{t}-1\right) / k_{t}}-1}\right] \frac{W_{t}}{\left(W_{t}-W_{c}\right)},
$$

$\Delta P_{l}$ is hydraulic loss of the CHP system and the sum $P_{l}+\Delta P_{l}$ is the gas pressure at the outlet of the recuperator when the CHP system imposes back pressure on the micro-turbine.

For the micro-turbine generator efficiency, the correction is as follows

$$
\begin{gathered}
\eta_{m t g, a d j u s t e d}=\eta_{m t g}\left(1+\Delta \eta_{m t g}\right), \\
\frac{\Delta \eta_{m t g}}{\eta_{m t g}}=Z 1 \frac{\Delta P_{l}}{P_{l}}-\left(\frac{\Delta T_{4}}{T_{4}}+\frac{\Delta \dot{m}_{g}}{\dot{m}_{g}}\right),
\end{gathered}
$$

where 


$$
Z 1=Z-\frac{k_{t}-1}{k_{t}}\left[\frac{1-\frac{1}{r_{t}}}{r_{t}^{\left(k_{t}-1\right) / k_{t}}-1}\right] .
$$

Labinov et al. (2002) recommend that the values of $\mathrm{Z}$ and $\mathrm{Z} 1$ be determined after the values of all other variables are obtained from solving the system of equations for the micro-turbine generator, Eq. (26) through Eq. (39), for each mode of turbine operation, including modes with increased back pressure. The values of net micro-turbine output, $W_{p}$, and efficiency, $\eta_{m t g}$, adjusted for increased back pressure can then be determined.

\section{Heat Recover Unit}

We use the $\varepsilon$-NTU model to represent the heat recover unit. The heat exchanger effectiveness for the heat recover unit, $\varepsilon_{H R U}$, is defined by

$$
\varepsilon_{H R U}=\frac{Q_{H R U, a c t u a l}}{Q_{H R U, \max }},
$$

where $Q_{H R U, \text { actual }}$ is the actual rate of heat transfer from the exhaust gas to the water and $Q_{H R U, \max }$ is the maximum possible rate of heat transfer from the exhaust gas to the water, which is give by the relation

$$
Q_{H R U, \max }=\varepsilon_{H R U} C_{H R U, \min }\left(T_{H R U, e x, i}-T_{H R U, w, i}\right) .
$$

Here, $C_{H R U, \min }=\min \left(C_{e x}, C_{w}\right), C_{e x}=\dot{m}_{H R U, e x} C_{p, H R U, e x}, C_{w}=\dot{m}_{H R U, w} C_{p, H R U, w}, T_{H R U, e x, i}$ and $T_{H R U, w, i}$ are the temperatures of the exhaust gas and water, respectively, entering the heat recovery unit, and $\dot{m}_{H R U, e x}$ and $\dot{m}_{H R U, w}$ are the corresponding mass flow rates of exhaust and water through the HRU.

From Eq. (46) and Eq. (47), a relation can be obtained for the actual rate of heat transfer in the HRU in terms of $\varepsilon_{H R U}$,

$$
Q_{H R U, \text { actual }}=\varepsilon_{H R U} C_{m i n}\left(T_{H R U, e x, i}-T_{H R U, w, i}\right) .
$$

The actual rate of heat gain by the water in the HRU can also be expressed in terms of the waterside conditions alone as

$$
Q_{H R U, a c t u a l}=\dot{m}_{H R U, w} C_{p, H R U, w}\left(T_{H R U, w, o}-T_{H R U, w, i}\right)
$$

where $T_{H R U, w, o}$ is the temperature of the heated water leaving the HRU. Solving Eq. (49) for this exiting water temperature yields 


$$
T_{H R U, w, o}=T_{H R U, w, i}+Q_{H R U, a c t u a l} /\left(\dot{m}_{H R U, w} C_{p, H R U, w}\right) .
$$

Eq. (48) and Eq. (50) provide two equations that can be solved for the exit water temperature, $T_{H R U, w, o}$, provided the value of $\varepsilon_{H R U}$ is known. The value of $\varepsilon$ is often related to the number of transfer units $(N T U)$, which is a measure of the heat transfer size of a heat exchanger and is defined as $N T U=U A / C_{\min }$, where $U A$, the product of the overall heat transfer coefficient $(U)$ of the heat exchanger and its total heat transfer area $(A)$, is the overall conductance of the heat exchanger. For a counterflow heat exchanger (Kreith and Bohn 1986)

$$
\varepsilon_{H R U}=\frac{1-e^{-N T U_{H R U}(1-C)}}{1-C e^{-N T U_{H R U}(1-C)}},
$$

where $C=C_{\min } / C_{\max }$ and $C_{\max }=\max \left(C_{e x}, C_{w}\right)$. Given the flow rates, fluid properties, and $N T U_{H R U}$ for the specific heat recovery unit, Eq. (48), Eq. (50) and Eq. (51) provide a system of three equations that can be solved for the temperature, $T_{H R U, w, o}$, of the hot water produced by the HRU. This model is represented as an input/output diagram in Figure 11.

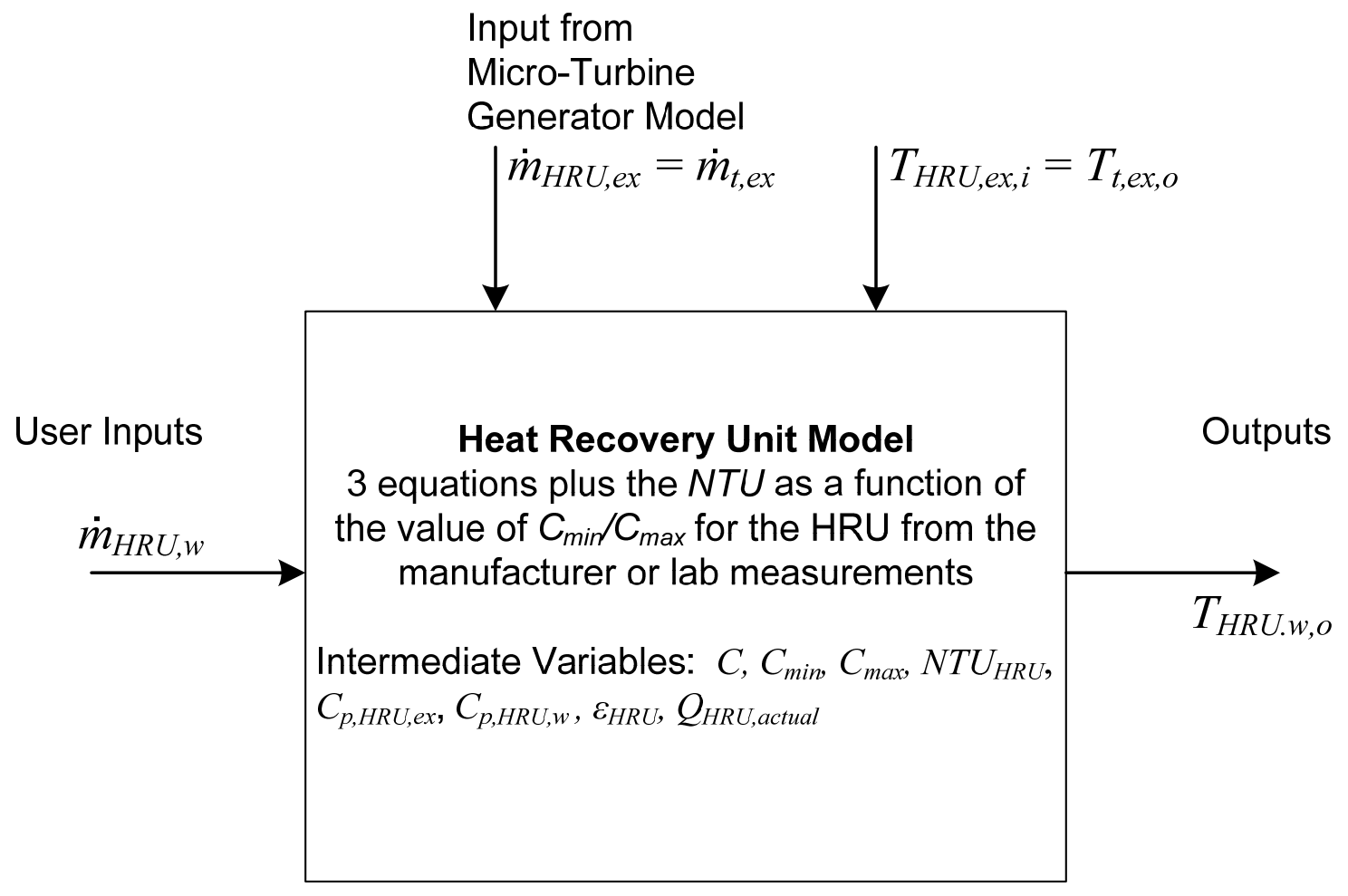

Figure 11. Input/output diagram for the heat recovery unit model. 


\section{Absorption Chiller}

For the absorption chiller, the quasi-empirical model of Gordon and $\mathrm{Ng}$ (2000) [G-N model] is used. This model provides a predictive relationship among chiller cooling rate $\left(Q_{A b C h i l l e r}=\right.$ $\left.Q_{\text {evap }}\right), C O P$, and three temperatures, namely

$$
\left(\frac{T_{\text {hotwater }, i}-T_{\text {cond,cw }, i}}{C O P \times T_{\text {hotwater }, i}}-\frac{T_{\text {hotwater }, i}-T_{\text {evap }, w, o}}{T_{\text {evap }, w, o}}\right) Q_{A b \text { Chiller }}=b_{0}+b_{1} \frac{T_{\text {cond }, c w, i}}{T_{\text {hotwater }, i}} .
$$

Here, $C O P$ is the coefficient of performance of the chiller, $T_{\text {hotwater }, i}$ is the temperature of the hot water leaving the heat recovery unit (HRU) and entering the chiller generator, $T_{\text {evap, w,o }}$ is the temperature of chilled water leaving the chiller evaporator (i.e., chilled-water supply temperature for building conditioning), and $T_{c o n d, c w, i}$ is the temperature of cooling water entering the condenser. There is no variable corresponding to $T_{c o n d, c w, i}$ in the CHP metrics (presented previously in this report) because it is an intermediate variable inside the chiller. Cooling water from the cooling tower first enters the absorber at temperature $T_{A b C h i l l e r, c w, i}$, where it is heated by heat rejected from the absorption of refrigerant vapor by solute inside the absorber (e.g., water vapor absorbed into solution with $\mathrm{LiBr}$ ), then flows to the condenser (at unknown temperature, $\left.T_{c o n d, c w, i}\right)$, where it absorbs additional heat from the condensing refrigerant, and then exits the condenser at temperature $T_{A b C h i l l e r, c w, o}$.

The constants $b_{0}$ and $b_{1}$ are determined by regression on test data for the specific absorption chiller, where all other variables in Eq. (52) are measured during the tests. Once the values of $b_{0}$ and $b_{1}$ are known, then Eq. (52) provides a relationship among $Q_{A b C h i l l e r}, C O P$, and $T_{c o n d, c w, i}$.

From the CHP absorption chiller metrics model, the cooling provided by the evaporator is given by

$$
Q_{\text {evap }}=Q_{\text {AbChiller }}=\dot{m}_{\text {evap }, w, i} c_{p, w}\left(T_{\text {evap }, w, i}-T_{\text {evap }, w, o}\right) .
$$

Substituting this expression for $Q_{c h}$ in the G-N model yields

$$
\left(\frac{T_{\text {hotwater }, i}-T_{\text {cond }, c w, i}}{C O P \times T_{\text {hotwater }, i}}-\frac{T_{\text {hotwater }, i}-T_{\text {evap }, w, o}}{T_{\text {evap }, w, o}}\right) \times \dot{m}_{\text {evap }, w, i} c_{p, w}\left(T_{\text {evap }, w, i}-T_{\text {evap }, w, o}\right)=b_{0}+b_{1} \frac{T_{\text {cond }, c w, i}}{T_{\text {hotwater }, i}} \text {. Eq. (5 }
$$

Here, $\dot{m}_{\text {evap }, w, i}$ and $T_{\text {evap }, w, i}$ are externally controlled and in the absence of an air handling unit model or building thermal model are user selectable variables. The mass flow rate, $\dot{m}_{\text {evap }, w, i}$, is for water returned to the chiller from the chilled water loop. The temperature of that chilled water return, $T_{\text {evap }, w, i}$, would ordinarily be determined by the temperature of the chilled water leaving the chiller, $T_{\text {evap, w,o }}$, the mass flow rate of water through the chilled water loop, and the thermal load on the chilled water loop, but in the absence of the corresponding models, this temperature becomes a user specified input. The heat capacity of water, $c_{p, w}$, is essentially 
constant over the range of temperatures of the chilled water. Therefore, we have a model of the absorption chiller in terms of COP, $T_{\text {evap }, w, i}, T_{\text {hotwater, } i}, T_{c o n d, c w, i}$, and $T_{\text {evap }, w, o}$, where $T_{\text {evap }, w, i}$ is a user input, $T_{\text {hotwater }, i}$ is determined by the HRU model (external to the absorption chiller model), $T_{\text {evap }, w, o}$ is determined by this chiller model, $T_{c o n d, c w, i}$ is determined by the cooling tower model and the rate of heat rejection by the absorber, and $C O P$ must be determined from separate relations.

Neglecting the small energy input for the pump (i.e., assuming $W_{i n}<<Q_{g e n}$ ) and the small difference in $c_{p, w}$ between the temperature of the chilled water and temperature of the hot water,

$$
\mathrm{COP}=Q_{\text {evap }} / Q_{g e n}=Q_{A b \text { Chiller }} / Q_{g e n}=\frac{\dot{m}_{\text {evap }, w, i}\left(T_{\text {evap }, w, i}-T_{\text {evap }, w, o}\right)}{\dot{m}_{\text {hotwater }, i}\left(T_{\text {hotwater }, i}-T_{\text {hotwater }, o}\right)}
$$

Together, Eq. (54) and Eq. (55) still have three unknowns that are not user inputs or provided by other component models, $T_{c o n d, c w, i}, T_{\text {evap }, w, o}$, and $T_{\text {hotwater,o }}$, the last of which was introduced by Eq. (55).

Following the fundamental development of Gordon and $\mathrm{Ng}$, we can introduce the parameter, $\xi$, which is defined as the fraction of the heat rejection for the absorption chiller system taking place in the condenser, i.e.,

$$
\xi=Q_{\text {cond }} /\left(Q_{\text {cond }}+Q_{\text {absorber }}\right)=\frac{T_{\text {cond }, c w, o}-T_{\text {cond }, c w, i}}{T_{\text {cond }, c w, o}-T_{A b \text { Chiller }, c w, i}}
$$

The parameter $\xi$ is determined by the design of the absorption chiller, specifically the absorber and condenser heat exchangers, and its value can be determined by selecting the specific value that gives the best fit to data for the absorption chiller being modeled.

Solving Eq. (56) for the temperature of the cooling water entering the condenser yields

$$
T_{\text {cond }, c w, i}=T_{\text {cond }, c w, o}-\xi\left(T_{\text {cond }, c w, o}-T_{A b C h i l l e r, c w, i}\right) .
$$

The heat balance on the absorption chiller is

$$
Q_{\text {evap }}+Q_{\text {gen }}-Q_{\text {absorber }}-Q_{\text {cond }}=0
$$

or

$$
\begin{gathered}
\dot{m}_{\text {evap }, w, i}\left(T_{\text {evap }, w, i}-T_{\text {evap }, w, o}\right)+\dot{m}_{\text {hotwater }, i}\left(T_{\text {hotwater }, i}-T_{\text {hotwater }, o}\right)- \\
\dot{m}_{c w, i}\left(T_{\text {cond }, c w, o}-T_{\text {absorber }, c w, i}\right)=0,
\end{gathered}
$$

assuming negligible heat loss in the tubing between the absorber heat exchanger and the condenser heat exchanger. 
Eq. (58) provides an additional equation without introducing any additional unknowns.

The system of four equations, Eq. (54), Eq. (55), Eq. (56) [or Eq. (57)], and Eq. (58), provides a model of the absorption chillers, where (see Figure 10):

- $T_{\text {evap }, w, i}, \dot{m}_{\text {evap }, w, i}, \dot{m}_{\text {hotwater }, i}$, and $\dot{m}_{c w, i}$ are user inputs

- $T_{\text {hotwater }, \text { is an input from the HRU model }}$

- $T_{A b c h i l l e r, c w, i}$ is an input from the cooling tower model

- $b_{0}, b_{1}$ and $\xi$ are determined by best fit to measured data for the specific chiller modeled

- $C O P, T_{\text {cond,cw, },}, T_{\text {evap }, w, o}, T_{\text {hotwater }, o}$, and $T_{\text {cond,w,o }}$ are unknowns.

By specifying one of these variables, e.g., the temperature of the chilled water leaving the evaporator, $T_{\text {evap, w,o }}$, the model can be solved for the remaining unknown variables. Specifying $T_{\text {evap }, w, o}$ is equivalent to specifying the load that must be met by the chiller, $Q_{A b C h i l l e r}$, once values of $T_{\text {evap }, w, i}$ and $\dot{m}_{\text {evap }, w, i}$ have been selected. The resulting input/output diagram for the absorption chiller model is shown in Figure 12.

Input from HRU model
Input from cooling tower model

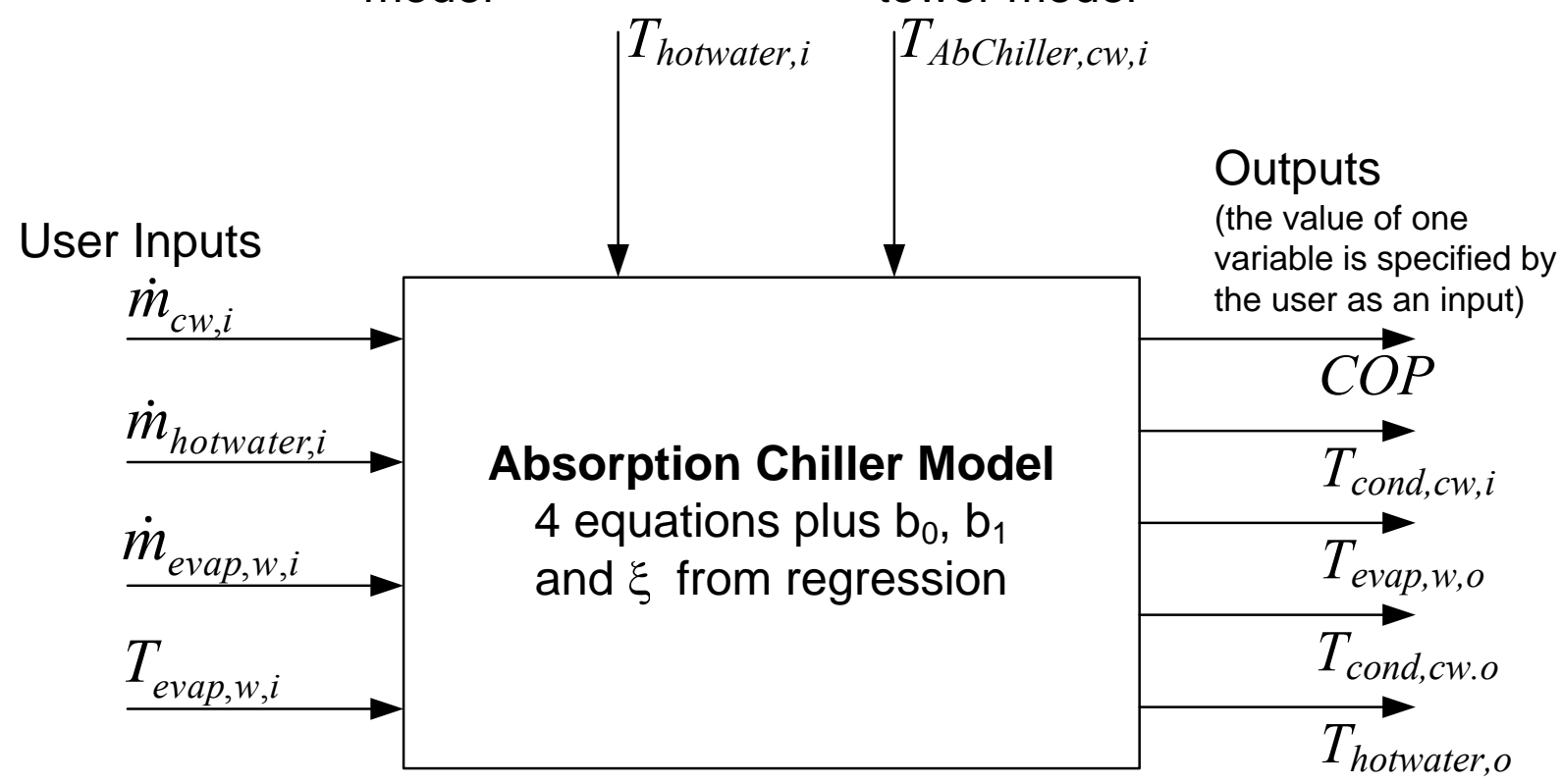

Figure 12. Input/output diagram for the absorption chiller model. 


\section{Cooling Tower}

The simplified effectiveness model of Braun et al. (1989) for counterflow cooling towers is used for simulating the cooling tower in the CHP system model. The assumptions on which this model is based and the resulting equations are presented in this section. Details of the derivation of the model can be found in Braun et al. (1989). A schematic of the counterflow cooling tower is shown with the important variables identified in Figure 13.

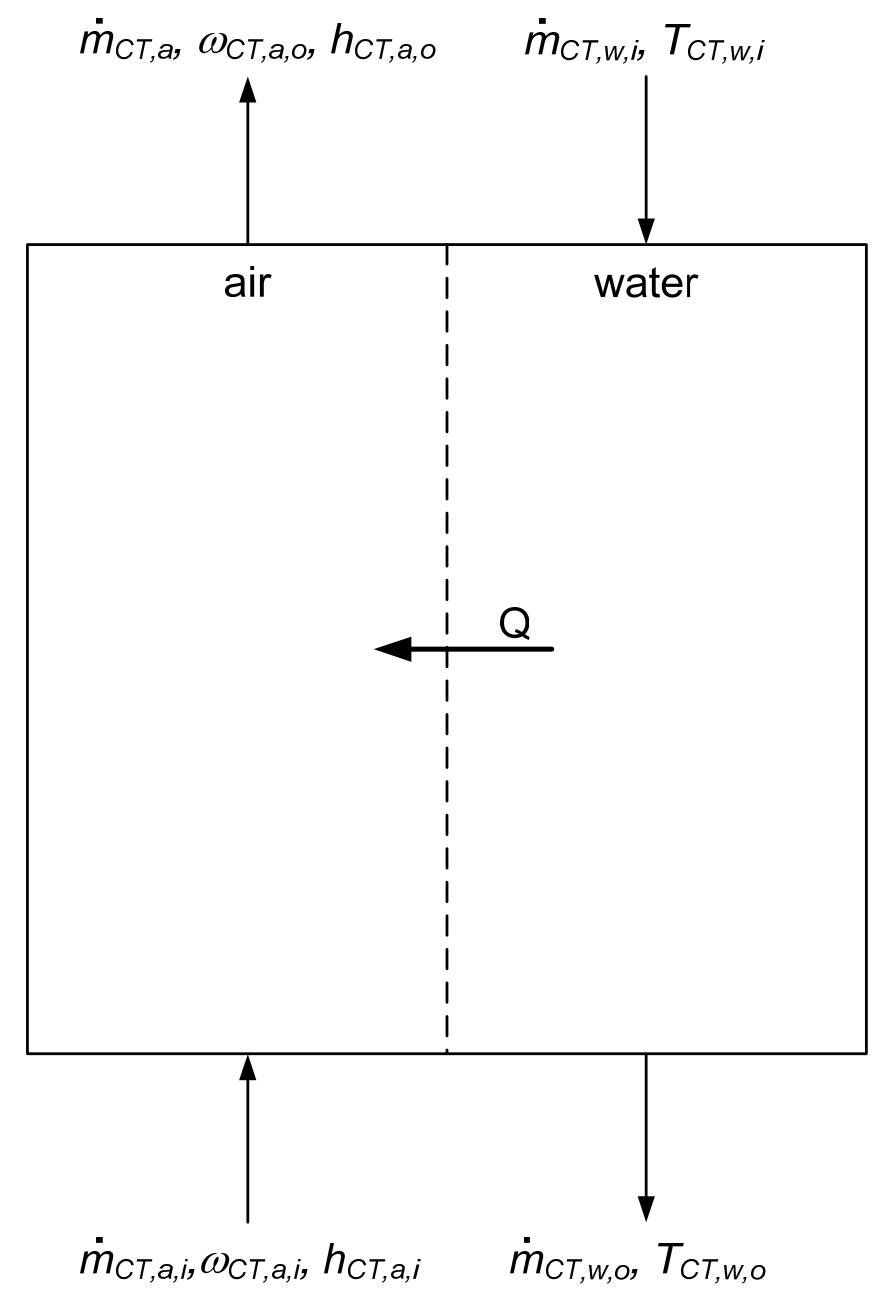

Figure 13. Schematic diagram of a counterflow cooling tower (after Braun et al. 1989).

Key assumptions in deriving the effectiveness model include:

- Heat loss through the sides of the cooling tower is negligible.

- The bulk flows of air and water occur only in the vertical direction (along the height of the cooling tower) and in directions opposite one another, with water falling under gravity and air flowing upward propelled by cooling tower fans.

- Heat and mass transfer occur only in a direction normal to the bulk flows. 
- Heat transfer from the cooling tower fans to the fluids is negligible.

- The specific heats of water and dry air are constant.

- The mass fraction of water vapor in the moist air mixture is approximately equal to the humidity ratio.

- The water stream temperature is uniform at any cross section (vertical position).

- The cross sectional area of the cooling tower is uniform across all vertical positions.

- Cooling tower operation is in steady state.

- The Lewis number, $L e=h_{C} /\left(h_{D} C_{p a}\right)$ is unity, where $h_{C}$ is the convective heat transfer coefficient, $h_{D}$ is the mass transfer coefficient, and $C_{p a}$ is the constant-pressure specific heat of moist air.

- The water loss caused by evaporation is negligible.

Under these assumptions, the air-side cooling tower effectiveness, $\varepsilon_{C T, a}$, which is defined as the ratio of the actual air-side heat transfer to the maximum possible air-side heat transfer in the cooling tower, can be expressed by the relation (Braun et al. 1989)

$$
\varepsilon_{C T, a}=\frac{1-\exp \left[-N T U_{C T}\left(1-m^{*}\right)\right]}{1-m^{*} \exp \left[-N T U_{C T}\left(1-m^{*}\right)\right]},
$$

where $N T U_{C T}$, the number of (mass) transfer units for the cooling tower, is defined by

$$
N T U_{C T}=\text { number of (mass) transfer units }=\frac{h_{D} A_{V} V_{C T}}{\dot{m}_{C T, a}}
$$

In Eq. (59) and Eq. (60),

$$
m^{*}=\frac{\dot{m}_{C T, a}}{\dot{m}_{C T, w, i}\left(C_{p w} / C_{s}\right)},
$$

where $A_{V}$ is the surface area of water per unit volume of the cooling tower, $V_{C T}$ is the total volume of the cooling tower, $\dot{m}_{C T, a}$ is the mass flow rate of air through the tower, $\dot{m}_{C T, w, i}$ is the mass flow rate of water entering the tower, which assuming no evaporative losses is constant through the tower (i.e., $\dot{m}_{C T, w, i}=\dot{m}_{C T, w, o}=\dot{m}_{C T, w}$ ), $C_{p w}$ is the constant-pressure specific heat of water, and $C_{S}$ is average saturation specific heat evaluated based on water inlet and outlet conditions, i.e., 


$$
C_{s}=\frac{h_{C T, s, w, i}-h_{C T, s, w, o}}{T_{C T, w, i}-T_{C T, w, o}} .
$$

Here, $T_{C T, w, i}$ and $T_{C T, w, o}$ are the temperatures of the water at the inlet to and outlet from the cooling tower, and $h_{s, C T, w, i}$ and $h_{s, C T, w, o}$ are the corresponding saturation specific enthalpies of water at the temperatures, $T_{C T, w, i}$ and $T_{C T, w, o}$, respectively.

The actual rate of heat transfer $\left(Q_{C T}\right)$ in terms of the air-side effectiveness is given by

$$
Q_{C T}=\varepsilon_{C T, a} \dot{m}_{a}\left(h_{s, C T, w, i}-h_{C T, a, i}\right),
$$

where $h_{C T, a, i}$ represents the specific enthalpy of air entering the cooling tower, which is determined by the temperature and humidity ratio of the entering ambient air $\left(T_{C T, a, i}\right.$ and $\omega_{C T, a, i}$, respectively).

Overall energy balances on the air and water streams provide equations for the exit air enthalpy, $h_{C T, a, o}$, and outlet water temperature, $T_{C T, w, o}$, viz.

$$
h_{C T, a, o}=h_{C T, a, i}+\varepsilon_{C T, a}\left(h_{s, C T, w, i}-h_{C T, a, i}\right)
$$

and

$$
T_{C T, w, o}=T_{r e f}+\frac{\dot{m}_{C T, w, i}\left(T_{C T, w, i}-T_{r e f}\right) C_{p w}-\dot{m}_{C T, a}\left(h_{C T, a, o}-h_{C T, a, i}\right)}{\dot{m}_{C T, w, o} C_{p w}},
$$

where $T_{r e f}$ is the reference temperature at which the enthalpy of liquid water is zero.

Equations Eq. (59) through Eq. (65) can be solved iteratively given the flow rates for entering air and water, the corresponding $N T U$ for the cooling tower at those flow rates, and the temperatures of the water and air entering the cooling tower.

Given empirical data for a specific cooling tower are available, the correlation

$$
N T U_{C T}=c\left(\dot{m}_{C T, w} / \dot{m}_{C T, a}\right)^{1+n}
$$

can be used to relate the mass flow rates for air and water to the $N T U_{C T}$ for the specific cooling tower, where $c$ and $n$ are constants determined from a best fit of measured data for the tower to Eq. (66).

The corresponding input/output diagram for the cooling tower model is shown in Figure 14.

\section{Relations Integrating the Components}

The individual component models are integrated by two requirements on flow loops shared by two components, namely, 
1. From conservation of mass considerations for steady, incompressible flow, the mass flow rate is constant throughout the loop, i.e., the mass flow rate exiting one component must equal the mass flow rate entering the other component connected by the same loop, and

2. Assuming that no heat losses occur from connecting piping, the temperature of fluid leaving a component equals the temperature of the fluid entering the connected component.

These conditions are expressed for each shared flow loop below.

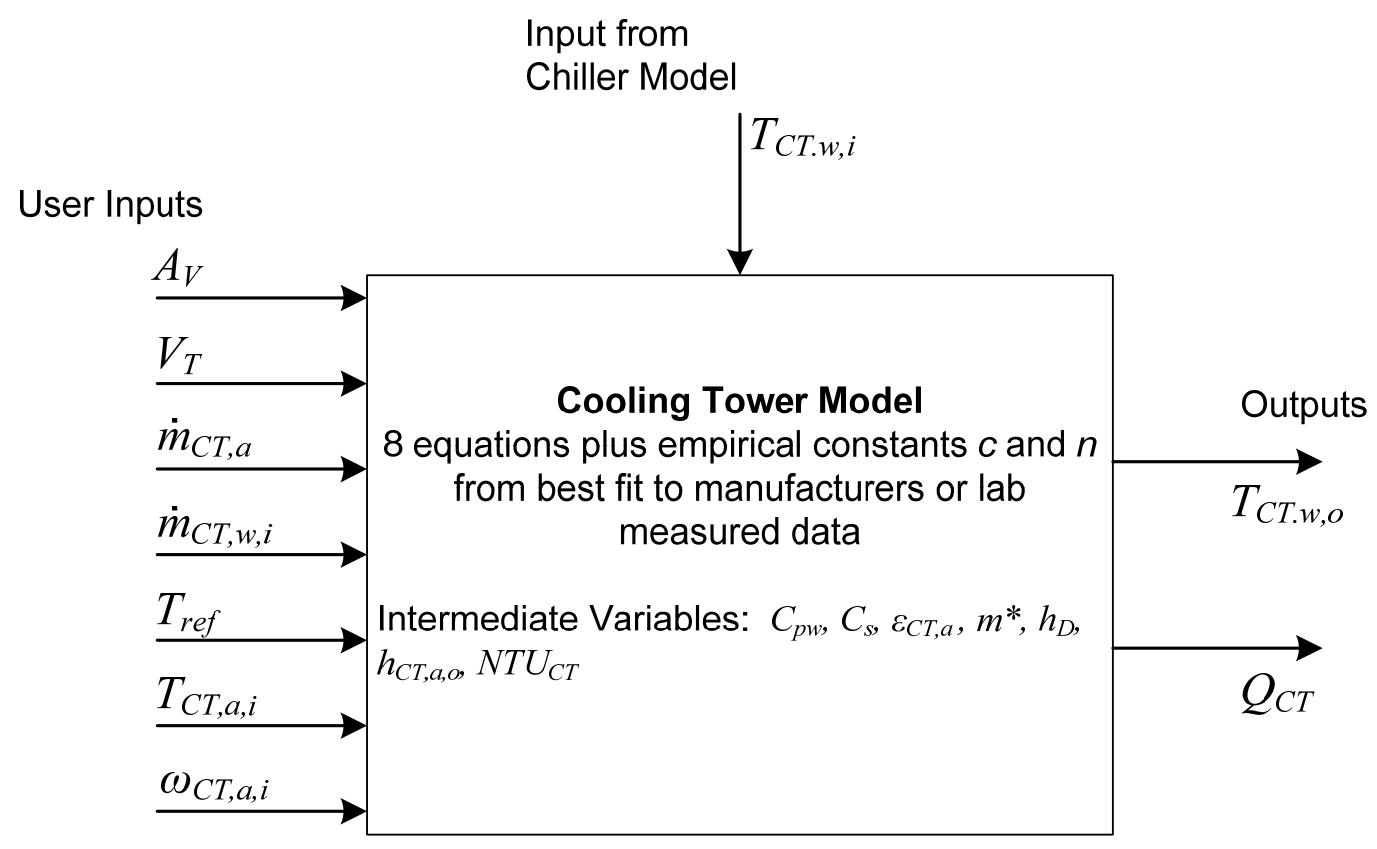

Figure 14. Input/output diagram for the cooling tower model.

Micro-Turbine Exhaust

The hot exhaust gas leaving the micro-turbine flows into the heat recovery unit. In this case, there is no return flow to the micro-turbine, so application of the two requirements yields

$$
\dot{m}_{t, e x}=\dot{m}_{H R U, e x}
$$

and

$$
T_{6}=T_{t, e x, o}=T_{H R U, e x, i}
$$

Hot Water Loop Between the HRU and Absorption Chiller Hot water produced in the HRU flows to the absorption chiller, where it is used to regenerate working fluid from solution, and then returns to the HRU to be reheated. Application of the 
requirements on this loop provides three relations, one for mass flow rate and two for the water temperatures. For mass flow of hot water between the HRU and the absorption chiller,

$$
\dot{m}_{H R U, w}=\dot{m}_{\text {hotwater }, i}=\dot{m}_{\text {hotwater }, o} .
$$

For the temperature of the water leaving the HRU and entering the chiller,

$$
T_{H R U, w, o}=T_{\text {hotwater }, i} \text {. }
$$

For flow of the cooled hot water from the chiller back to the HRU,

$$
T_{\text {hotwater }, o}=T_{H R U, w, i}
$$

Cooling Water Loop Between the Absorption Chiller and the Cooling Tower

Warmed water leaving the condenser of the absorption chiller flows to the cooling tower, where it is cooled and then returned to the chiller, where it cools the absorber first and then flows to the condenser. Application of the requirements stated earlier for the cooling water loop, yields three relations integrating the chiller and the cooling tower. From conservation of mass for the cooling water loop tying together the chiller and cooling tower,

$$
\dot{m}_{c w, i}=\dot{m}_{c w, o}=\dot{m}_{C T, w} .
$$

For the temperature of the water leaving the chiller condenser and entering the cooling tower,

$$
T_{c o n d, w, o}=T_{C T, w, i}
$$

For flow of the cooling water from the cooling tower back to the chiller (absorber),

$$
T_{C T, w, o}=T_{A b c h i l l e r, c w, i}
$$

Equations Eq. (67) through Eq. (74) provide eight relations that integrate the CHP system components into a system.

\section{Solution Procedure}

The CHP system simulation model is implemented in the Engineering Equation Solver (EES) for Microsoft Windows Operating Systems (F-Chart Software 2007). EES uses a modified form of Newton's method to solve systems of algebraic equations, using enhancements to improve calculation efficiency and enable solution of large sets of equations on personal computers. A summary of the methods used is provided in the software manual (F-Chart Software 2007). 


\section{Simulation Applications}

This section identifies applications that were selected for illustration using data generated by use of the simulation model. The general procedure was to create a data time series incorporating onset of the behavior to which the data set is intended to correspond by use of the CHP simulation implemented in EES. Then the CHP monitoring algorithms were applied to illustrate detection and identification of the faulty or degraded behavior possible by use of monitoring described earlier in this report. Termination of this project prevented completion of this analysis. As a result, only the types of behavior (proper [fault free] and faulty) and the monitoring plan are identified in this section.

\section{Properly Operating System}

Plots of $\eta_{F}, E U F_{V W}, Q_{t h}, Q_{F u e l}$, Cost $_{F u e l}, \eta_{E E}, \varepsilon_{H R U}, C O P_{A b C h i l l e r}, \eta_{C T}$, and $\eta_{C T, E l e c}$ as functions of time would be used to illustrate examples of proper, fault-free behavior of the selected CHP system.

\section{Gradual Degradation of Micro-turbine Efficiency}

Plots of $\eta_{F}, E U F_{V W}, Q_{t h}, Q_{F u e l}, C_{\text {Cost }} F_{\text {Ful }}, \eta_{E E}, \varepsilon_{H R U}, C O P_{A b c h i l l e r}, \eta_{C T}$, and $\eta_{C T, E l e c}$ as functions of time would be used to illustrate the use of monitoring to detect performance degradation for the case where the turbine efficiency, $\eta_{\mathrm{t}}$ in the micro-turbine model, is gradually decreased over time from its initial value, to say $15 \%$ lower.

\section{Deleterious Change in the Micro-turbine Air-Fuel Ratio}

Plots of $\eta_{F}, E U F_{V W}, Q_{t h}, Q_{F u e l}, C_{\text {Cost }} t_{\text {Fuel }}, \eta_{E E}, \varepsilon_{H R U}, C O P_{A b c h i l l e r}, \eta_{C T}$, and $\eta_{C T \text {,Elec }}$ as functions of time for a decrease in the air flow rate through the compressor, $\dot{m}_{t, a}$, by $10 \%$ or $15 \%$ to demonstrate the detection of this faults through performance monitoring. A plot of $T_{H R U, e x, o}$ would also be shown to illustrate its change over time.

\section{Degradation in Heat Transfer in the HRU}

Plots of $\eta_{F}, E U F_{V W}, Q_{t h}, Q_{F u e l}$, Cost $_{F u e l}, \eta_{E E}, \varepsilon_{H R U}, C O P_{A b c h i l l e r}, \eta_{C T}$, and $\eta_{C T, E l e c}$ as functions of time would be shown and discussed. Heat transfer degradation would be implemented in the simulation by decreasing the overall heat transfer coefficient $(U)$ or the effectiveness of the HRU heat transfer. This could be the result of corrosion of the heat transfer surfaces or a blockage of flow in the HRU. It should result in an increase in the exhaust gas temperature, $T_{H R U, e x, o}$, and a decrease in the temperature of the hot water leaving the HRU, $T_{H R U, w, o}$.

Plotting $T_{H R U, e x, o}$ and $T_{H R U, w, o}$ versus time for this case, the air-fuel ratio case and the properly operating case on the same plot would show the differences.

\section{Degradation of Cooling Tower Performance}

The case of the flow of air through the cooling tower being significantly reduced, as in the scenario described in Specification of Selected Performance Monitoring and Commissioning Verification Algorithms for CHP Systems, pp. 59 - 63, was to be simulated to illustrate with simulated data the case presented in this earlier report. 
Results would be shown in plots of $\eta_{F}, E U F_{V W}, Q_{t h}, Q_{F u e l}, C_{o s t} t_{F u l}, \eta_{E E}, \varepsilon_{H R U}$, $C O P_{A b c h i l l e r}, \eta_{C T}$, and $\eta_{C T, E l e c}$ as functions of time. Plots of $T_{C T, w, o}$ and $T_{C T, w, i}$ as functions of time would be shown to illustrate their use as part of isolating the cause of the problem through changes in values of measured parameters. 


\section{Application to Laboratory Data}

\section{Introduction to Section}

This section demonstrates the use of the algorithms developed in this project for monitoring the performance of a CHP system.

\section{Application to Laboratory Data}

The data used for testing was recorded from the CHP system in the Integrated Energy Systems Laboratory at Oak Ridge National Laboratory (Rizy et al. 2002; Rizy et al. 2003; Zaltash et al. 2006). It consists of a micro-turbine generator (MTG), exhaust-to-water heat recovery unit (HRU), hot-water-fired absorption chiller, and cooling tower (see Figure 7). The MTG is a 30$\mathrm{kW}$ natural-gas fired Capstone unit that produces three-phase 480-volt AC electric power and releases exhaust gases in the approximate temperature range 480 to $560^{\circ} \mathrm{F}$. A gas compressor is used to raise the pressure of the natural gas provided by the distributor (at 5 psig) to the pressure of 55 psig required by the MTG. The unit uses heat recuperation to preheat the air before it enters the combustion chamber. The hot exhaust gases pass through a gas-to-water heat recovery unit, producing hot water at 185 to $203^{\circ} \mathrm{F}$. The exhaust gases are then vented to the atmosphere at approximately $248^{\circ} \mathrm{F}$. These vented gases could be used to feed a direct-fired desiccant unit, which is possible at the IES Lab, but the IES system is configured with exhaust gases venting from the HRU directly to the atmosphere. The hot water output from the heat recovery unit is used to regenerate refrigerant in a 10 -ton $(35 \mathrm{~kW})$ single-effect $\mathrm{LiBr}$-water absorption chiller, providing chilled water at approximately $44^{\circ} \mathrm{F}$. Cooling of the chiller condenser is provided by a closed cooling water loop that uses a wet cooling tower to reject heat to the environment.

The schematic of the CHP monitoring system is shown in Figure 15. The monitoring system not only shows the measured data from the sensors, it also shows the calculated performance data. The data collected at ORNL was feed into the monitoring system to simulate a real-time CHP operation. The calculated values are shown in the left bottom portion of the monitoring screen (Figure 15) or inside the component. The monitoring system is also capable of setting alarm limits for the sensor values and the calculated values. Although the monitoring system shows measured or calculated values for any given time and alarm if a certain value(s) is out-of-bound, it doesn't show the trends. The sensor and the calculated data can be stored and plotted to see the trends. The CHP monitoring system that was prototyped records data to a database. This stored data can be used at any time to see the trends.

The turbine efficiency was calculated using the basic efficiency equation for small turbine generators from Table 2. The HRU effectiveness is computed using the detailed effectiveness equation tabled for the HRU in Table 2. The chiller COP is computed using detailed efficiency equation for hot water fired absorption chillers in Table 2. CT (cooling tower) utilization efficiency and CT efficiency is computed using the detailed equations tabulated for cooling tower in Table 2. The system efficiency is computed using the equation tabulated for fuel utilization efficiency in Table 1. The energy utilization factor is computed using the equation for the value weighted energy utilization factor tabulated in Table 1. 
The trends for the efficiency, effectiveness and energy utilization factor are shown in Figure 16 and Figure 17.

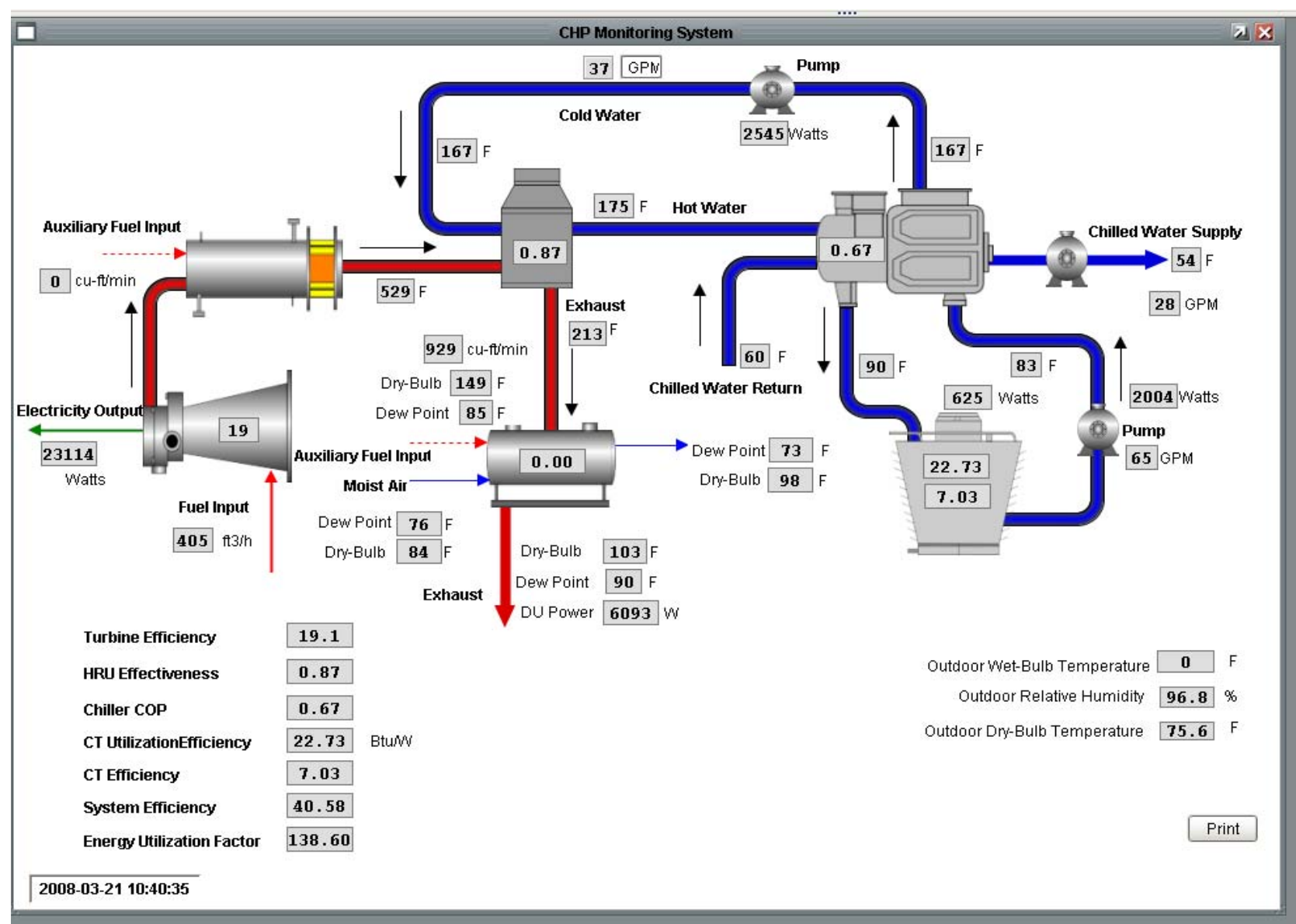

Figure 15. Schematic of CHP monitoring system used to test performance monitoring algorithms 


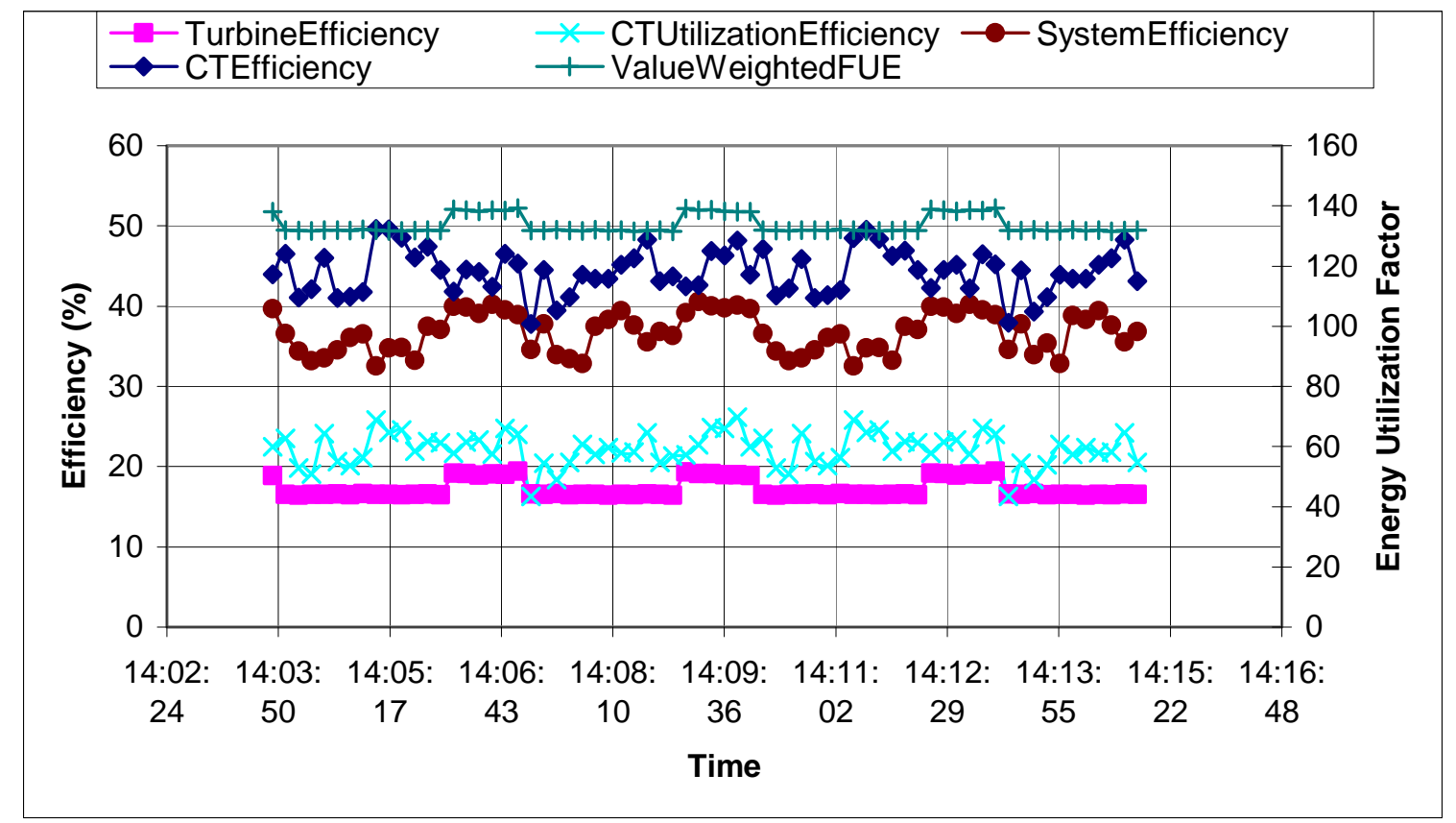

Figure 16. Trends of turbine, cooling tower, and system efficiency, cooling tower utilization efficiency and value weighted fuel utilization factor

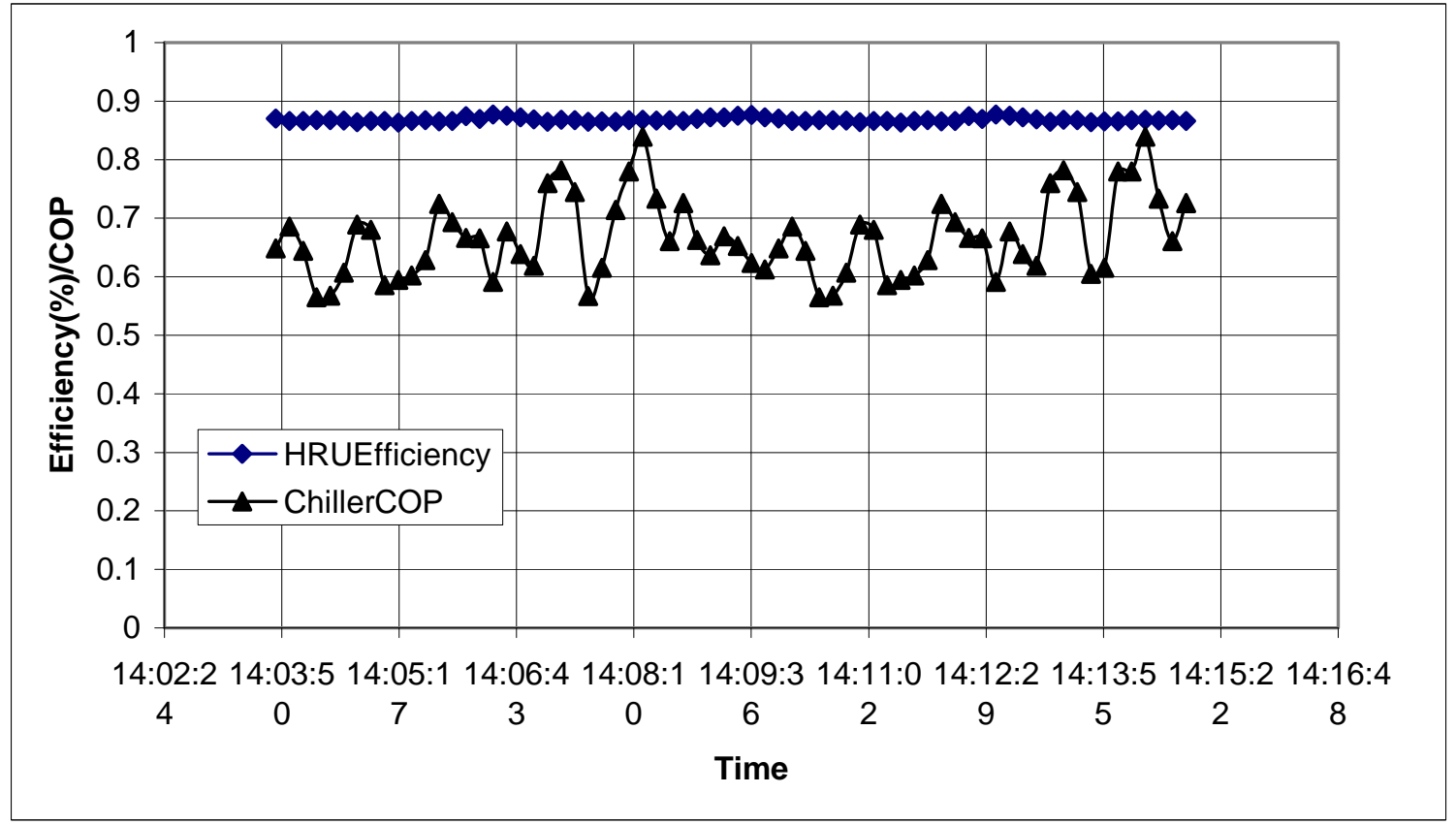

Figure 17. Trends of HRU efficiency and COP of the absorption chiller 


\section{Need for Lab and Field Testing/Demonstration}

This report provides algorithms for monitoring CHP system and component performance during operation to enable detection and correction of degradation in a timely manner to preserve efficient operation. It also provides algorithms for verification that commissioning has been performed successfully during start-up or re-starting of CHP systems. In previous section of this report, the algorithms have been applied to data from a laboratory CHP installation at Oak Ridge National Laboratory and to data from simulation of a representative CHP system to illustrate the potential value of these algorithms for performance monitoring and detection of performance degradation. Although the authors have exercised diligence in creating and exercising these algorithms and are confident in their value, as with all processes and technology, they should be tested over a range of conditions and causes of faults under controlled laboratory conditions and then on actual field-implemented CHP systems to validate their value, discover any unanticipated field conditions affecting their behavior, and to provide actual field evidence and demonstrate their value to practitioners. 


\section{Next Steps}

The work presented in this report should be followed by completion of testing against data from simulations by completing generation of the data for a properly operating system and for systems with the fault cases identified in the section "Example Application to Data From Simulations" and applying the CHP monitoring algorithms presented earlier in this report to illustrate detection and identification of faulty or degraded behavior. Upon successful testing against the data from simulations, the algorithms and procedures should be tested on a physical CHP system in a laboratory or field installation in real time under realistic operation conditions. These tests would serve to uncover practical implementation considerations that must be addressed for commercial application, as well as provide a demonstration of the value of these algorithms during CHP system operation. Laboratory tests have the advantage that faults can be imposed without interrupting supply of energy to a site, and several fault scenarios can be run over a limited period of time, something not practical with a field installation. Pilot demonstration at an actual field installation could be done after laboratory testing to provide data to support commercial deployment of the technology. 


\section{References}

Anderson K.K, and T.A. Reddy, 2002. The Error in Variables (EIV) Regression Approach as a Means of Identifying Unbiased Physical Parameter Estimates: Application to Chiller

Performance Data. International Journal of HVAC\&R Research, Vol. 8, No. 3, July 2002.

Abernethy, R. B and J.W. Thompson, Jr. 1973. Uncertainty in Gas Turbine Measurements. American Institute of Aeronautics and Astronautics and Society of Automotive Engineers, Propulsion Conference, 9th, Las Vegas, Nev., Nov5-7, 1973.

ASHRAE. 2003. Guideline 2-1986R Engineering Analysis of Experimental Data, First Public Review. American Society of Heating, Refrigerating and Air-Conditioning Engineers, Inc. 1791 Tullie Circle, NE Atlanta, Georgia.

ASME, 1985. ANSI/ASME PTC 6 Report-1985 Guidance for Evaluation of Measurement Uncertainty in Performance Test of Steam Turbines. American Society of Mechanical Engineers, New York, New York.

ASME, 2005. ASME PTC 19.1-2005 Test Uncertainty. American Society of Mechanical Engineers, New York, New York.

Brambley, M.R. and S. Katipamula. 2006. Specification of Selected Performance Monitoring and Commissioning Verification Algorithms for CHP Systems. PNNL-16068, Pacific Northwest National Laboratory, Richland, Washington

Braun, J.E., S.A. Klein, and J.W. Mitchell. 1989. "Effectiveness Models for Cooling Towers and Cooling Coils.” In ASHRAE Transactions, Vol. 95, Part 2, pp. 164-174.

Burghardt, D.M. 1982. Engineering Thermodynamics and Applications. John Wiley and Sons, New York.

Chatterjee, S. and B. Price. 1981. Regression Analysis by Example. John Wiley \& Sons, New York, NY.

Dettinger, M. D. and J.L. Wilson. 1981. "First Order Analysis of Uncertainty in Numerical Models of Groundwater Flow. Part 1: Mathematical Development.” Water Resour. Res. 17(1): 149-161.

Dieck, R. H. 1992. Measurement Uncertainty Methods and Applications, 2nd edition, John Wiley \& Sons, New York.

Draper, N., and H. Smith. 1981. Applied Regression Analysis, 2d edition, John Wiley \& Sons, New York. 
EPA. 1999. Review of Methods for Conducting Uncertainty Analyses. U.S. Environmental Protection Agency. http://www.epa.gov/ttn/fera/data/trim/99st b.pdf (Accessed on January 31st, 2007)

Fairchild, P.D., S. Labinov, A. Zaltash, and D.T. Rizy. 2001. "Experimental and Theoretical Study of Gas Microturbine-Based BCHP System." In Proceedings of the 2001 International ASME Mechanical Engineering Congress and Exposition, November 11-16, 2001, pp. 1-12, New York.

F-Chart Software. 2007. EES, Engineering Equation Solver for Microsoft Windows Operating Systems, Commercial and Professional Versions user manual. F-Chart Software, Madison, Wisconsin.

Gordon, J.M. and K.C. Ng. 2000. Cool Thermodynamics. Cambridge: Cambridge Press, London, England.

Katipamula, S. and M.R. Brambley. 2006. Advanced CHP Control Algorithms: Scope Specification. PNNL-15796, Pacific Northwest National Laboratory, Richland, Washington.

Kreith, F. and M.S. Bohn. 1986. Principles of Heat Transfer, $4^{\text {th }}$ edition, pp. 407-416. Harper \& Row Publishers, New York.

Labinov, S.D., A. Zaltash, D.T. Rizy, P.D. Fairchild, R.C. DeVault and E.A. Vineyard. 2002. "Performance Algorithms for Microturbine Performance for BCHP Systems." In ASHRAE Transactions, Vol. 108, Part 2, pp. 670-681, The American Society Heating, Refrigerating and Air-Conditioning Engineers, Atlanta, Georgia.

Nexant. 2001. M\&V Value Tool Alpha Version Specifications. Nexant, 1333 Broadway, Suite 1015, Oakland, California.

Reddy, T.A., J.S. Haberl and J.S. Elleson. 1999. Engineering Uncertainty Analysis in the Evaluation of Energy and Cost Savings of Cooling System Alternatives Based on FieldMonitored Data. ASHRAE Transactions, 1999 (2) pp: 1047-1057.

Rizy, D. Tom, Abdi Zaltash, Solomon Labinov, Andrei Petrov and Phil Fairchild. 2002. "DER Performance Testing of a Microturbine-Based Combined Cooling, Heating, and Power (CHP) System." In Transactions of Power System 2002 Conference, South Carolina.

Rizy, D.T. , A. Zaltash, S.D. Labinov, A.Y. Petrov, E.A. Vineyard, R.L. Linkous. 2003. “CHP Integration (or IES): maximizing the efficiency of distributed generation with waste heat recovery." In Proceedings of the Power System Conference, 2003, pp. 1-6.

Taylor, B. N. and C. E. Kuyatt, 1994. Guidelines for Evaluating and Expressing the Uncertainty of NIST Measurement Results. Physics Laboratory, National Institute of Standards and Technology, Gaithersburg, Maryland. 
Vidal, A., J. C. Bruno, R. Best, and A. Coronas. 2006. "Performance characteristics and modeling of a micro gas turbine for their integration with thermally activated cooling technologies." International Journal of Energy Research (pre-press “early view" version posted on journal web site www3.interscience.wiley.com/cgi-bin/jissue/109060949).

Vose, D., 1996. Quantitative Risk Analysis: A Guide to Monte Carlo Simulation Modeling. John Wiley \& Sons, New York.

Zaltash, A., A.Y. Petrov, D.T. Rizy, S.D. Labinov, E.A. Vineyard, and R.L. Linkous. 2006. "Laboratory R\&D on Integrated Energy Systems (IES). Applied Thermal Energy 26, 28-35. 